\title{
Rhodium-Catalyzed Selective C-H Trideuteromethylation of Indole at C7 Position Using D6-Acetic Anhydride
}

(Supporting Information)

\author{
Xiaowei Han ${ }^{1,2}$, Yu Yuan, ${ }^{1}$ and Zhuangzhi $\mathrm{Shi}^{1,2} *$ \\ ${ }^{1}$ College of Chemistry and Chemical Engineering, Yangzhou University, Yangzhou 225002, China \\ ${ }^{2}$ State Key Laboratory of Coordination Chemistry, School of Chemistry and Chemical \\ Engineering, Nanjing University, Nanjing, 210093, China
}

*Corresponding authors:

Prof. Zhuangzhi Shi, E-mail: shiz@nju.edu.cn;

Prof. Yu Yuan, E-mail: yyuan@yzu.edu.cn 
${ }^{1} \mathrm{H}$ NMR (400 MHz, $\mathrm{CDCl}_{3}$ )

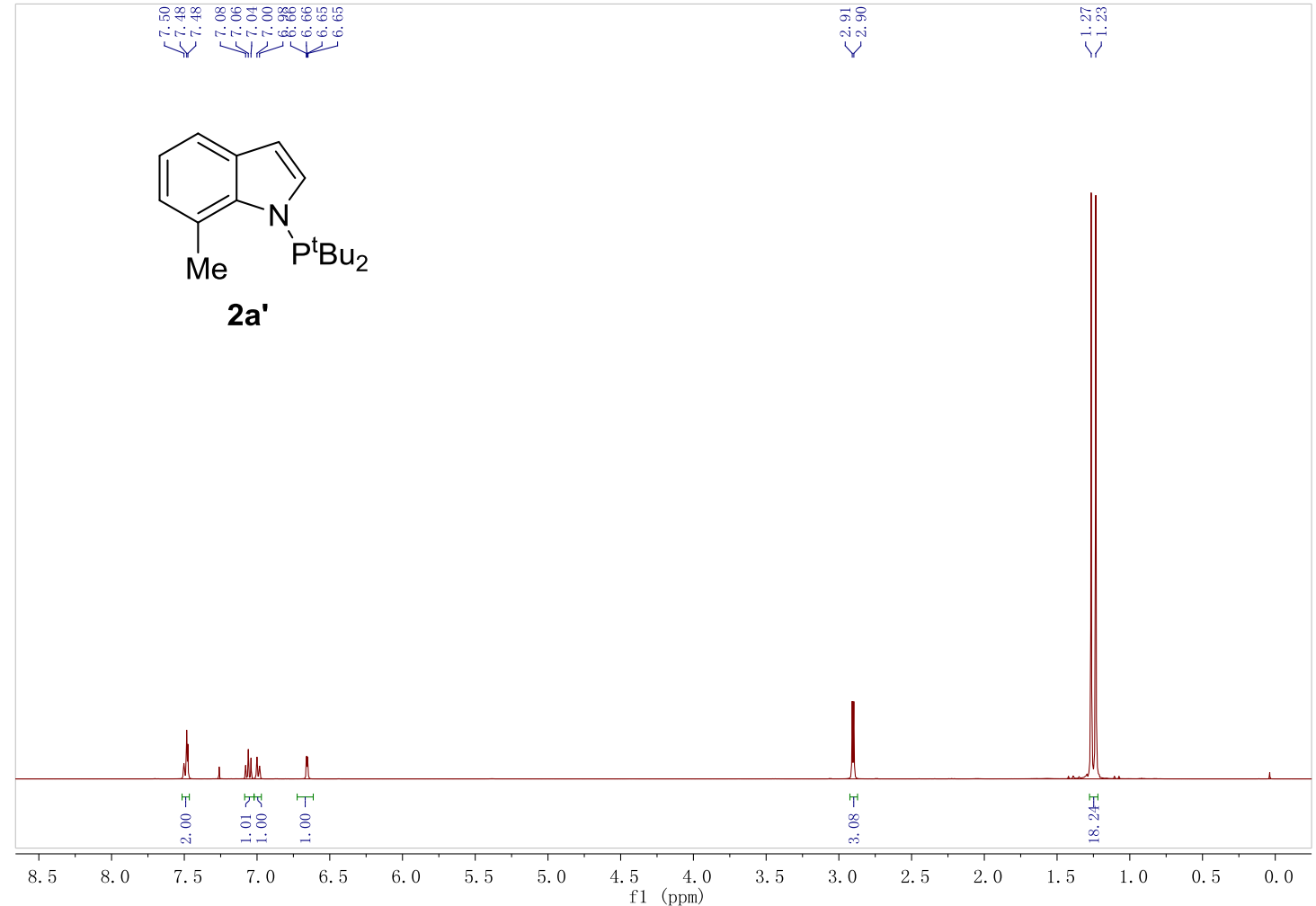

${ }^{13} \mathrm{C}$ NMR (400 MHz, $\mathrm{CDCl}_{3}$ )

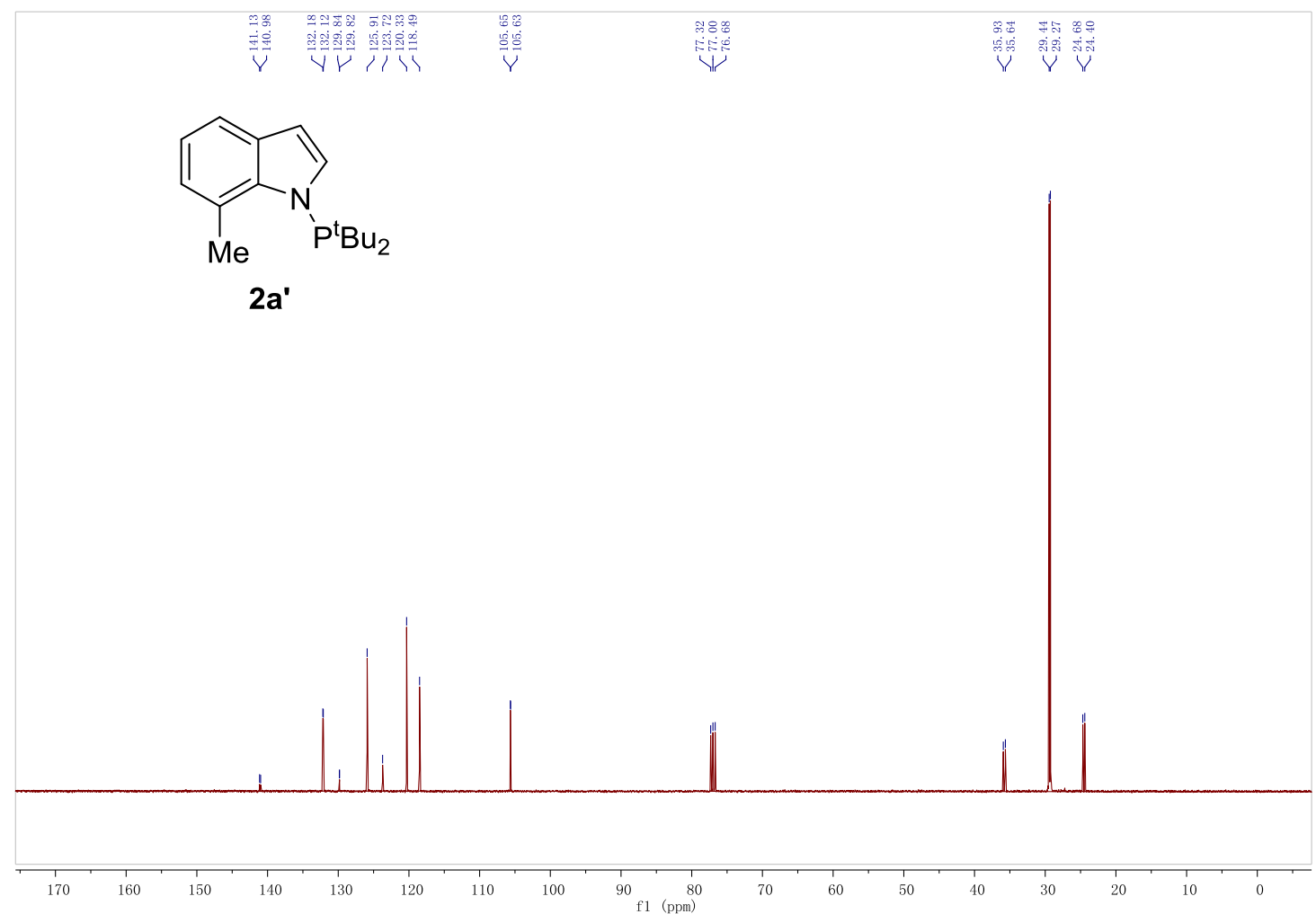


${ }^{31}$ P NMR (400 MHz, $\left.\mathrm{CDCl}_{3}\right)$

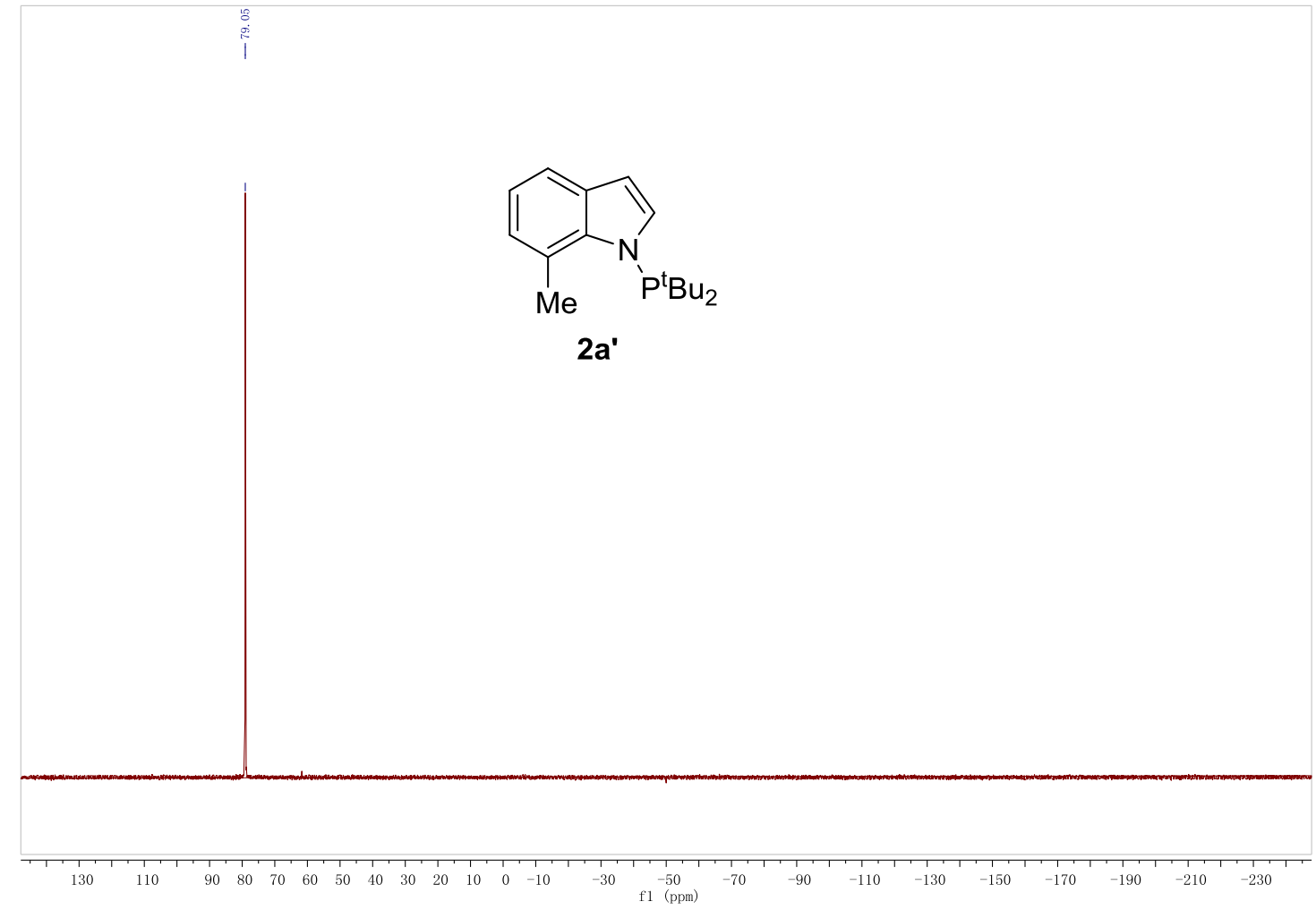

${ }^{1} \mathrm{H}$ NMR (400 MHz, $\left.\mathrm{CDCl}_{3}\right)$

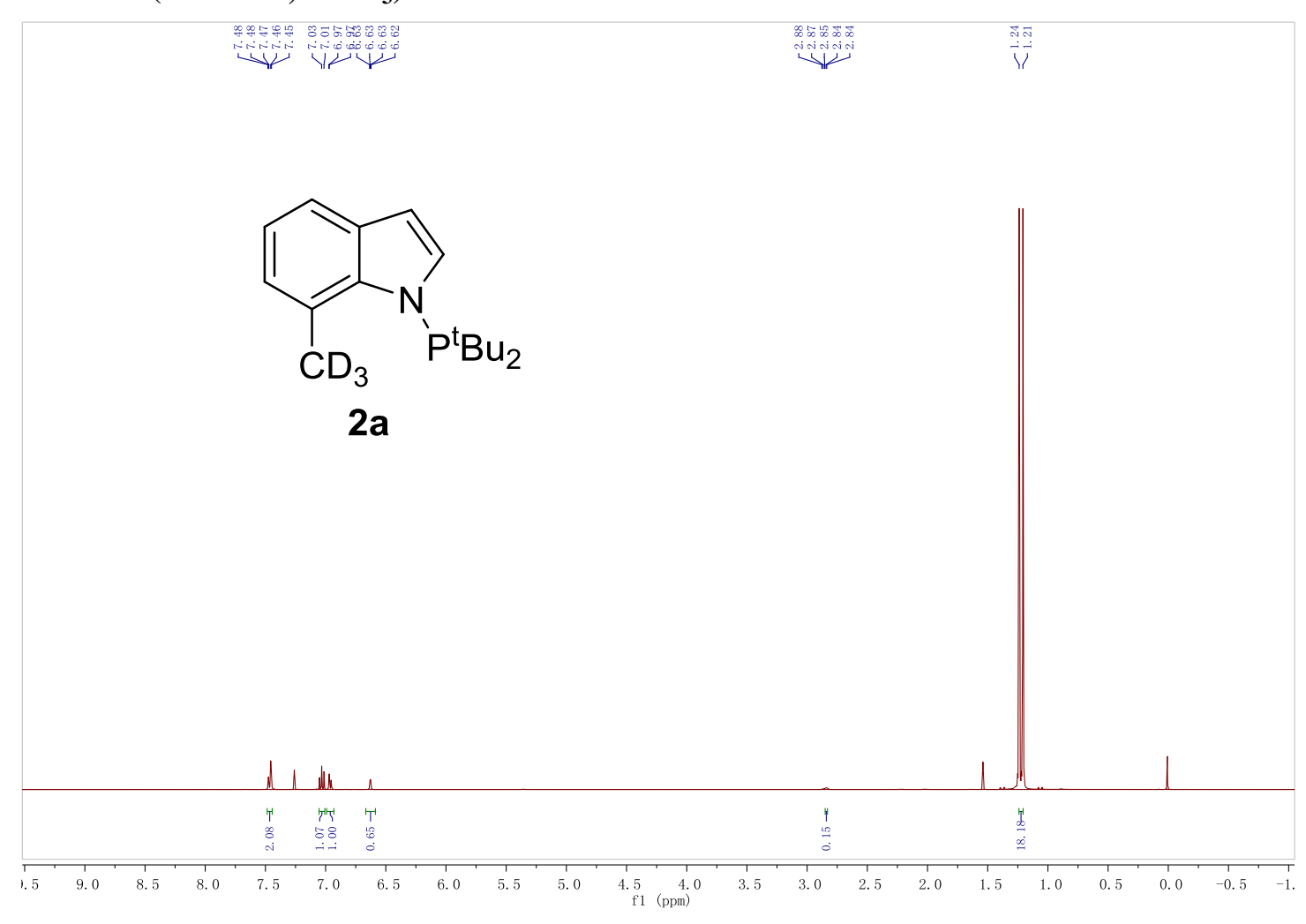


${ }^{1} \mathrm{H}$ NMR (400 MHz, $\mathrm{CDCl}_{3}$ )

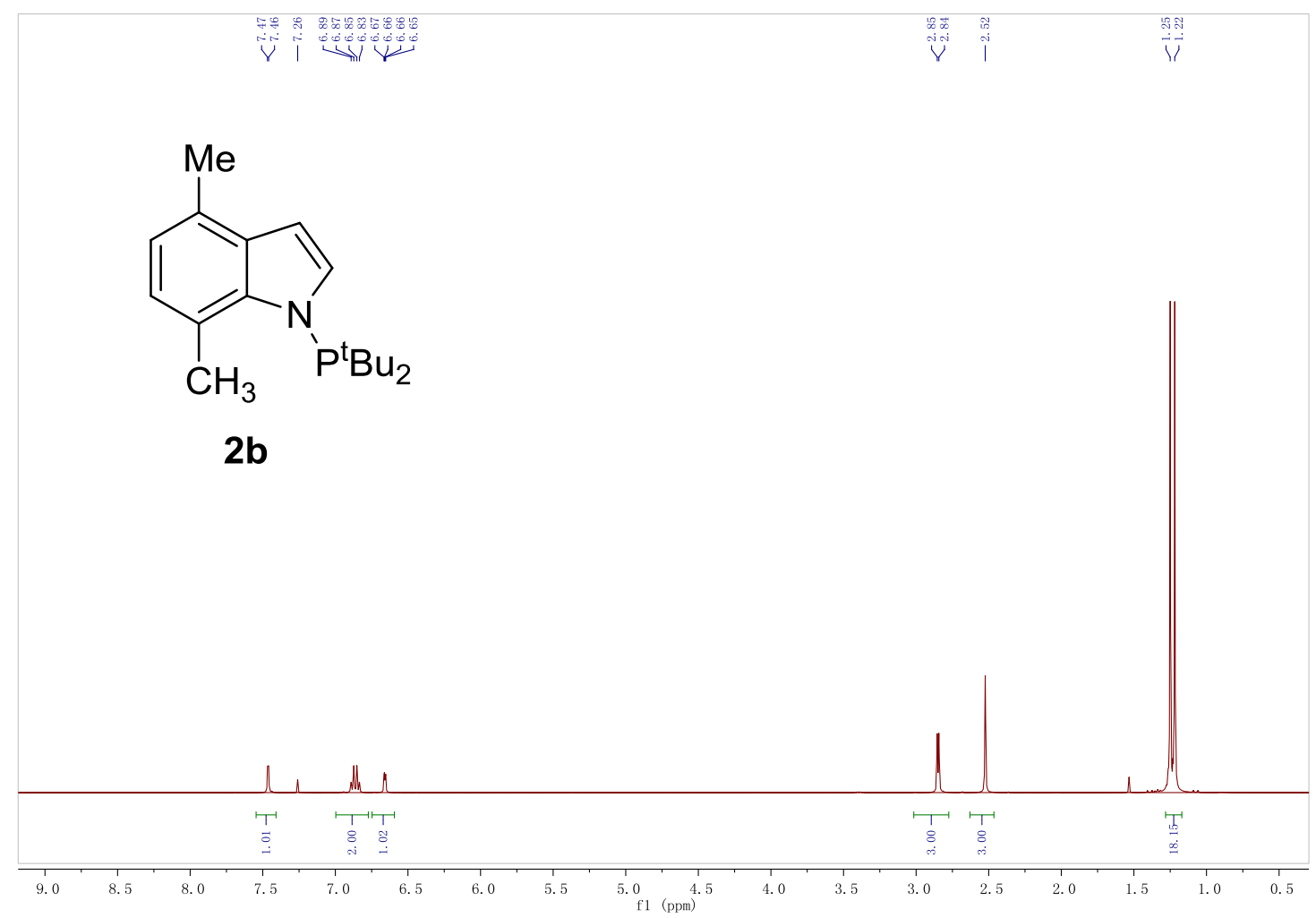

${ }^{13} \mathrm{C}$ NMR (400 MHz, $\mathrm{CDCl}_{3}$ )

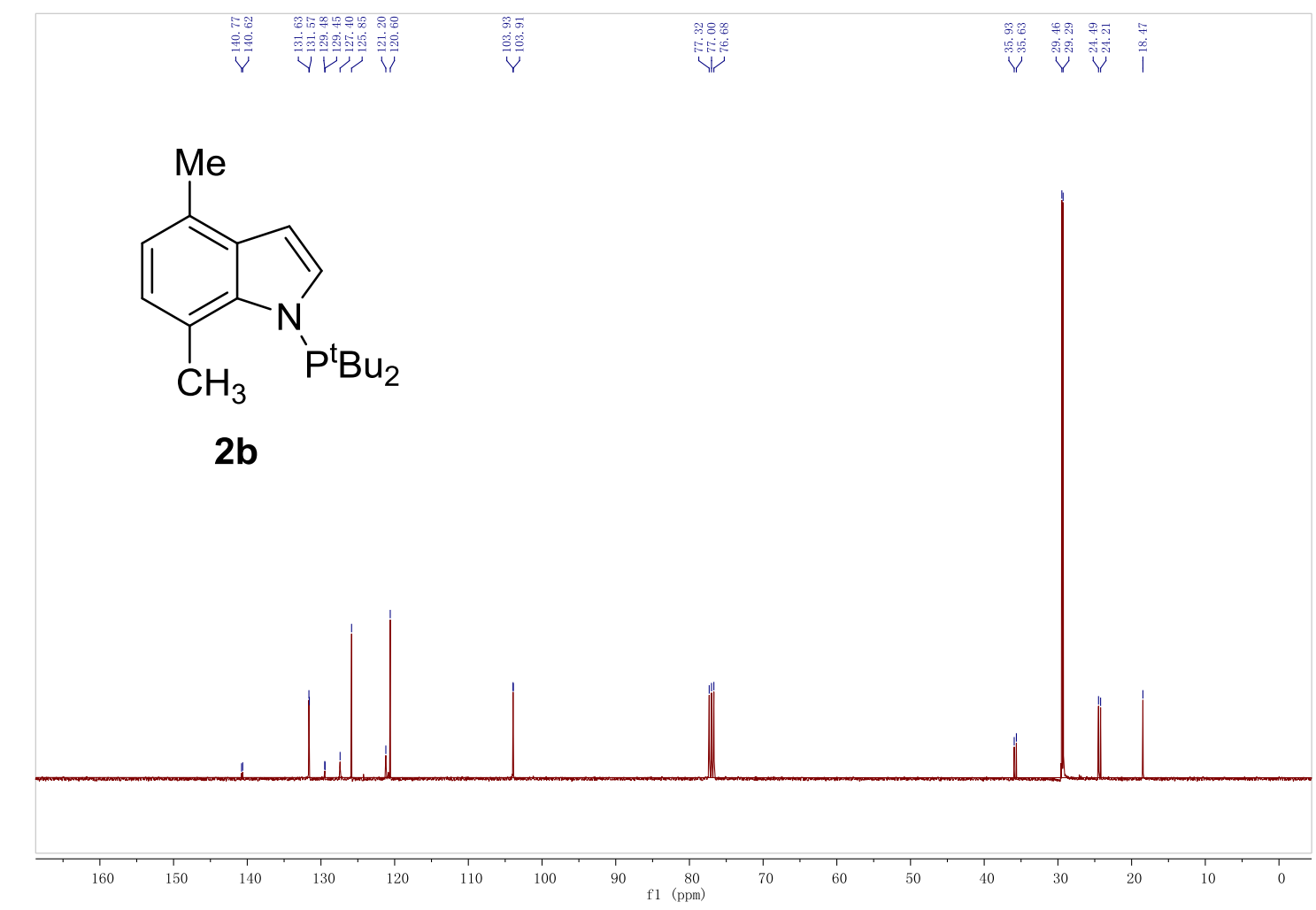


${ }^{31}$ P NMR (400 MHz, $\mathrm{CDCl}_{3}$ )

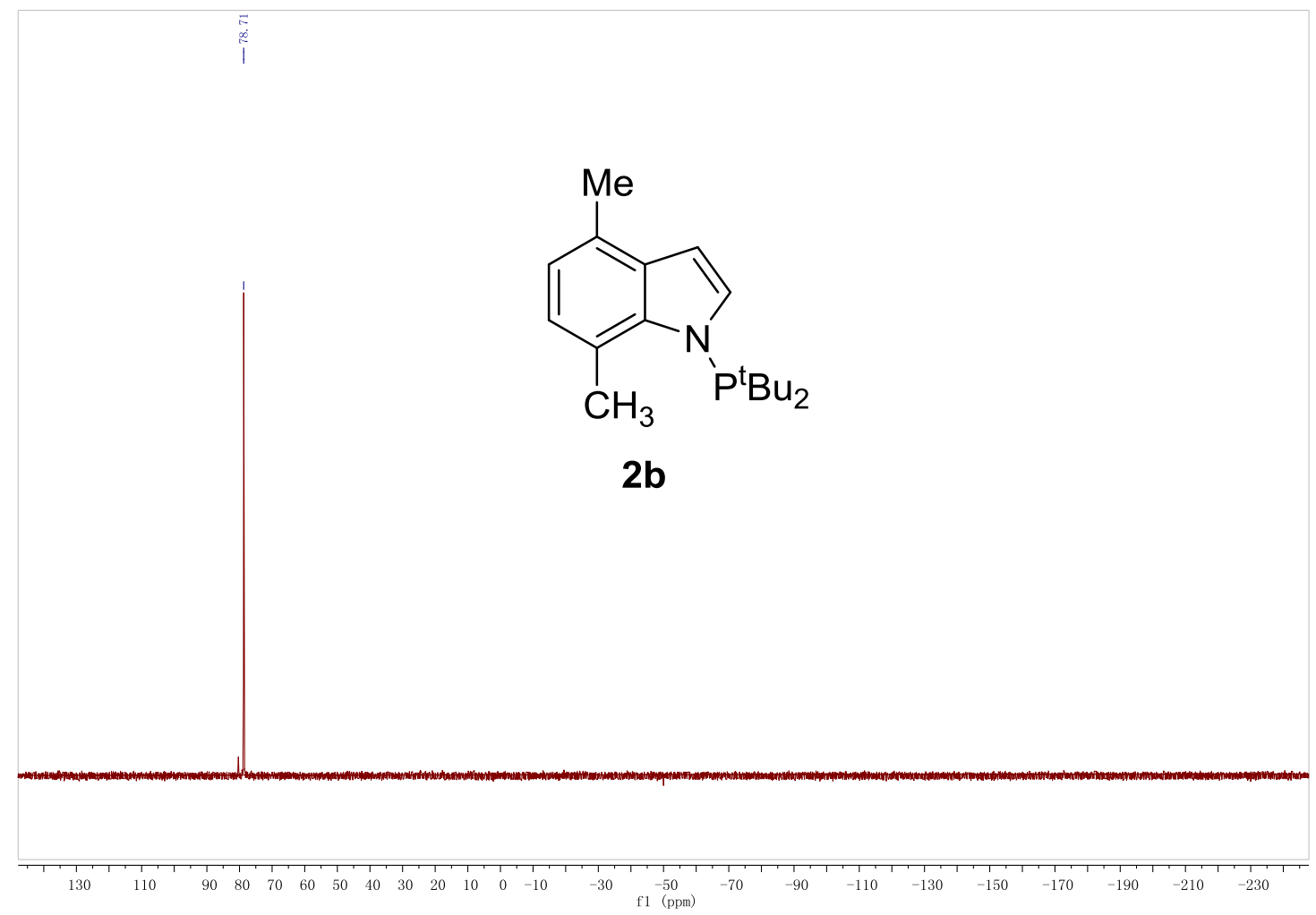

${ }^{1} \mathrm{H}$ NMR (400 MHz, $\mathrm{CDCl}_{3}$ )

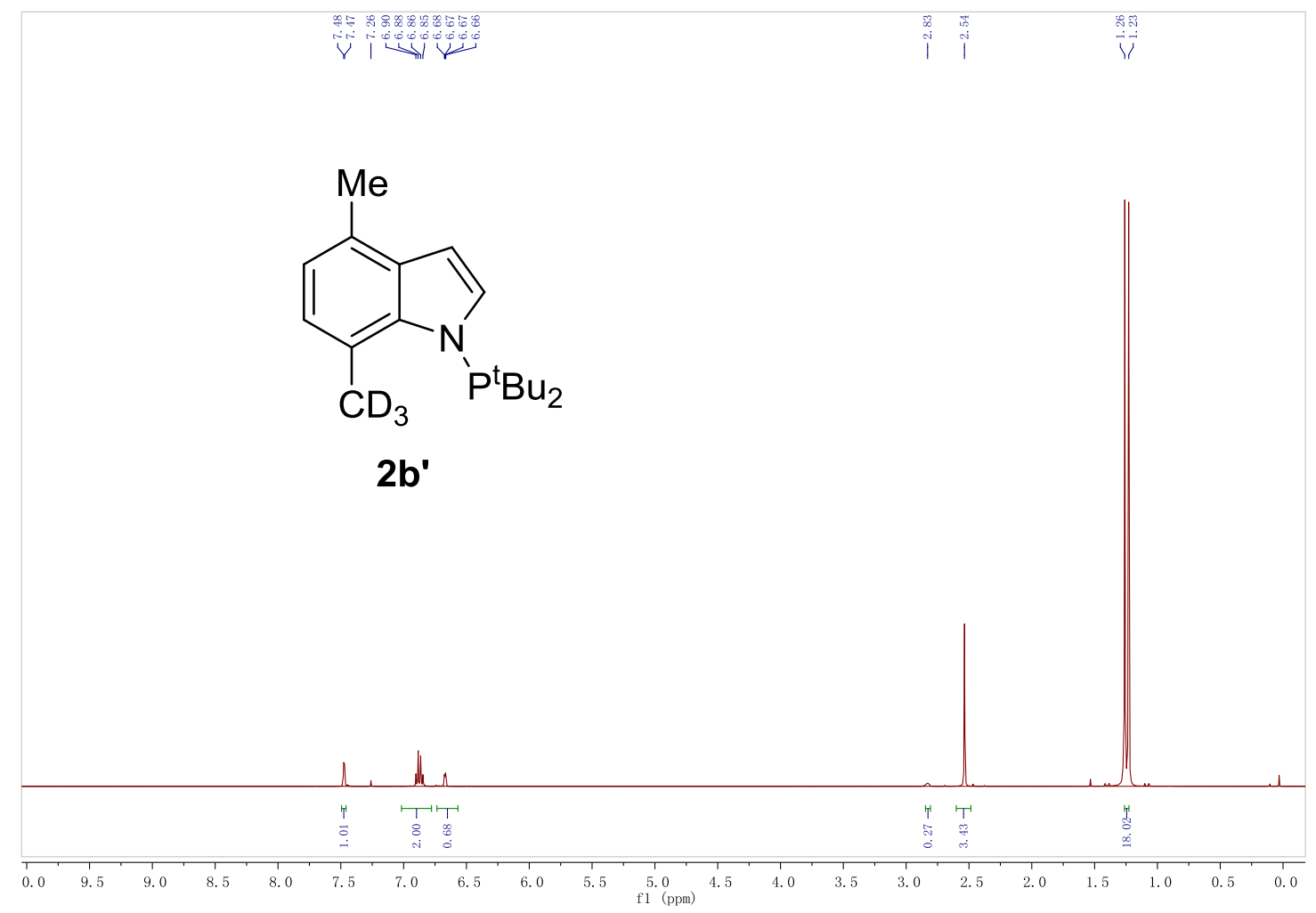


${ }^{1} \mathrm{H}$ NMR (400 MHz, $\mathrm{CDCl}_{3}$ )

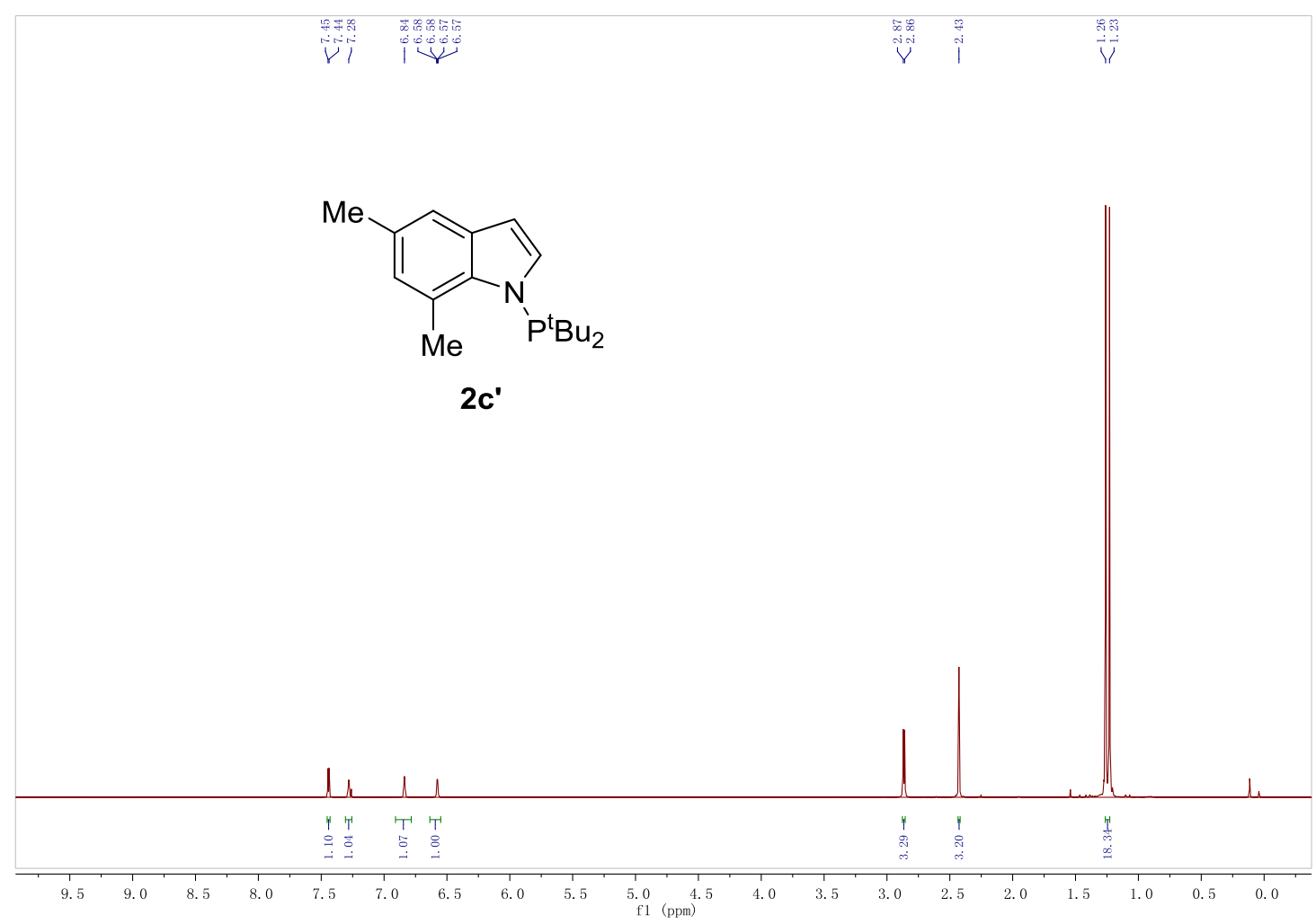

${ }^{13} \mathrm{C}$ NMR (400 MHz, $\mathrm{CDCl}_{3}$ )

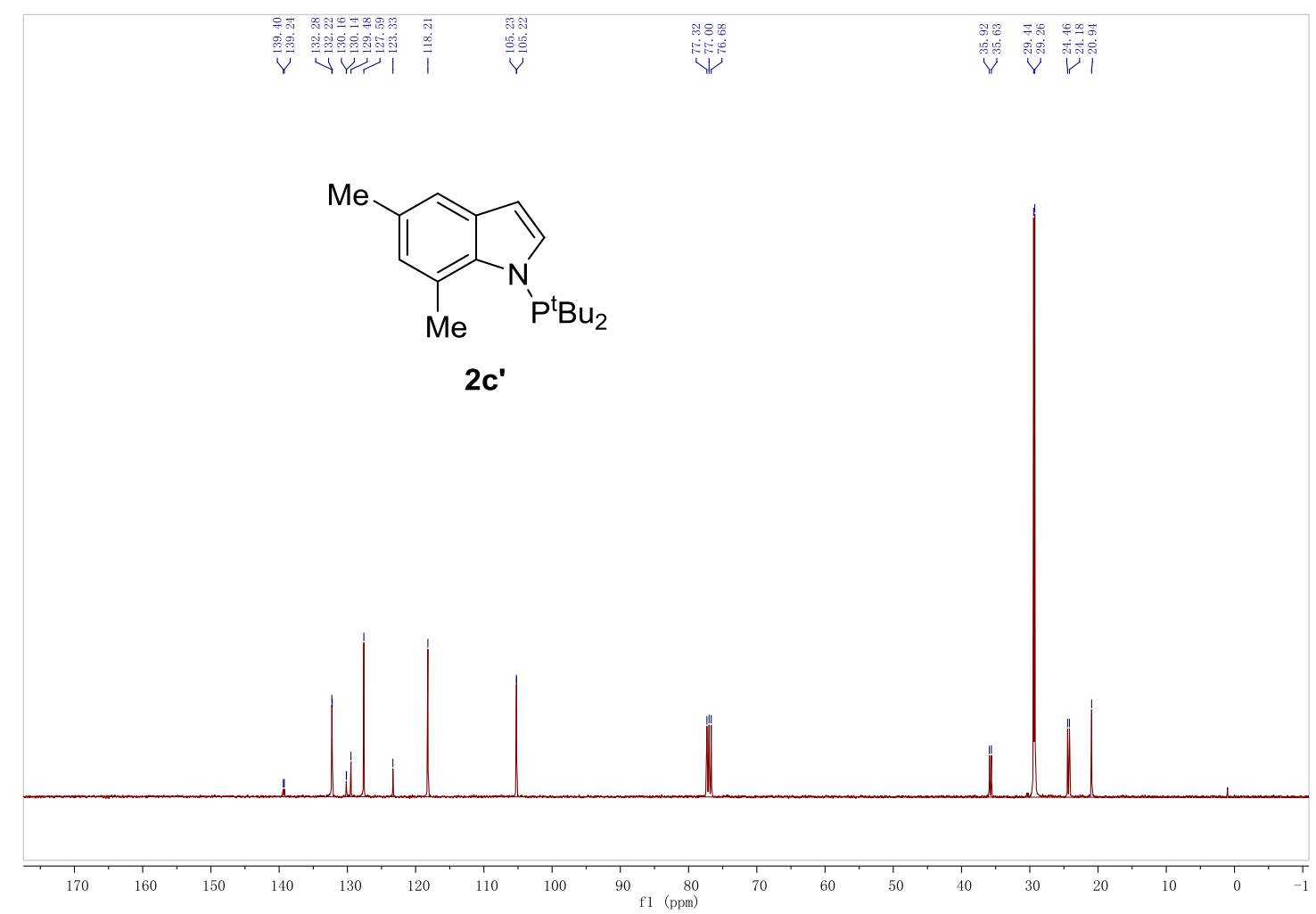


${ }^{31}$ P NMR (400 MHz, $\mathrm{CDCl}_{3}$ )

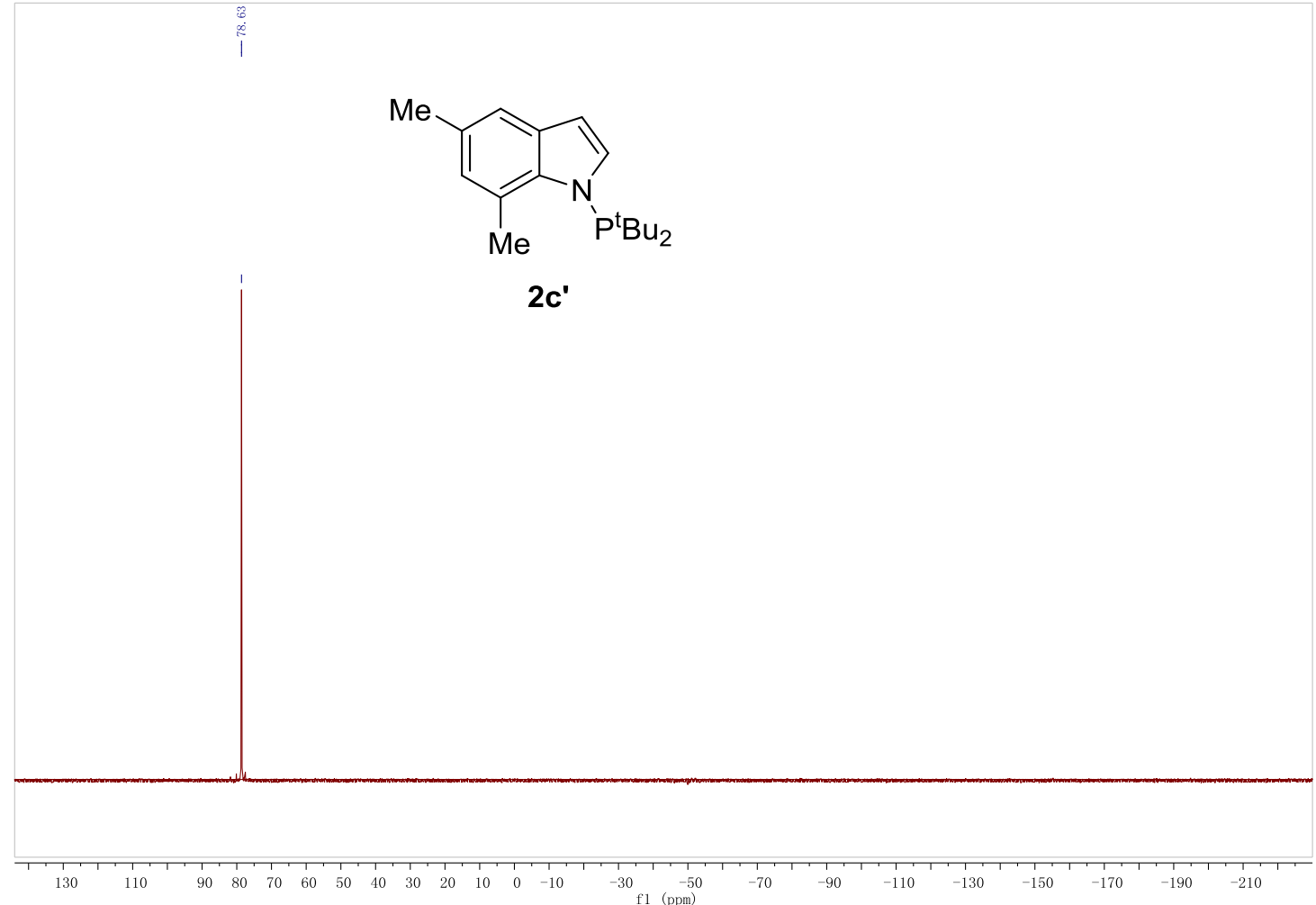

${ }^{1} \mathrm{H}$ NMR (400 MHz, $\mathrm{CDCl}_{3}$ )

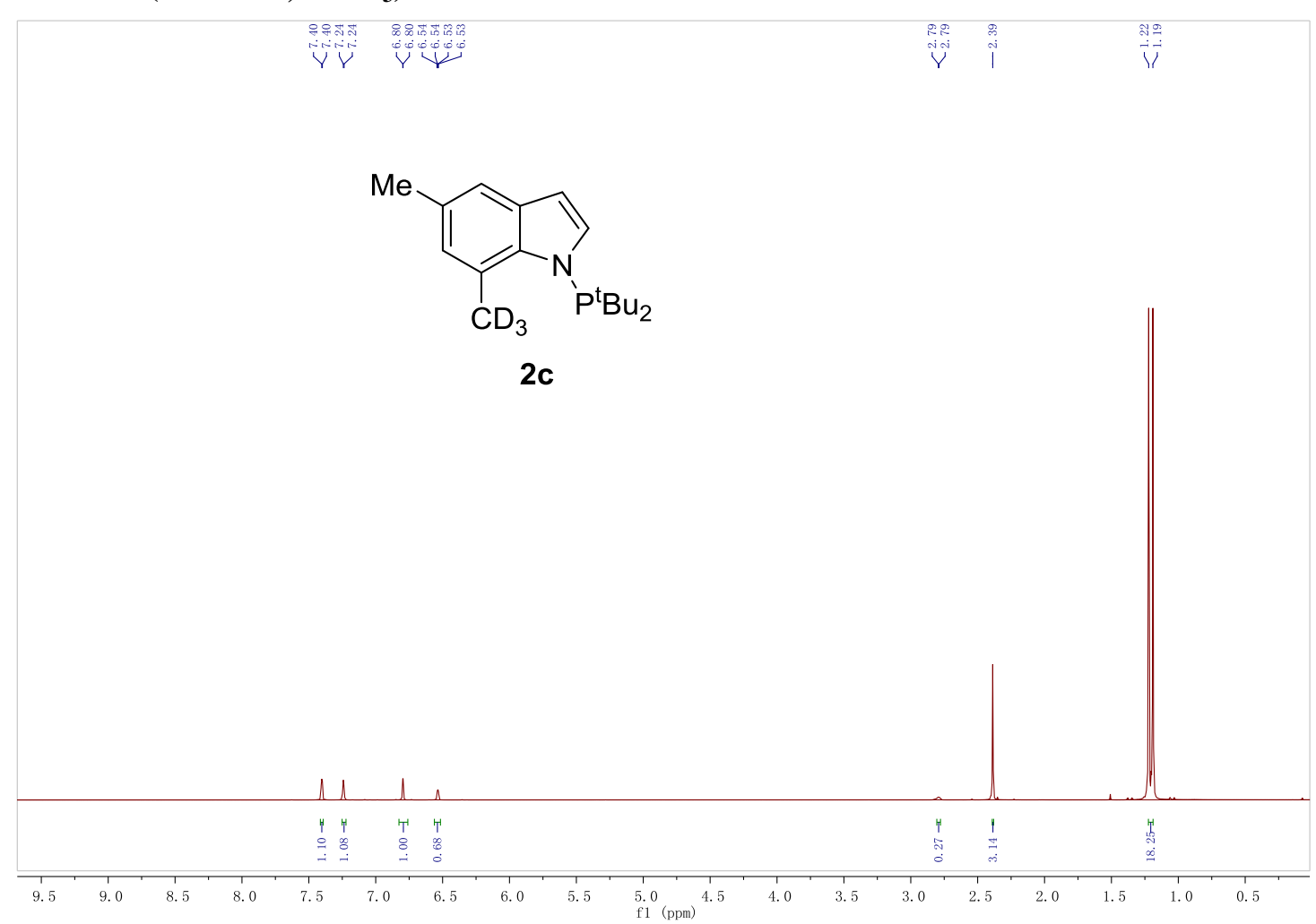


${ }^{1} \mathrm{H}$ NMR (400 MHz, $\left.\mathrm{CDCl}_{3}\right)$

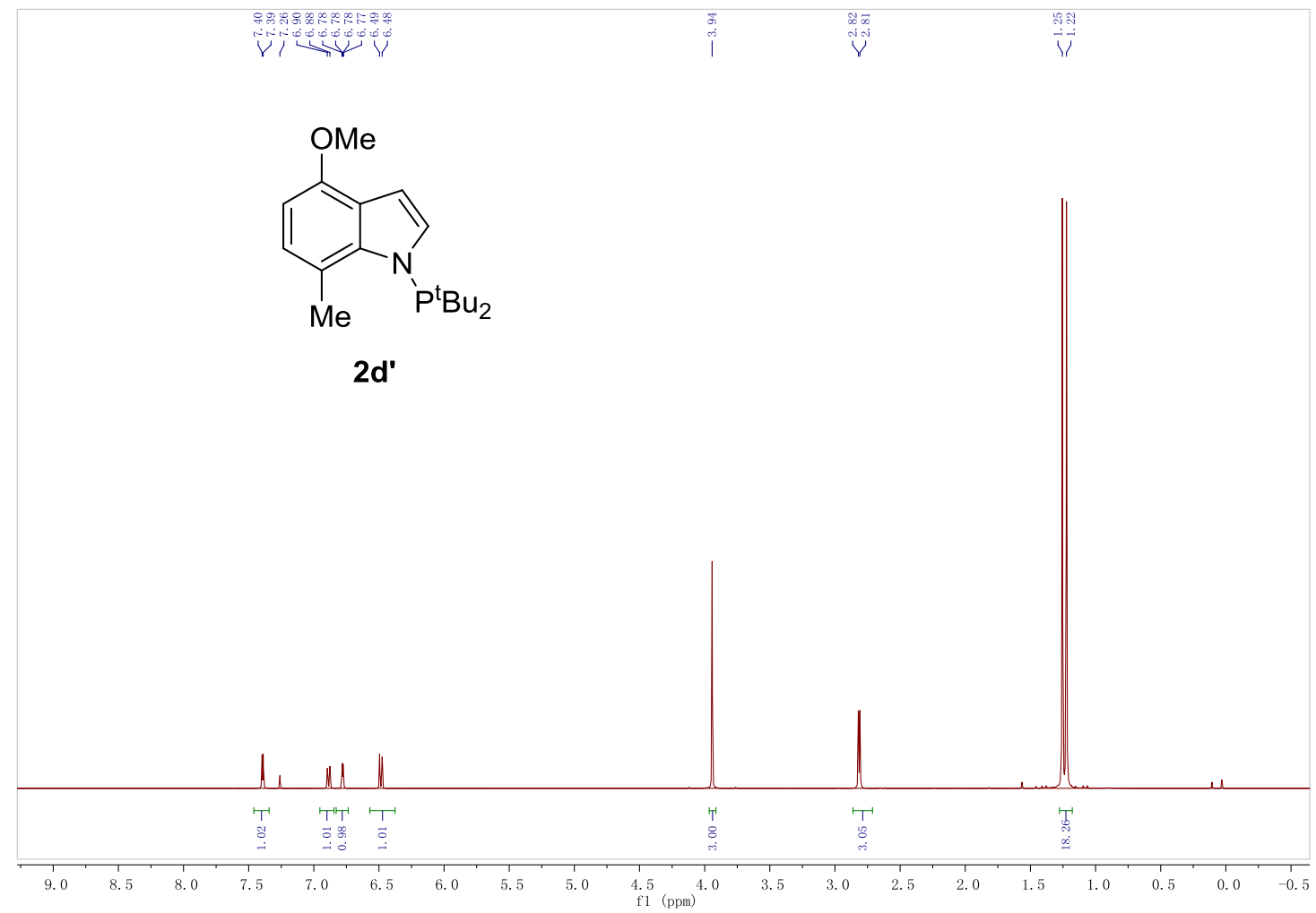

${ }^{13} \mathrm{C}$ NMR (400 MHz, $\left.\mathrm{CDCl}_{3}\right)$

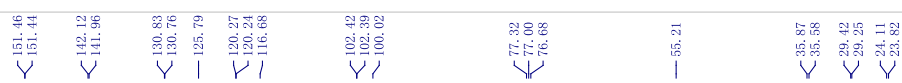

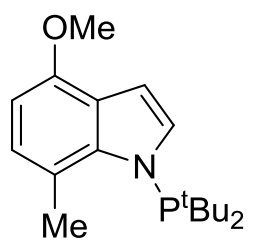

2d'

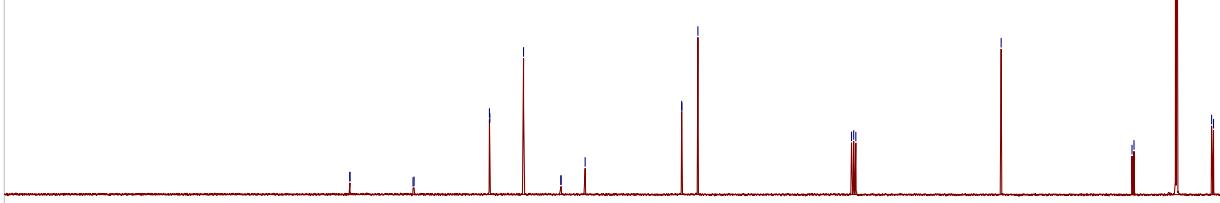

$\begin{array}{lllllllllll}200 & 190 & 180 & 170 & 160 & 150 & 140 & 130 & 120 & 110 & 100 \\ & & & & & 100 & \end{array}$ 
${ }^{31}$ P NMR (400 MHz, $\mathrm{CDCl}_{3}$ )

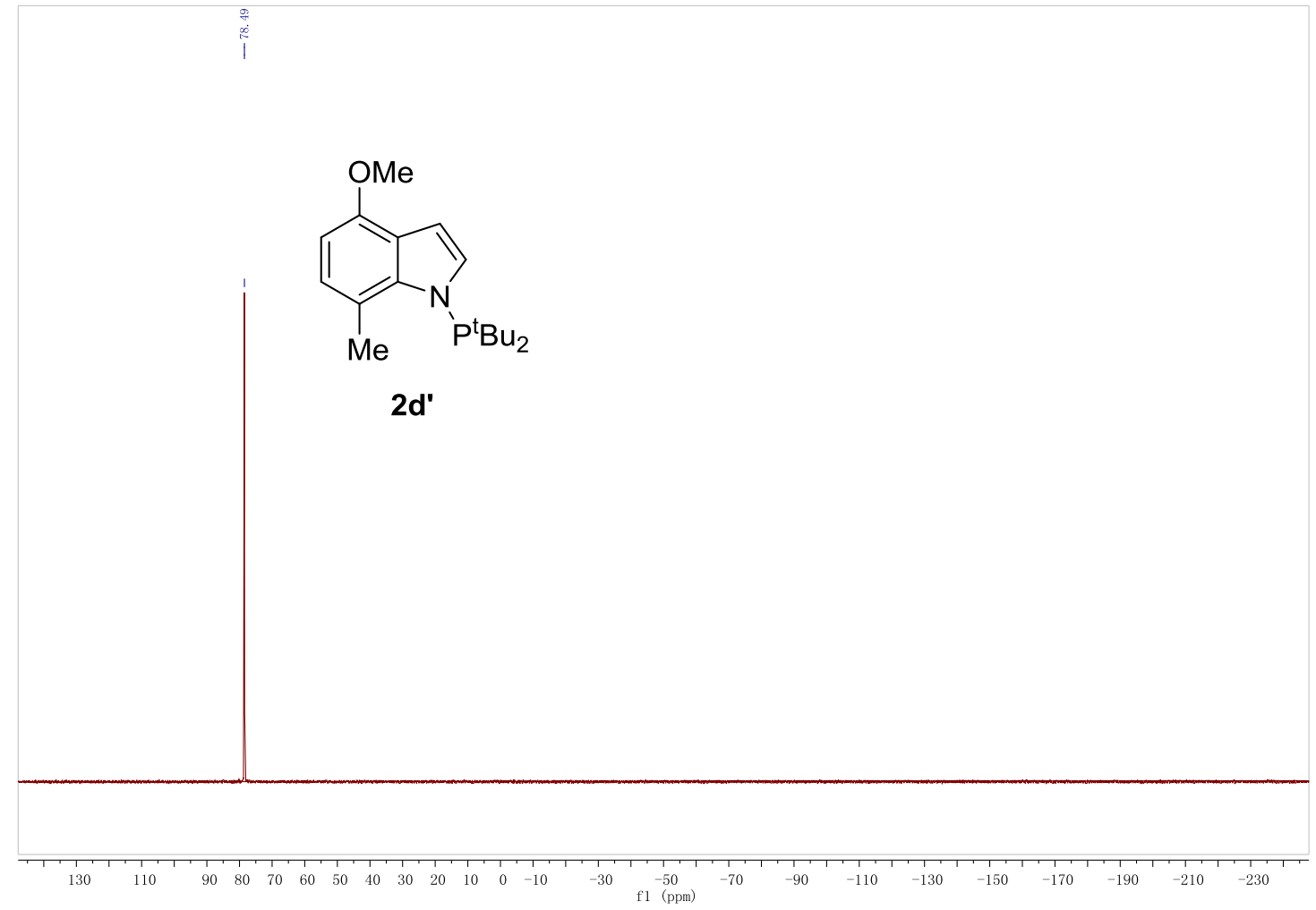

${ }^{1} \mathrm{H}$ NMR (400 MHz, $\left.\mathrm{CDCl}_{3}\right)$

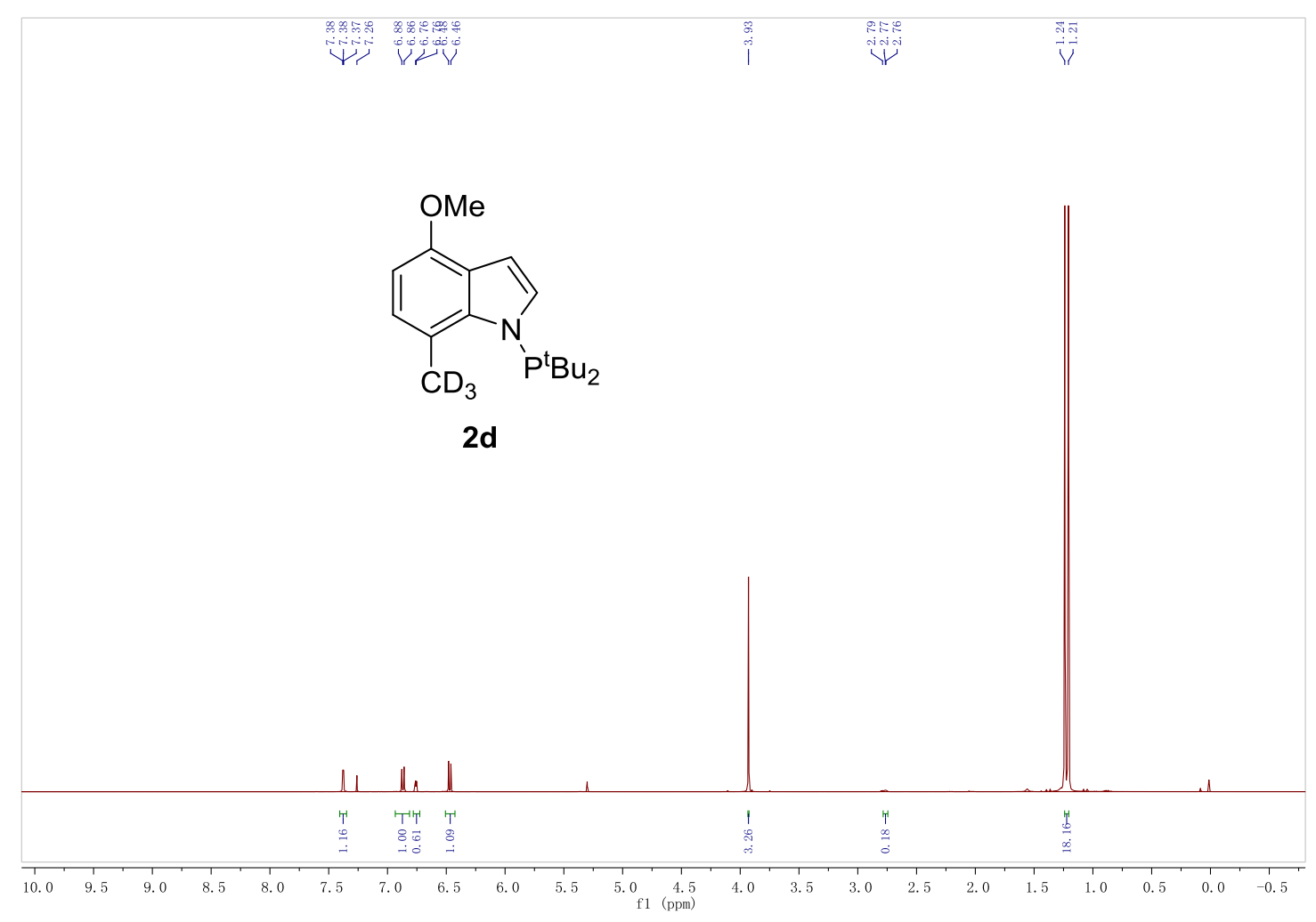


${ }^{1} \mathrm{H}$ NMR (400 MHz, $\left.\mathrm{CDCl}_{3}\right)$

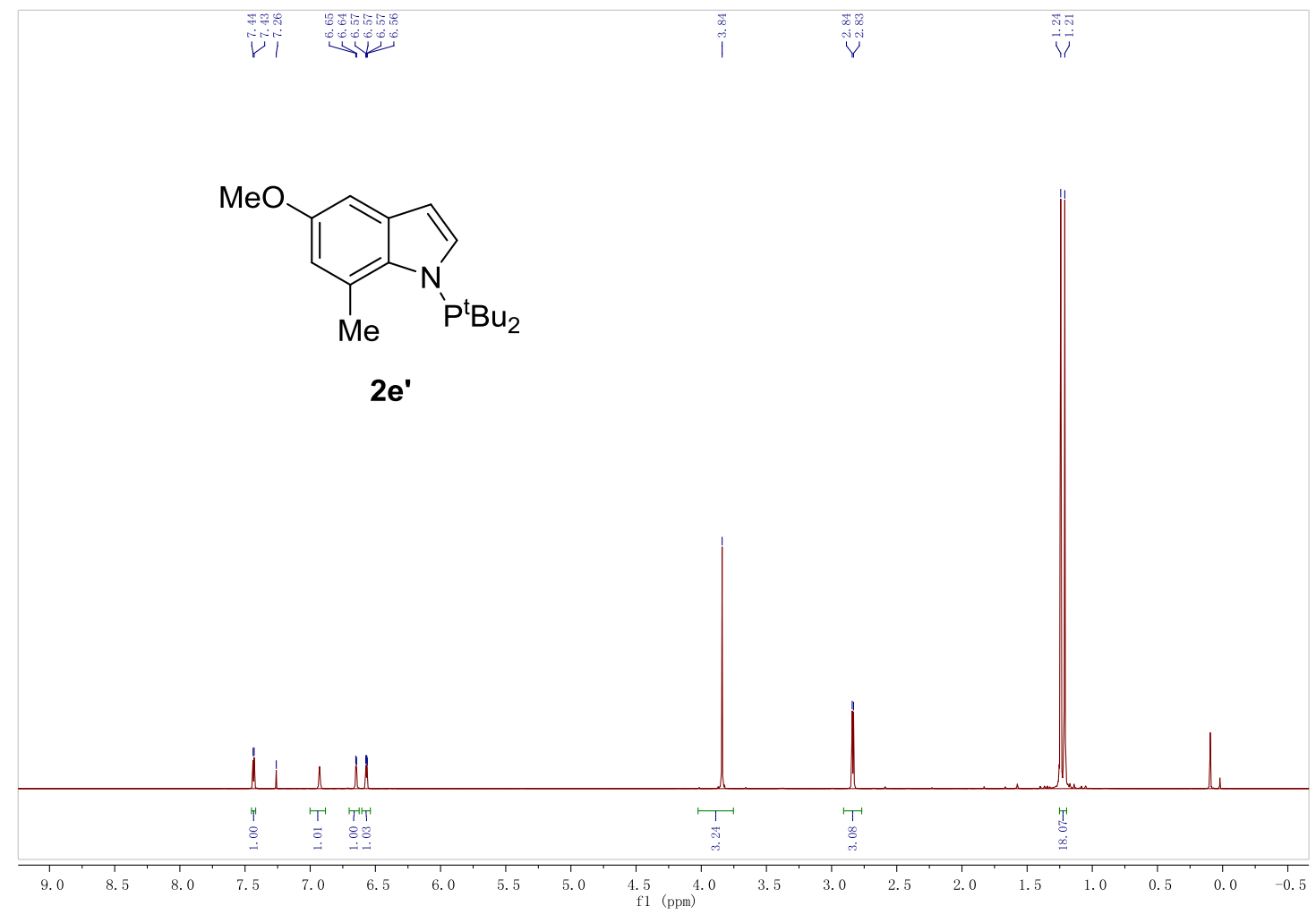

${ }^{13} \mathrm{C}$ NMR (400 MHz, $\mathrm{CDCl}_{3}$ )
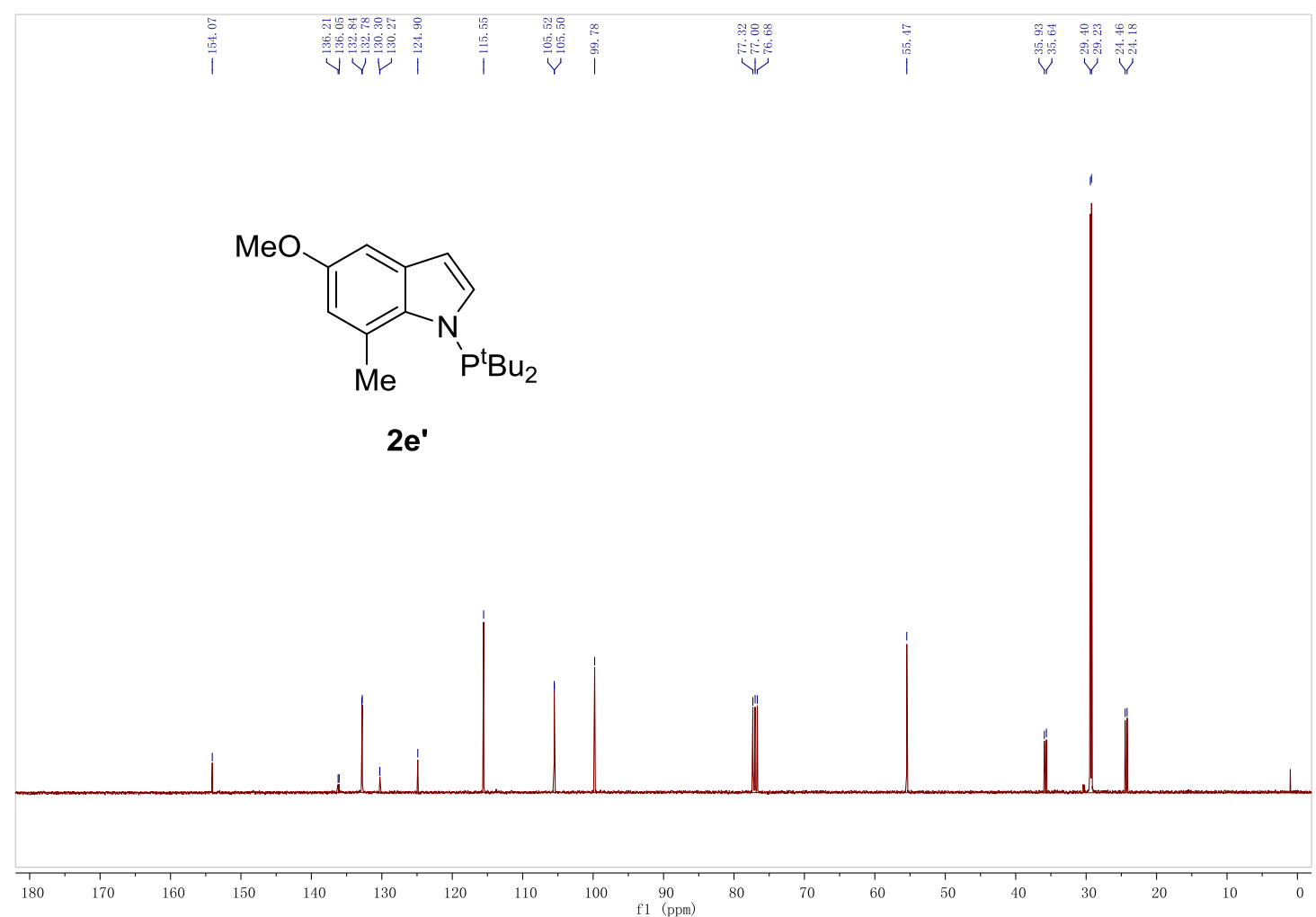
${ }^{31}$ P NMR (400 MHz, $\mathrm{CDCl}_{3}$ )

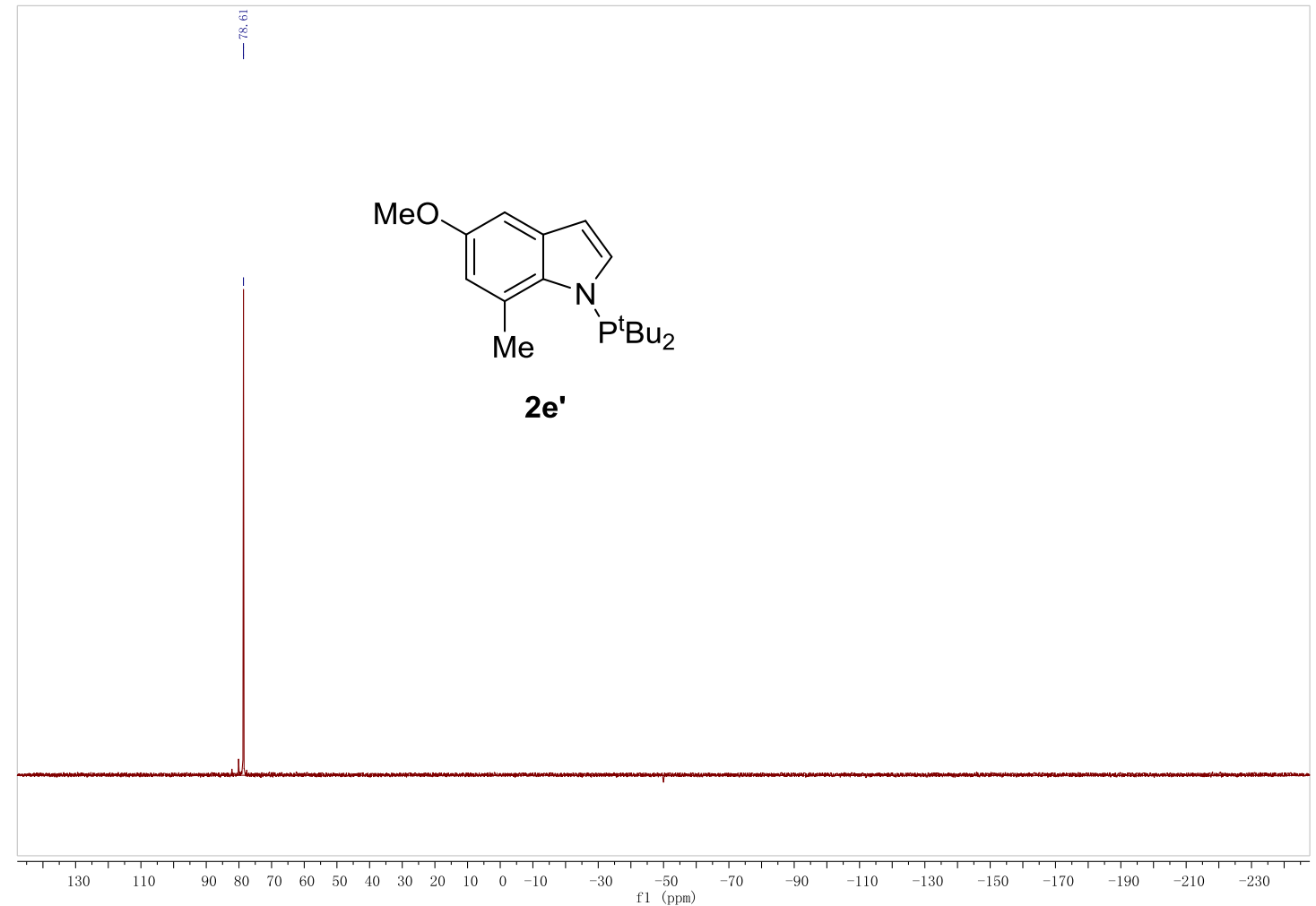

${ }^{1} \mathrm{H}$ NMR (400 MHz, $\left.\mathrm{CDCl}_{3}\right)$

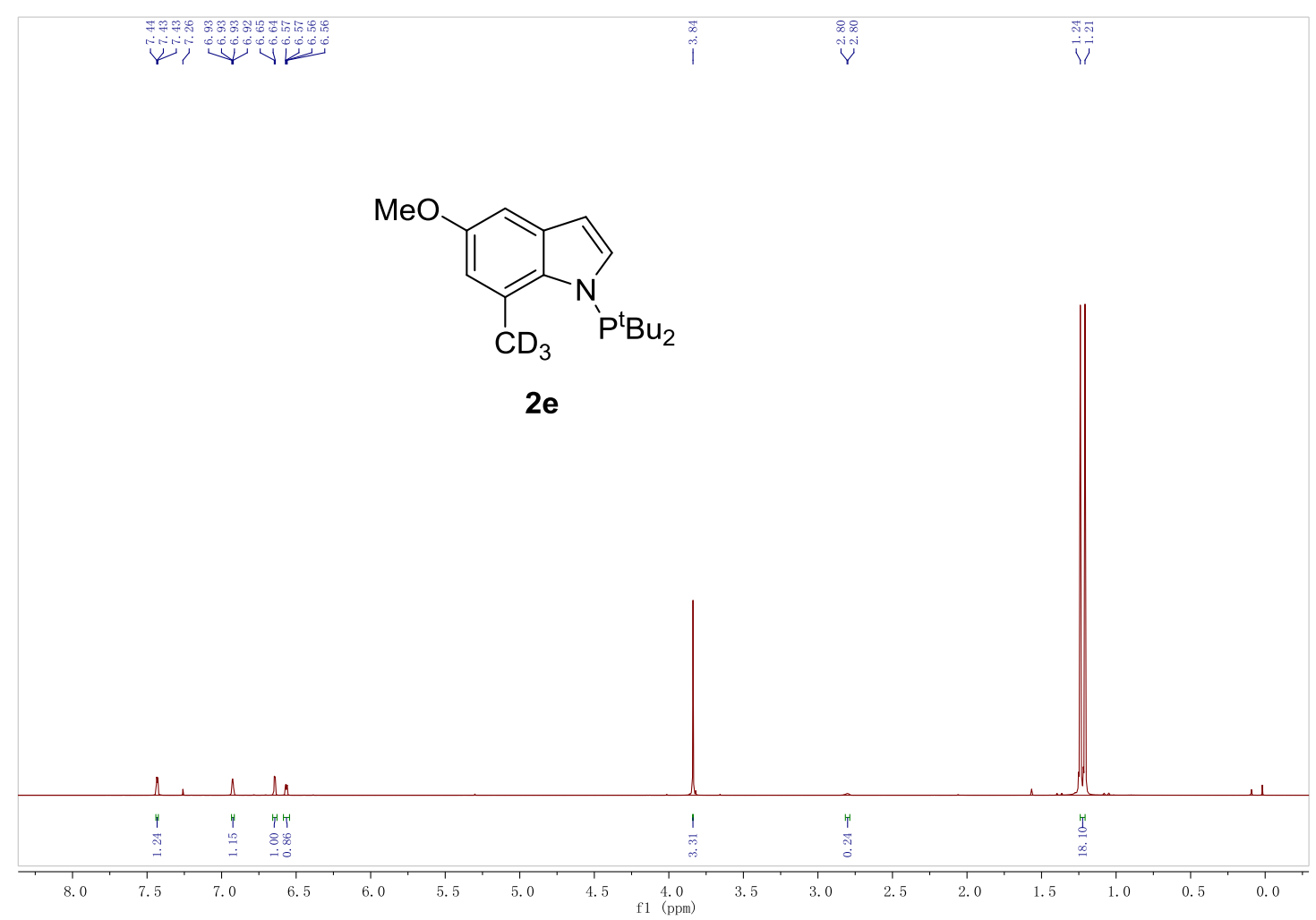


${ }^{1} \mathrm{H}$ NMR (400 MHz, $\mathrm{CDCl}_{3}$ )

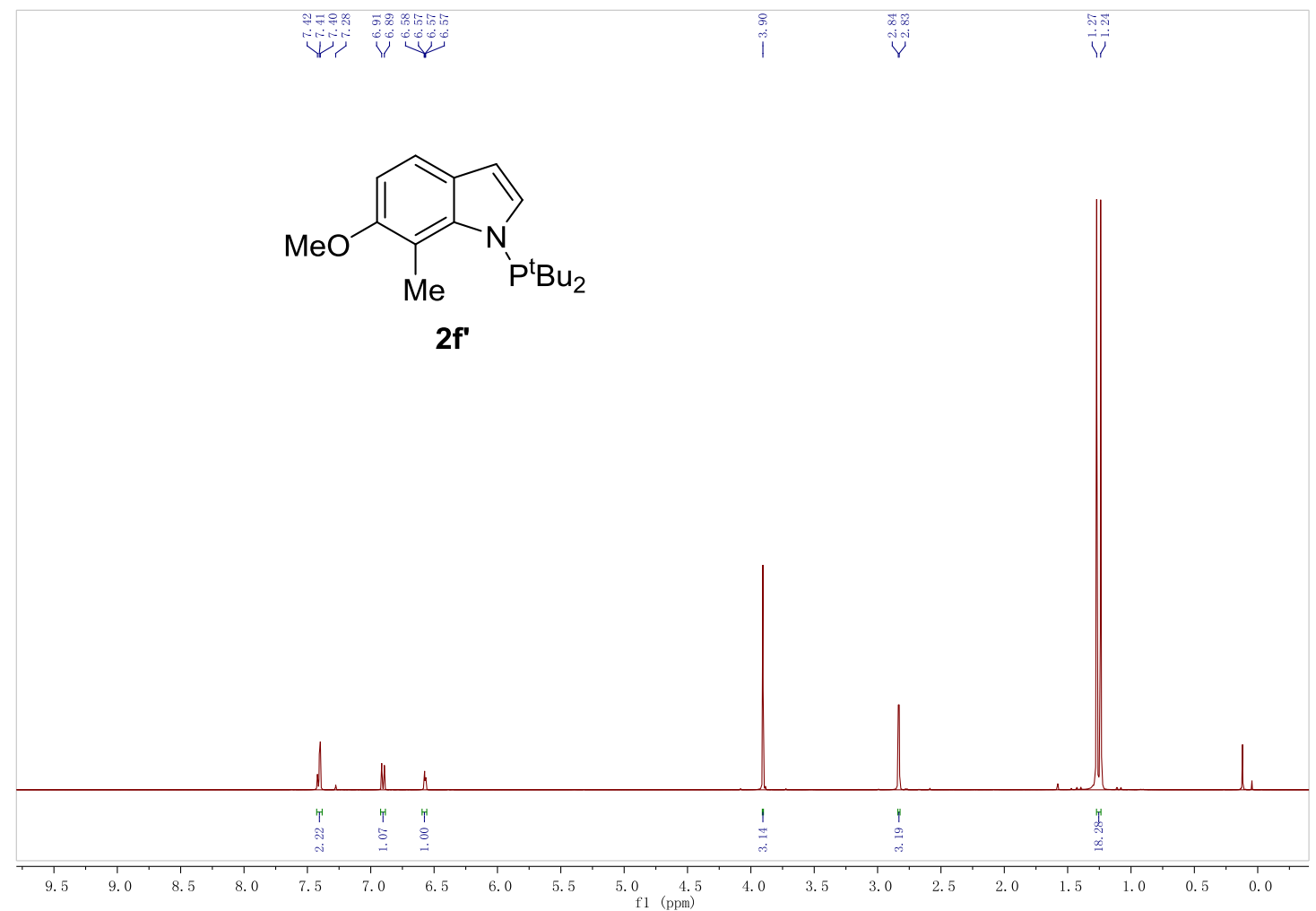

${ }^{13} \mathrm{C}$ NMR (400 MHz, $\mathrm{CDCl}_{3}$ )
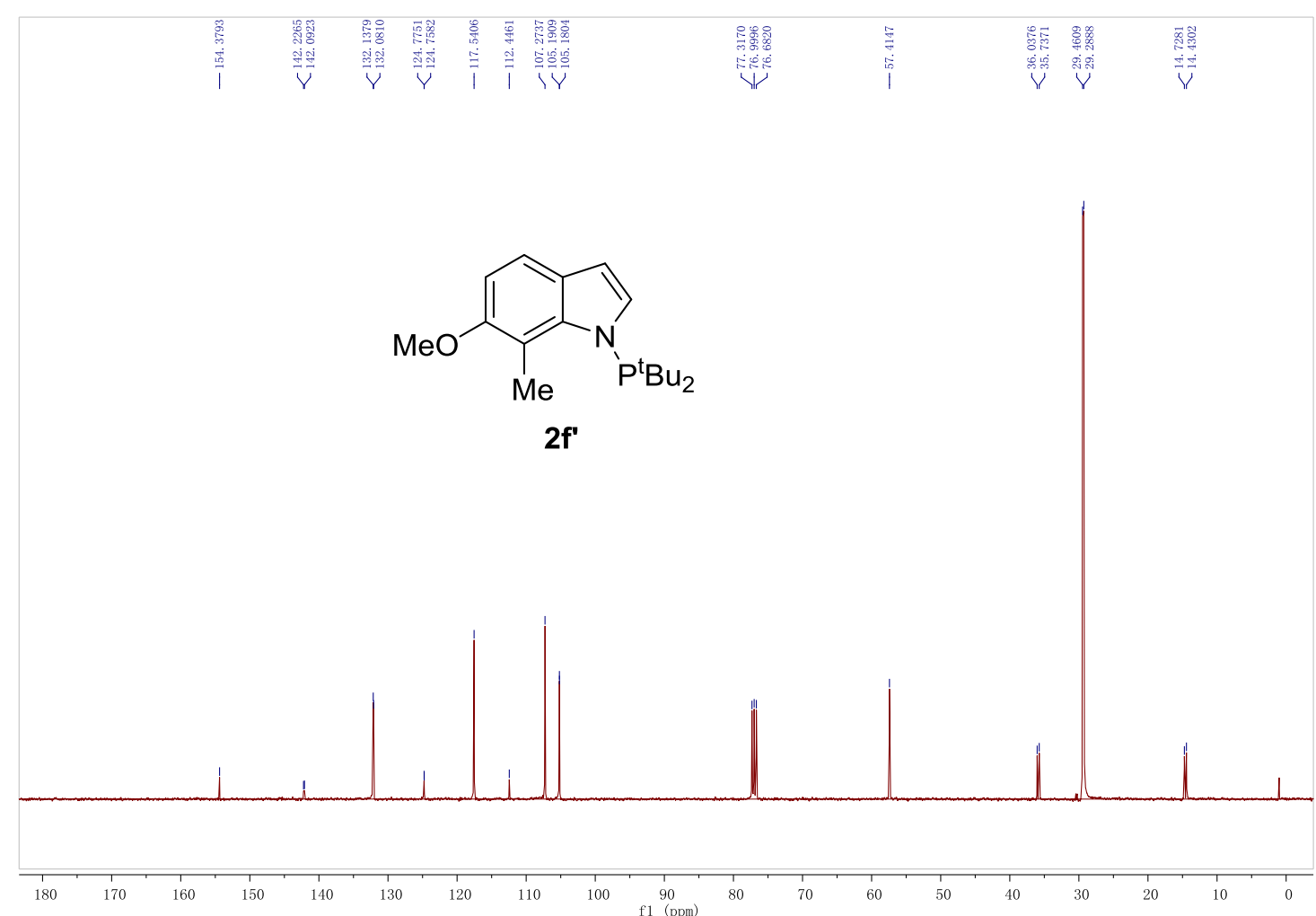
${ }^{31}$ P NMR (400 MHz, $\mathrm{CDCl}_{3}$ )

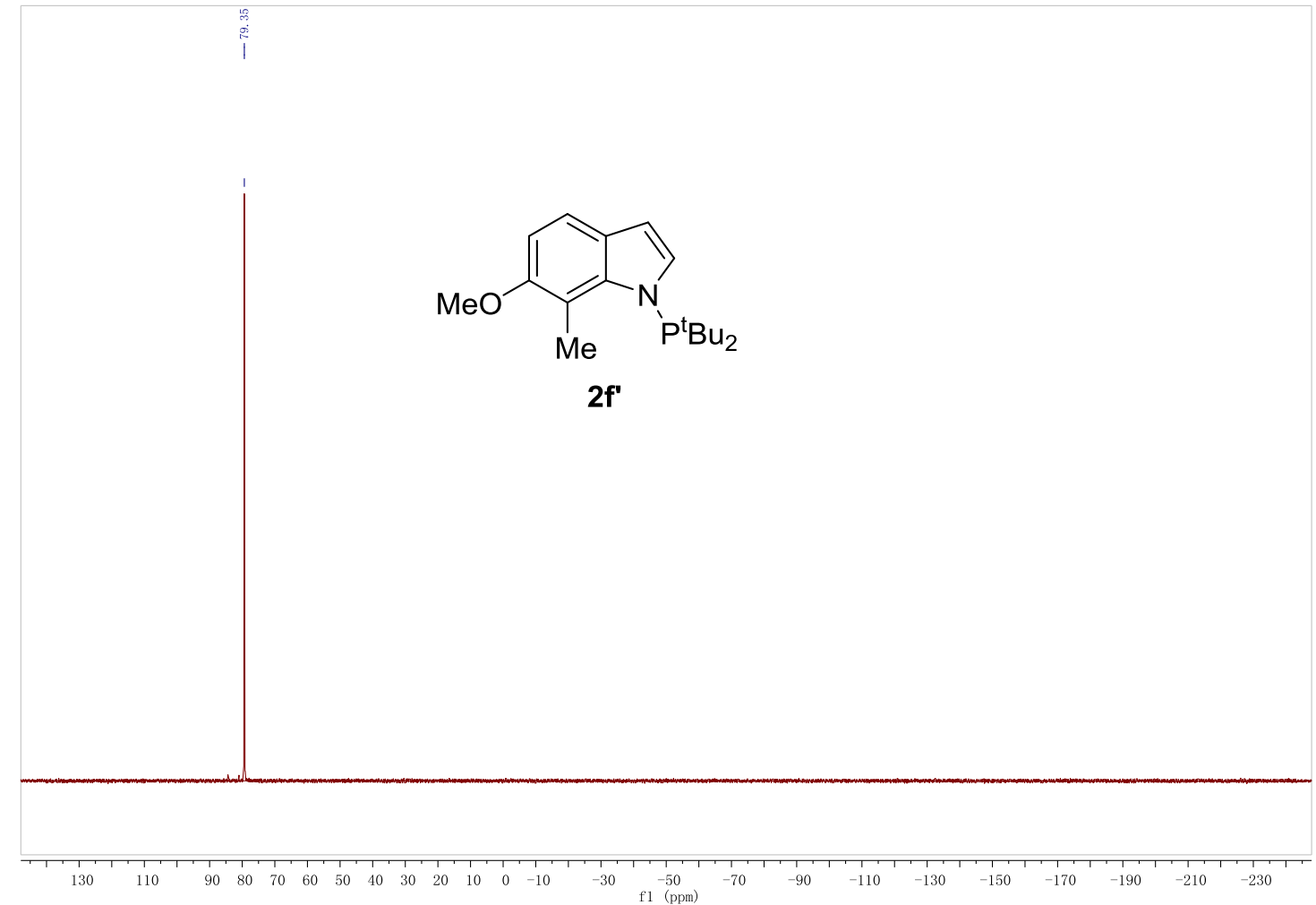

${ }^{1} \mathrm{H}$ NMR (400 MHz, $\left.\mathrm{CDCl}_{3}\right)$

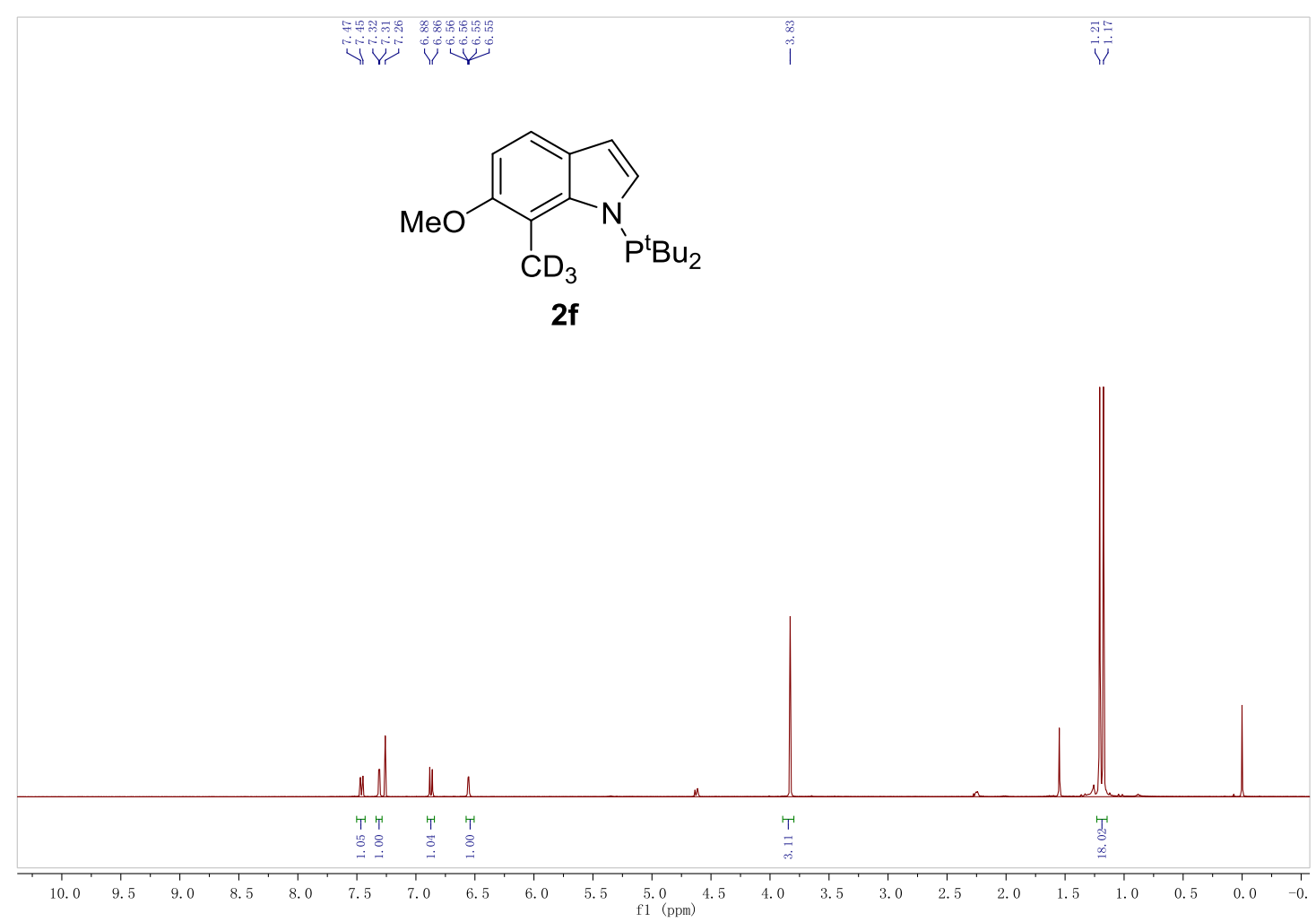


${ }^{1} \mathrm{H}$ NMR (400 MHz, $\left.\mathrm{CDCl}_{3}\right)$

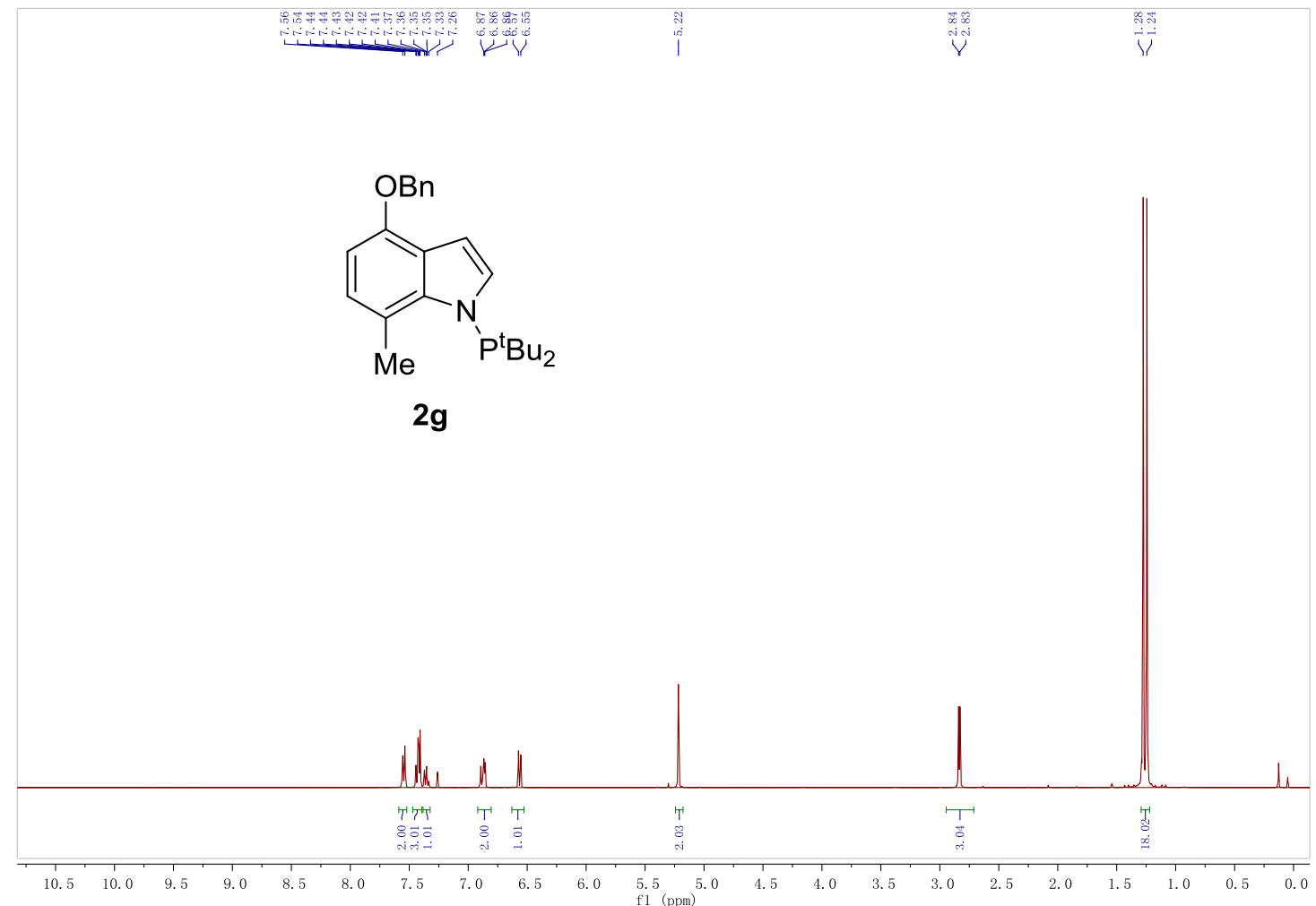

${ }^{13} \mathrm{C}$ NMR (400 MHz, $\mathrm{CDCl}_{3}$ )

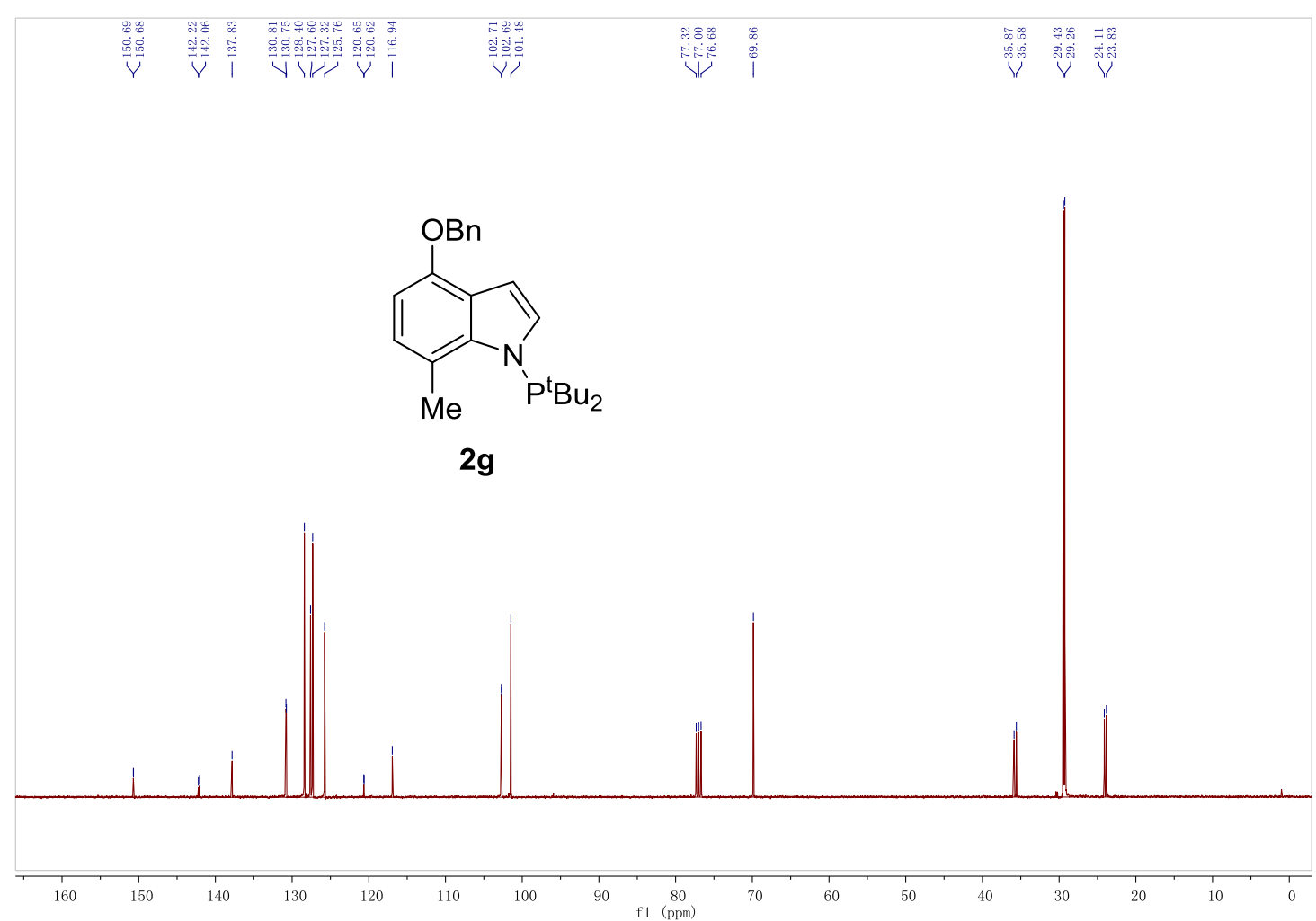


${ }^{31}$ P NMR (400 MHz, $\mathrm{CDCl}_{3}$ )

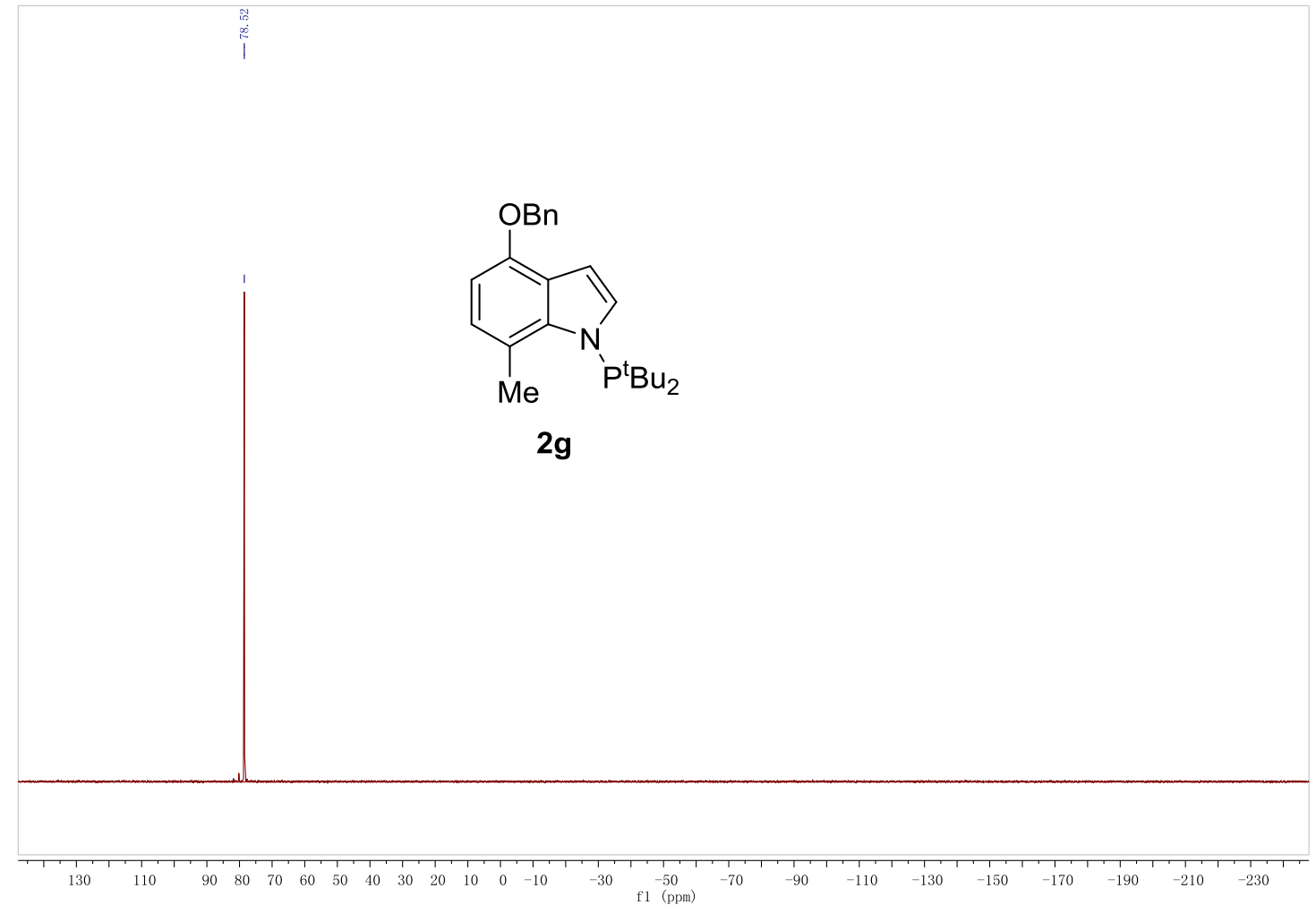

${ }^{1} \mathrm{H}$ NMR (400 MHz, $\left.\mathrm{CDCl}_{3}\right)$

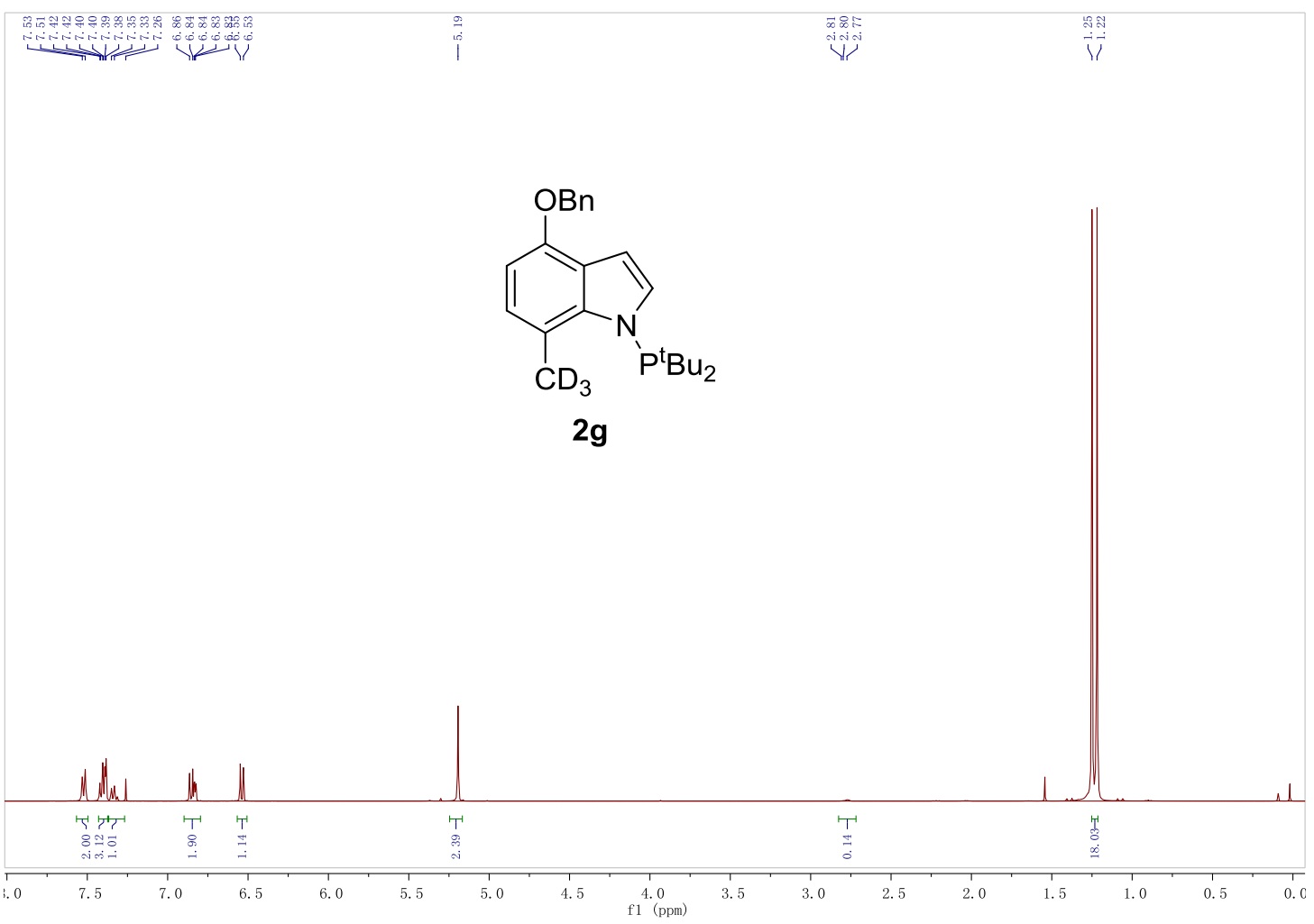


${ }^{1} \mathrm{H}$ NMR (400 MHz, $\left.\mathrm{CDCl}_{3}\right)$

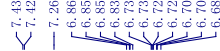
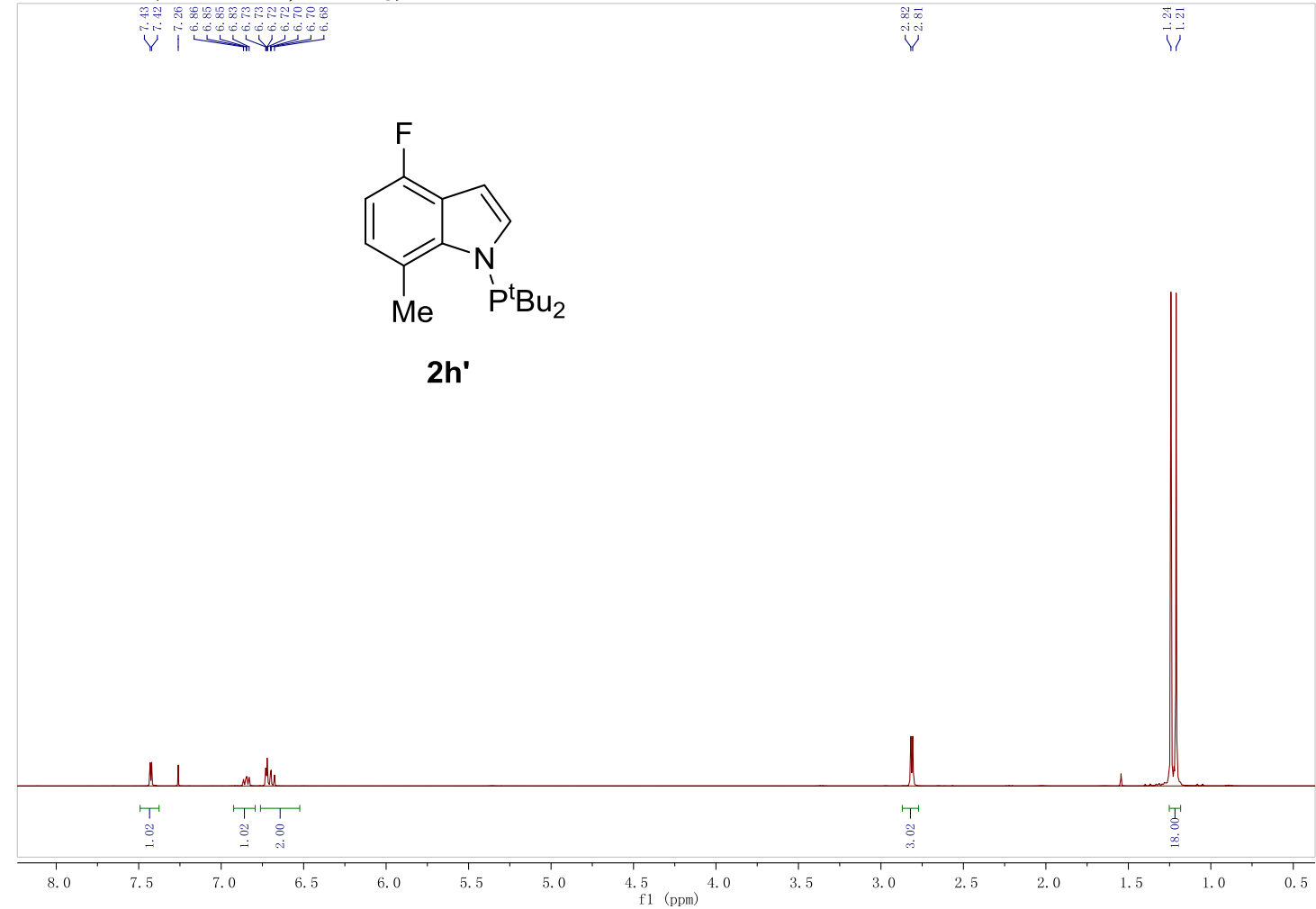

$2 h^{\prime}$

${ }^{13} \mathrm{C}$ NMR (400 MHz, $\mathrm{CDCl}_{3}$ )

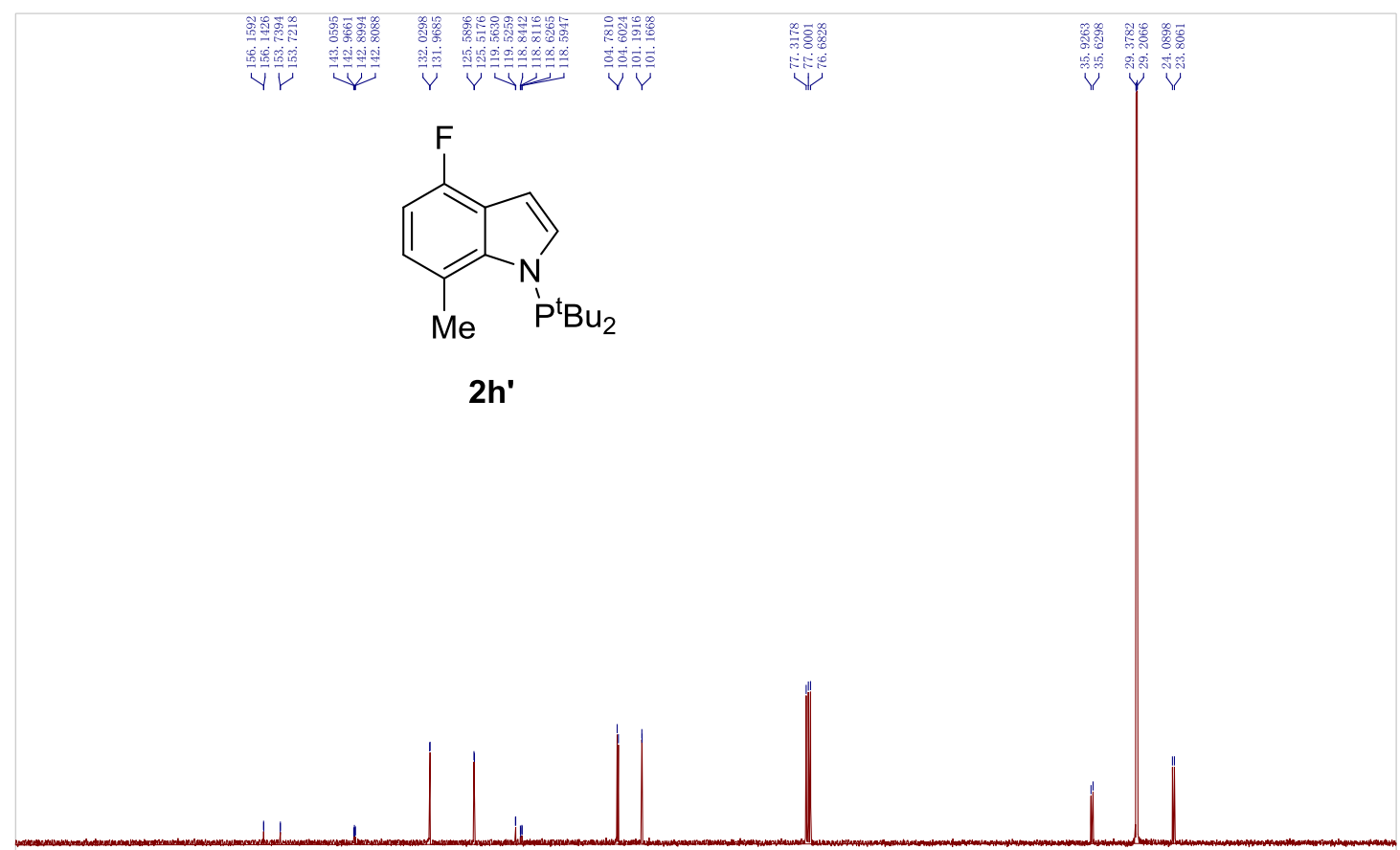

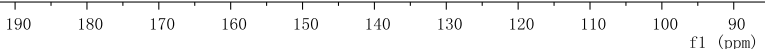


${ }^{31}$ P NMR (400 MHz, $\mathrm{CDCl}_{3}$ )
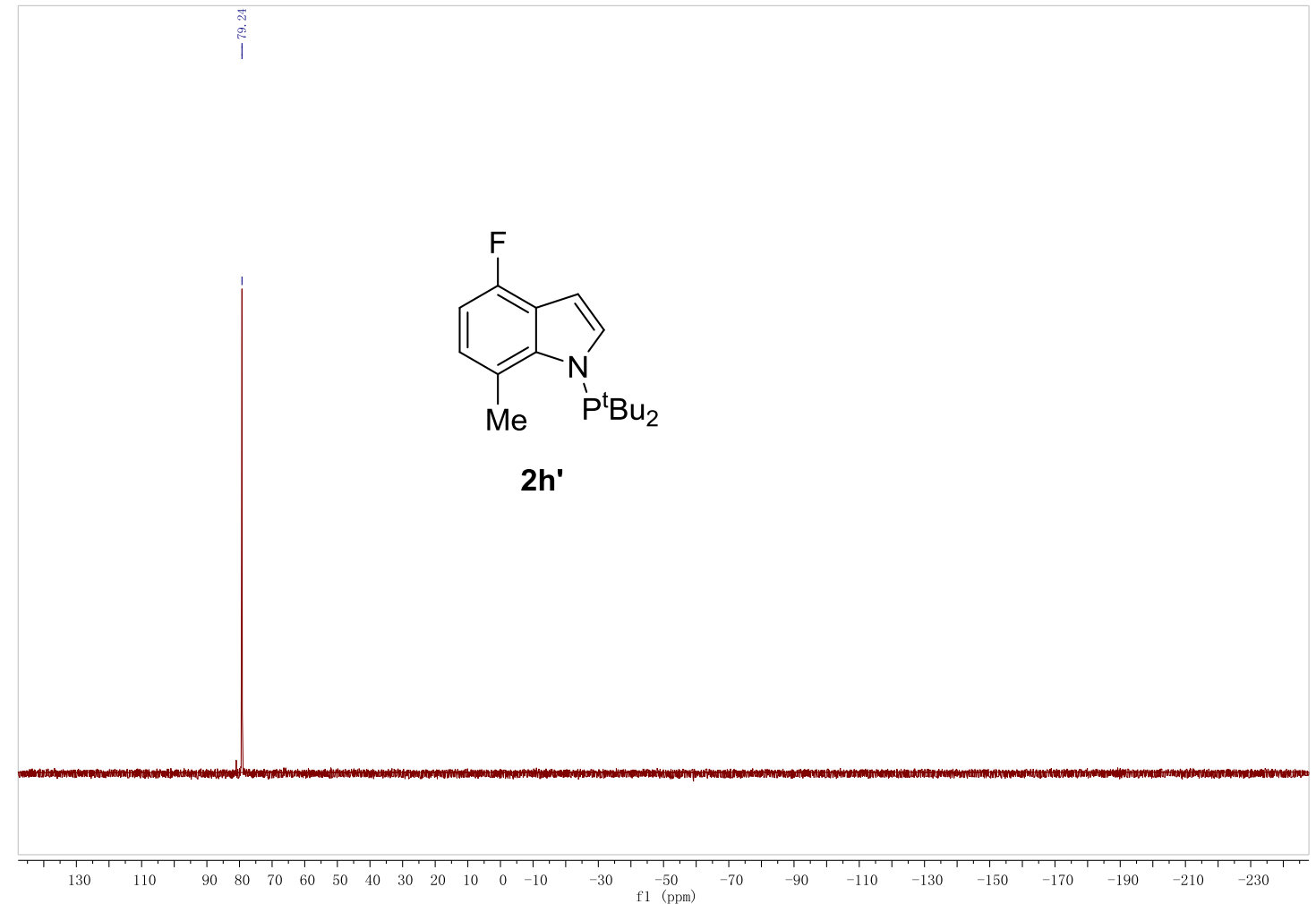

${ }^{19}$ F NMR (377 MHz, $\left.\mathrm{CDCl}_{3}\right)$

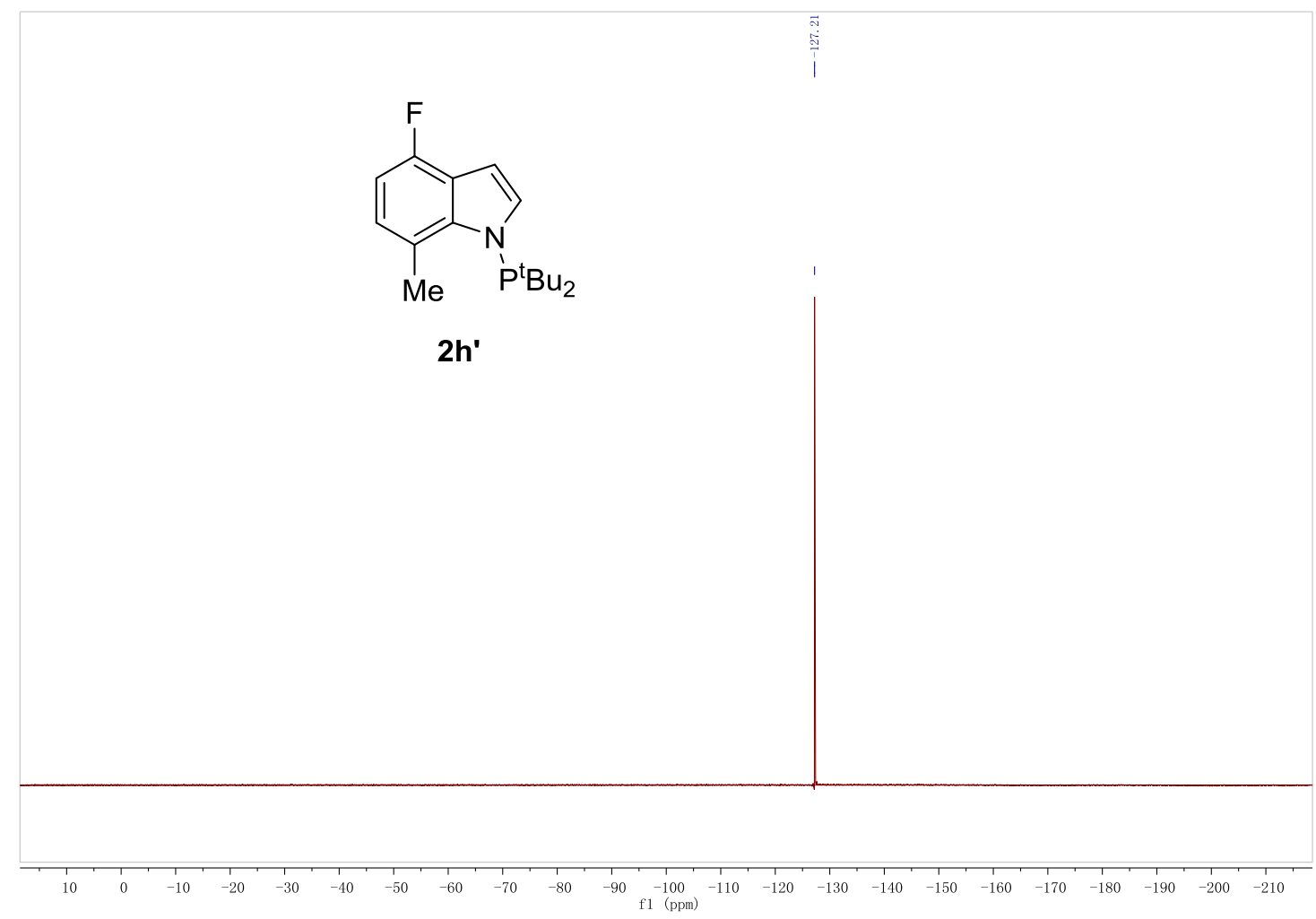


${ }^{1} \mathrm{H}$ NMR (400 MHz, $\mathrm{CDCl}_{3}$ )

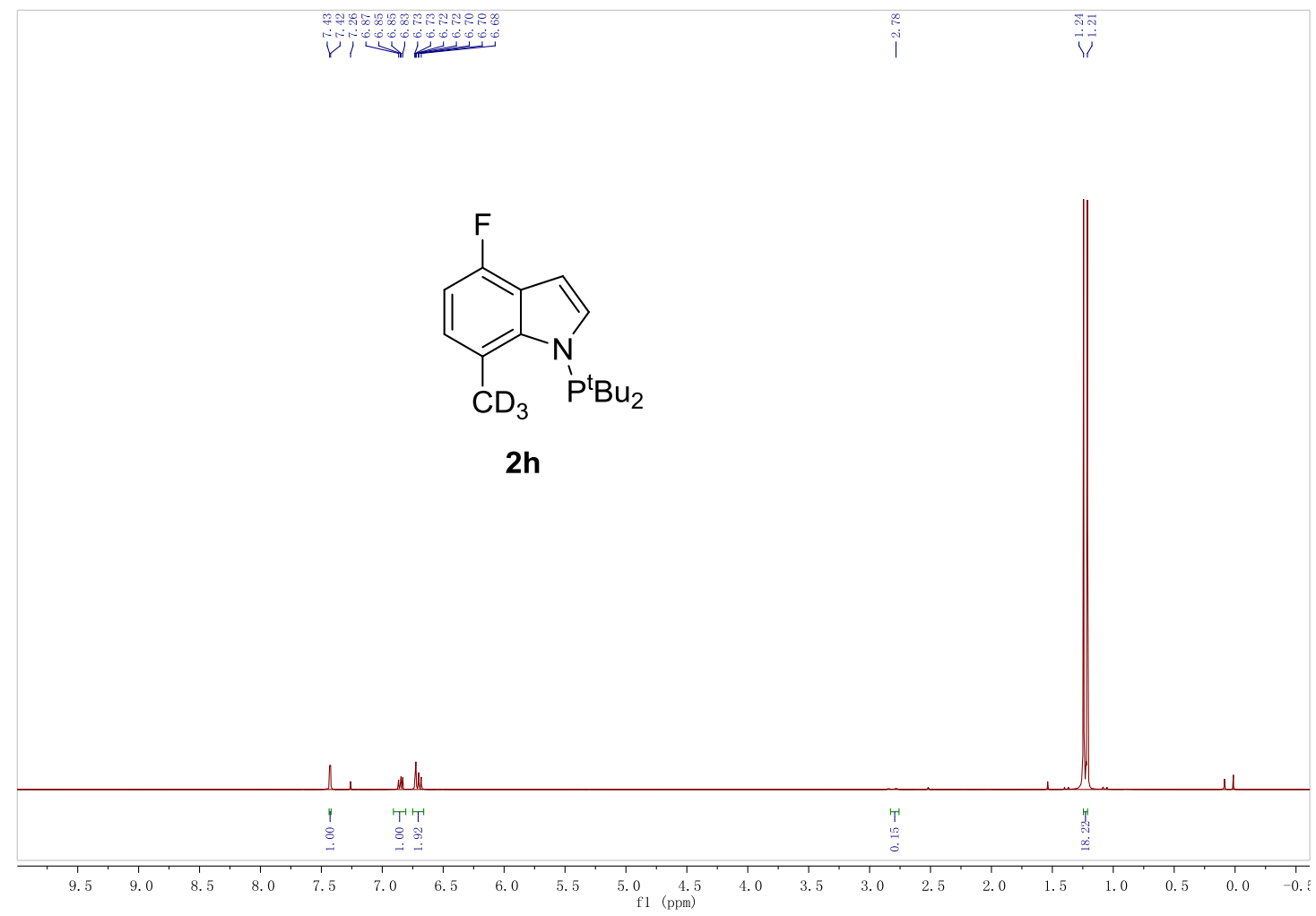

${ }^{1} \mathrm{H}$ NMR (400 MHz, $\left.\mathrm{CDCl}_{3}\right)$

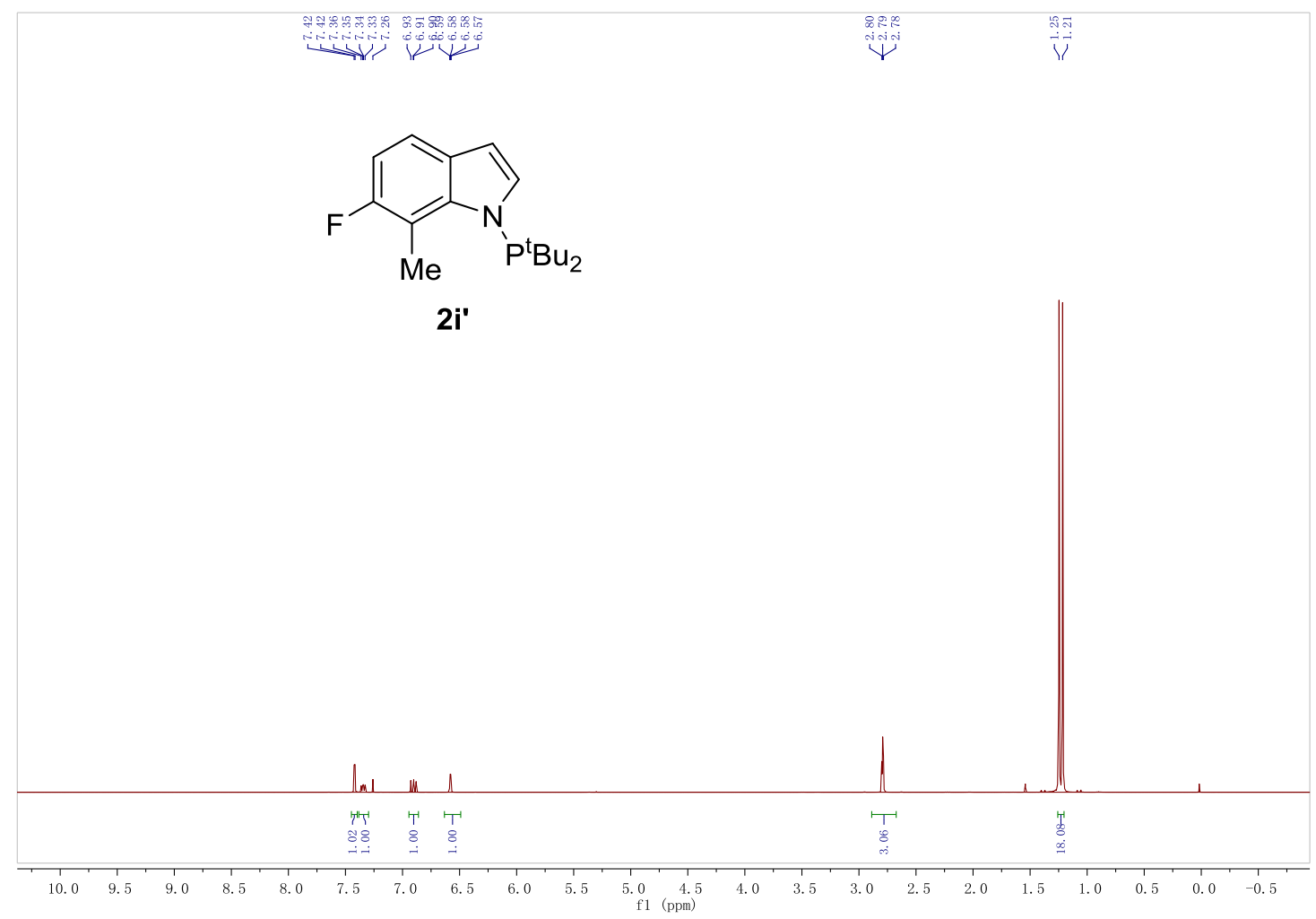


${ }^{13} \mathrm{C}$ NMR (400 MHz, $\left.\mathrm{CDCl}_{3}\right)$

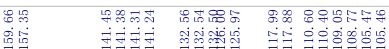

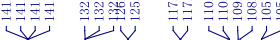

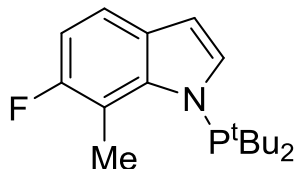

$2 i^{\prime}$
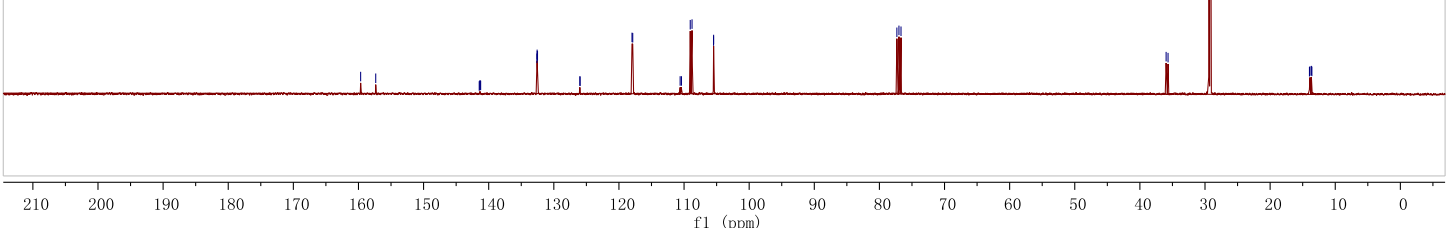

${ }^{31}$ P NMR (400 MHz, $\mathrm{CDCl}_{3}$ )

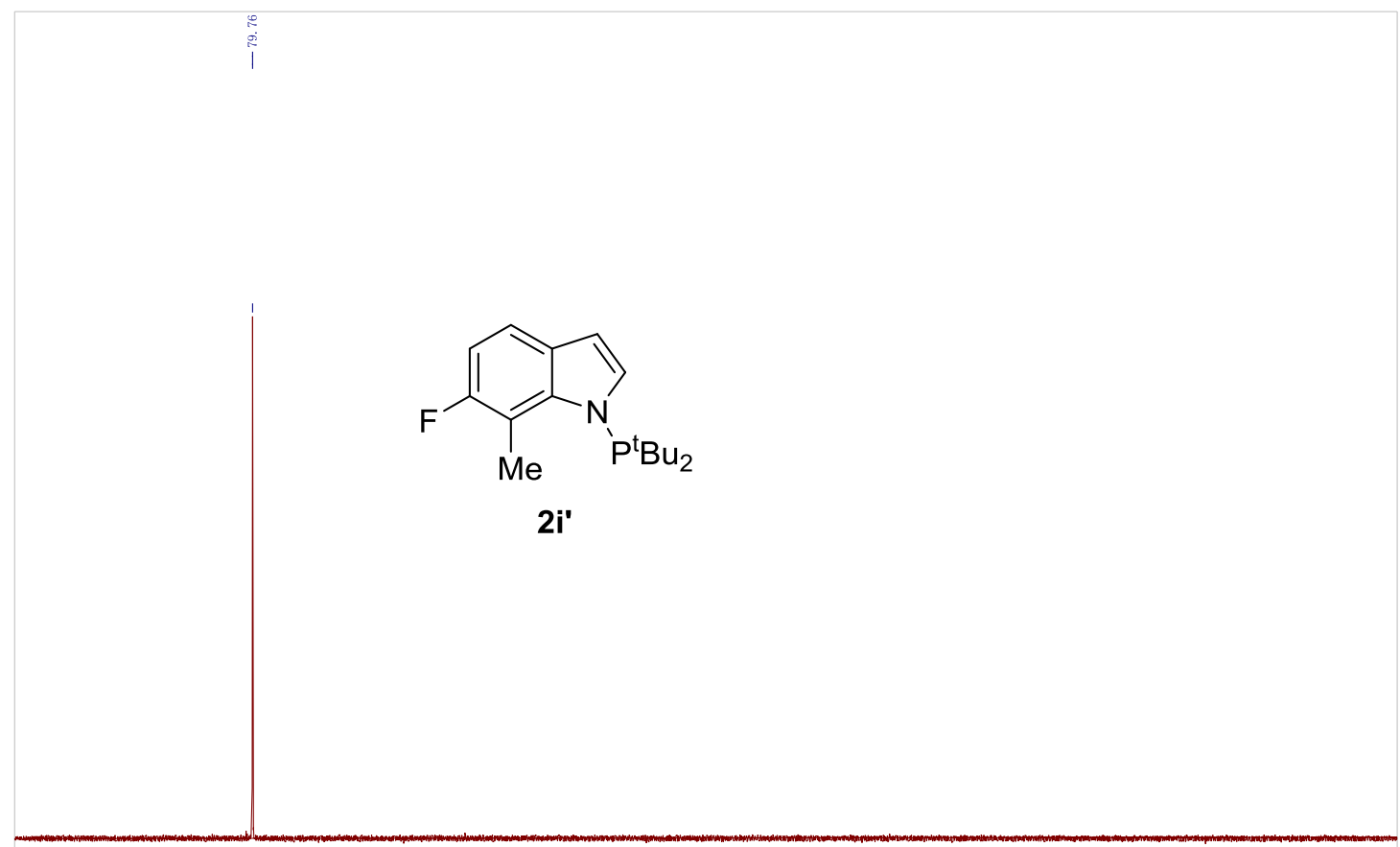

$\begin{array}{lllllllllllllllllllllllllllllllll}130 & 110 & 90 & 80 & 70 & 60 & 50 & 40 & 30 & 20 & 10 & 0 & -10 & -30 & -50 & -70 & -90 & -110 & -130 & -150 & -170 & -190 & -210 & -230 & 1\end{array}$ 
${ }^{19}$ F NMR (377 MHz, $\left.\mathrm{CDCl}_{3}\right)$

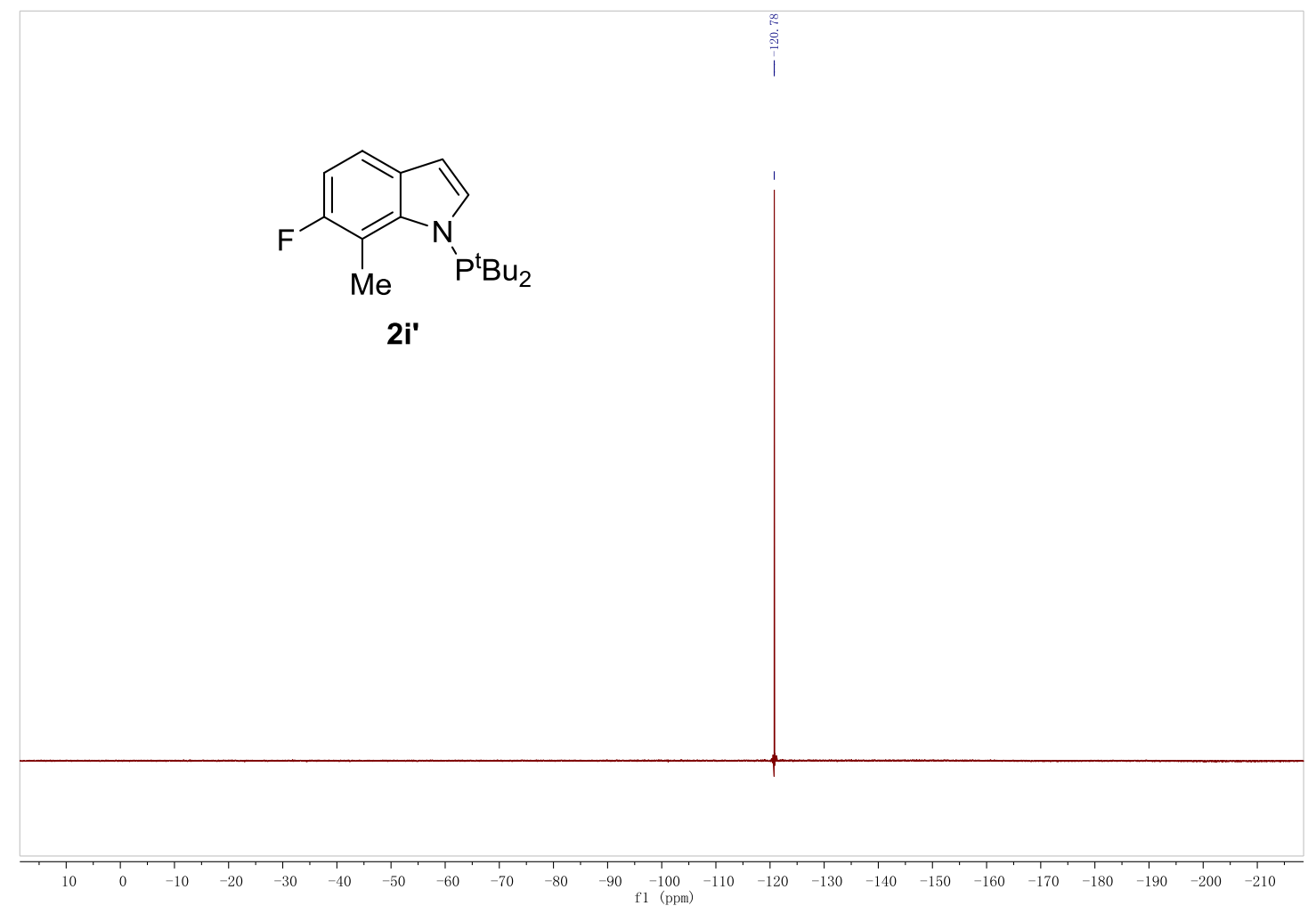

${ }^{1} \mathrm{H}$ NMR (400 MHz, $\mathrm{CDCl}_{3}$ )

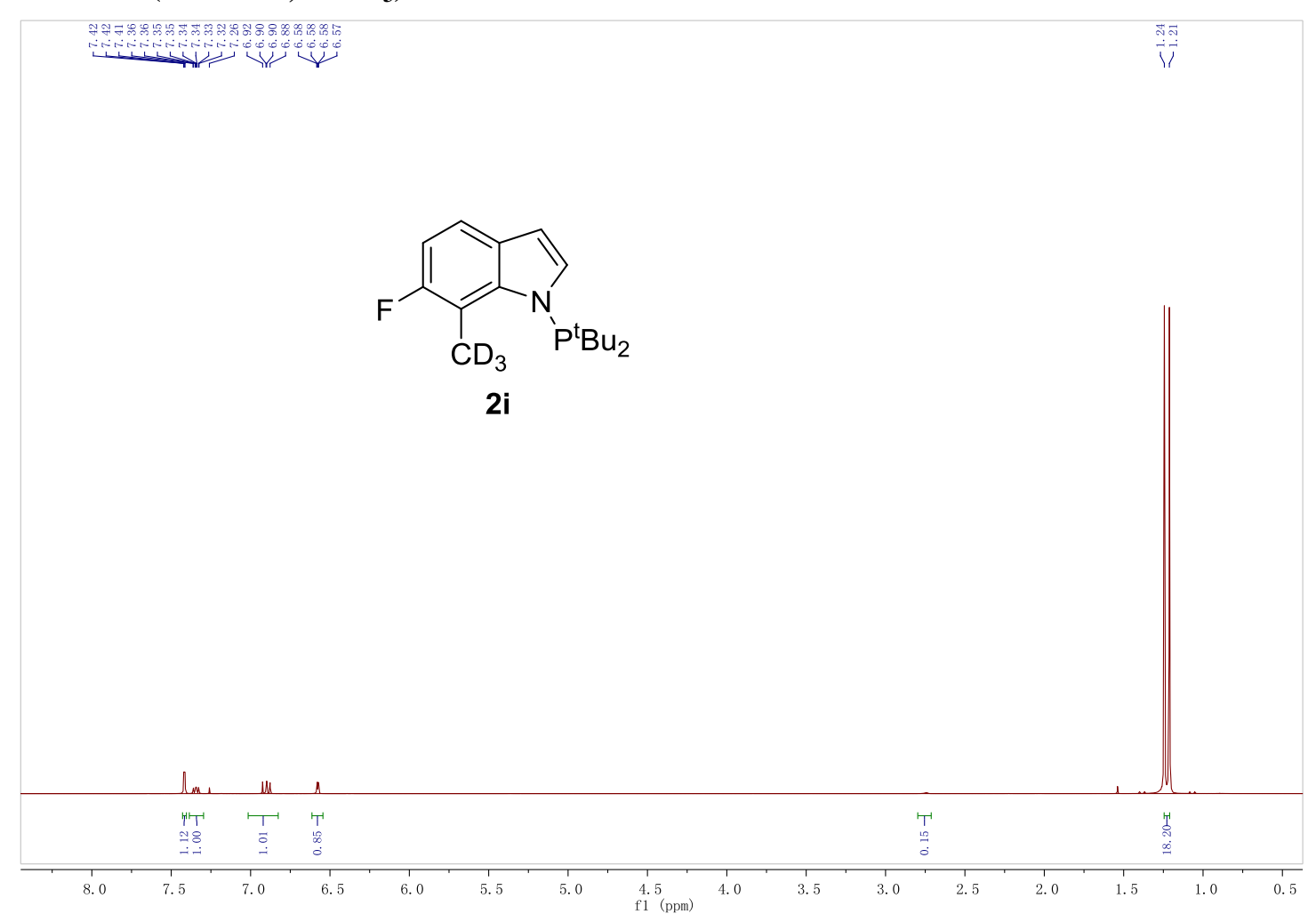

S20 
${ }^{1} \mathrm{H}$ NMR (400 MHz, $\left.\mathrm{CDCl}_{3}\right)$

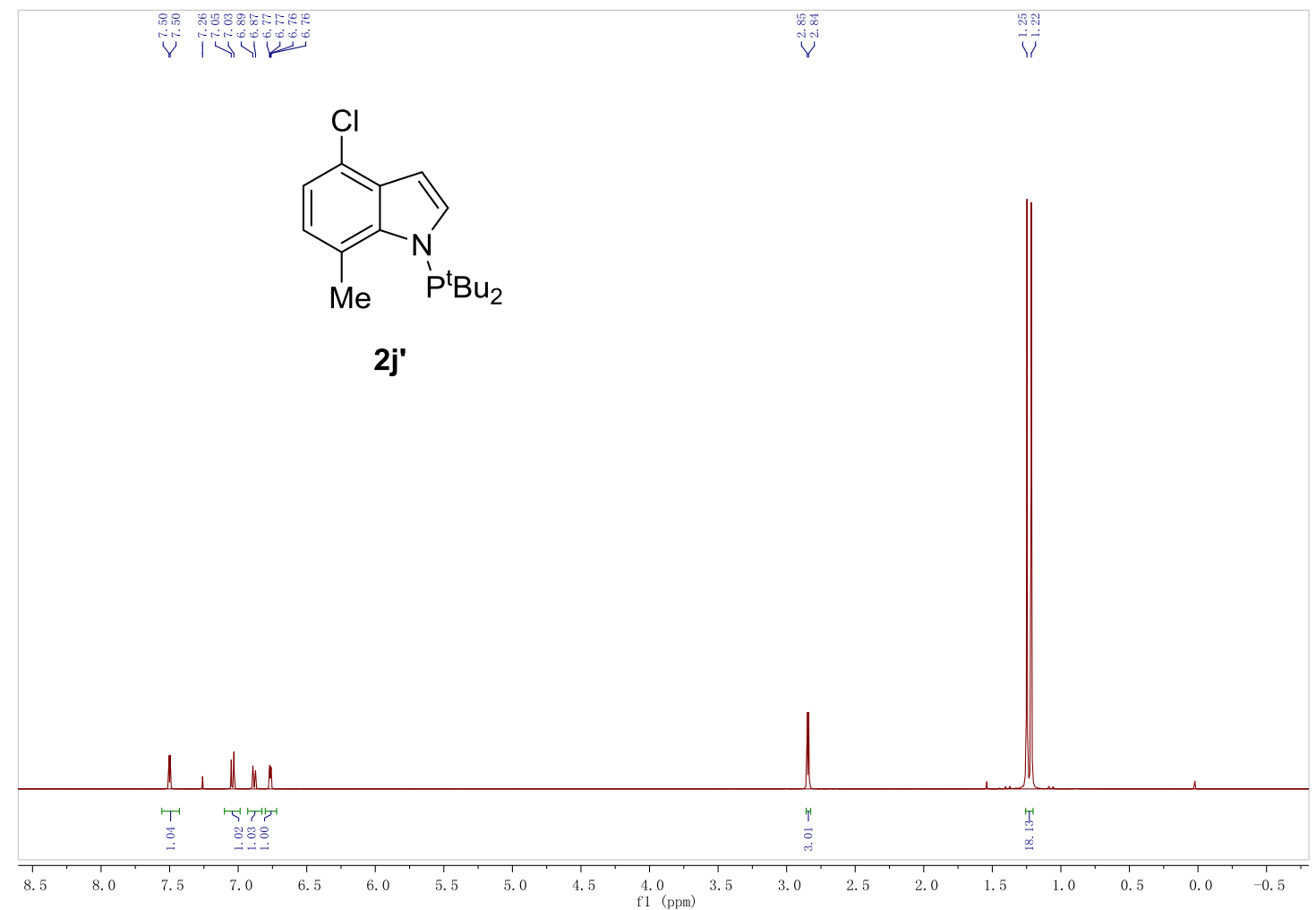

${ }^{13} \mathrm{C}$ NMR (400 MHz, $\mathrm{CDCl}_{3}$ )

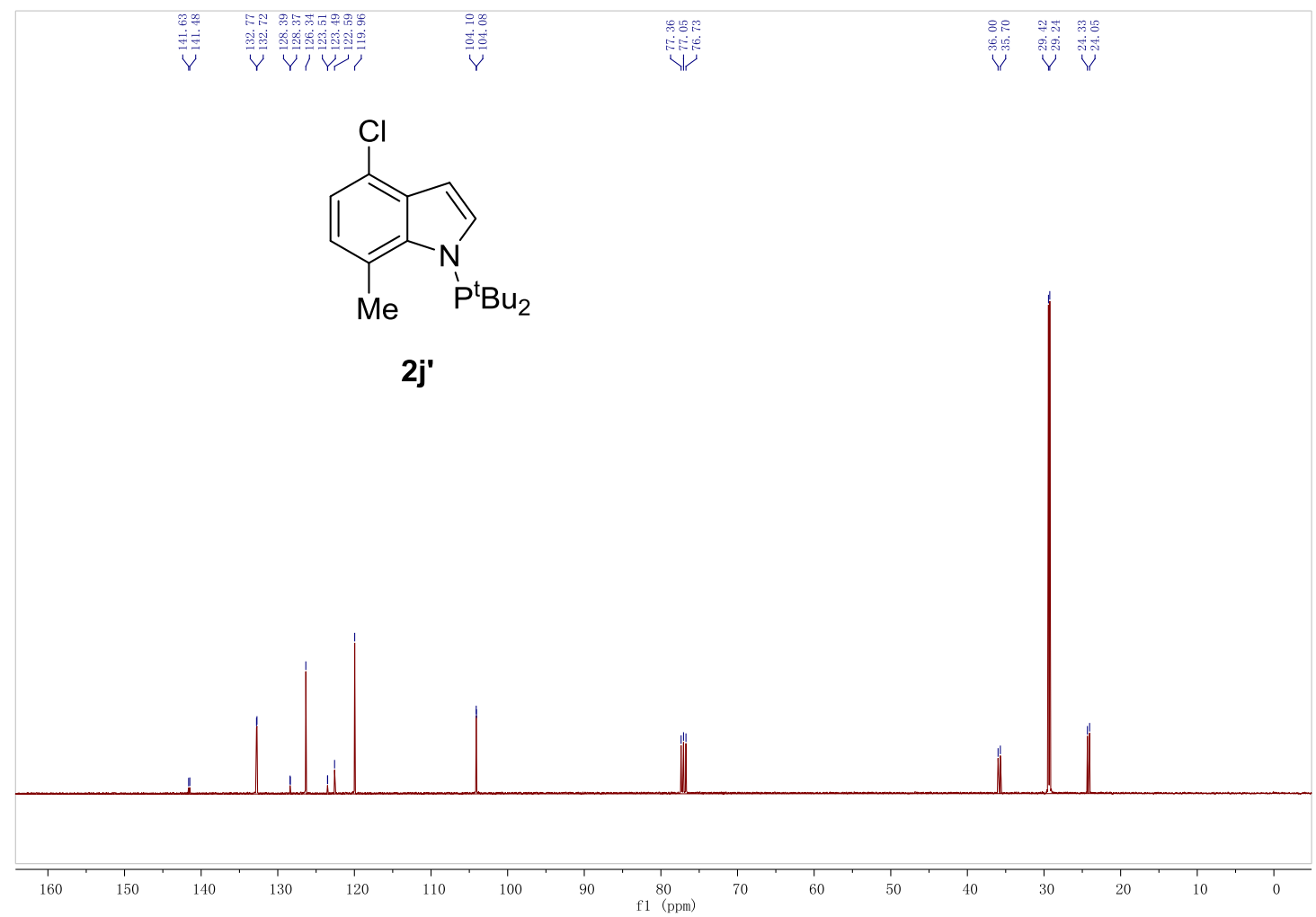


${ }^{31}$ P NMR (400 MHz, $\mathrm{CDCl}_{3}$ )

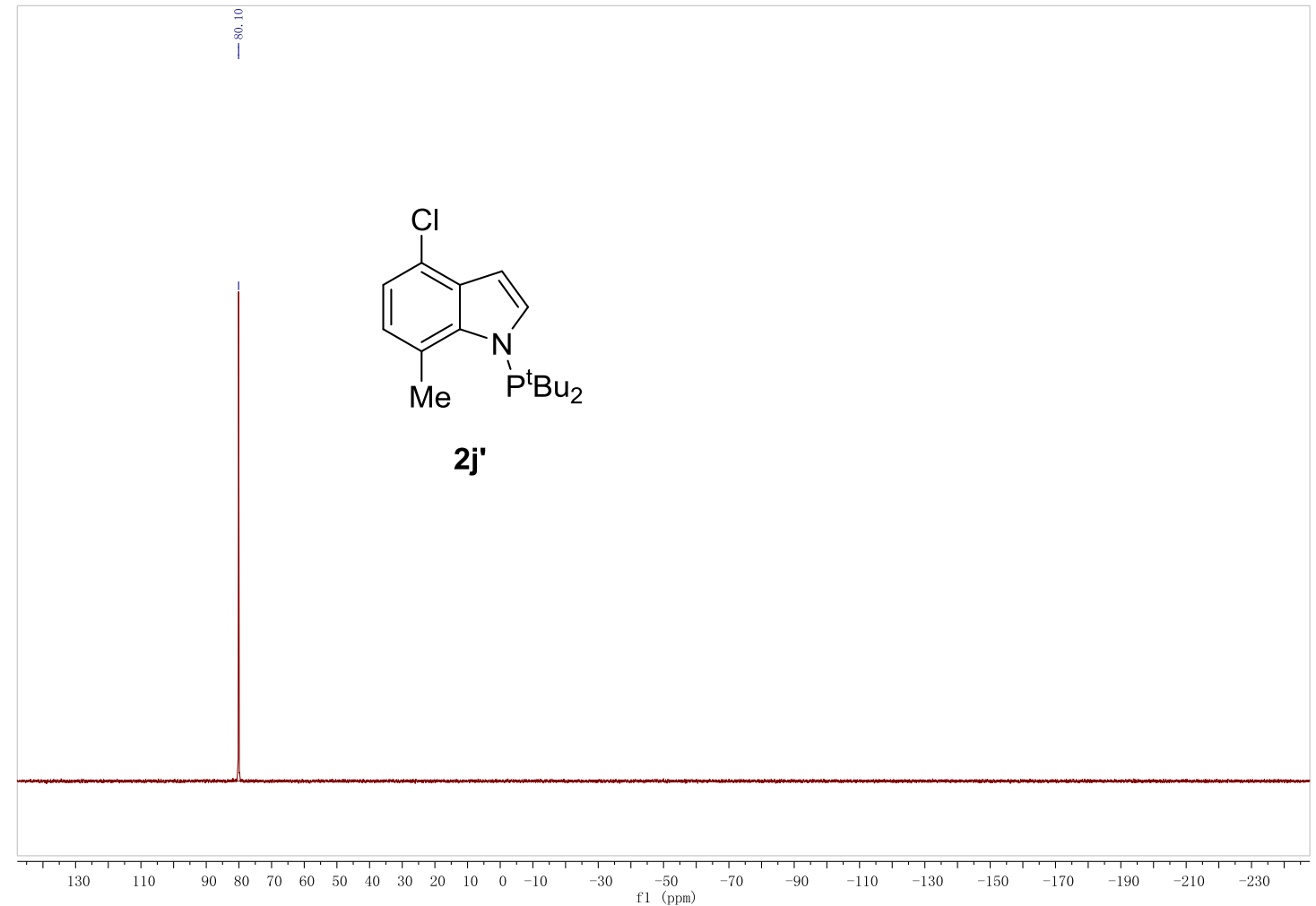

${ }^{1} \mathrm{H}$ NMR (400 MHz, $\mathrm{CDCl}_{3}$ )

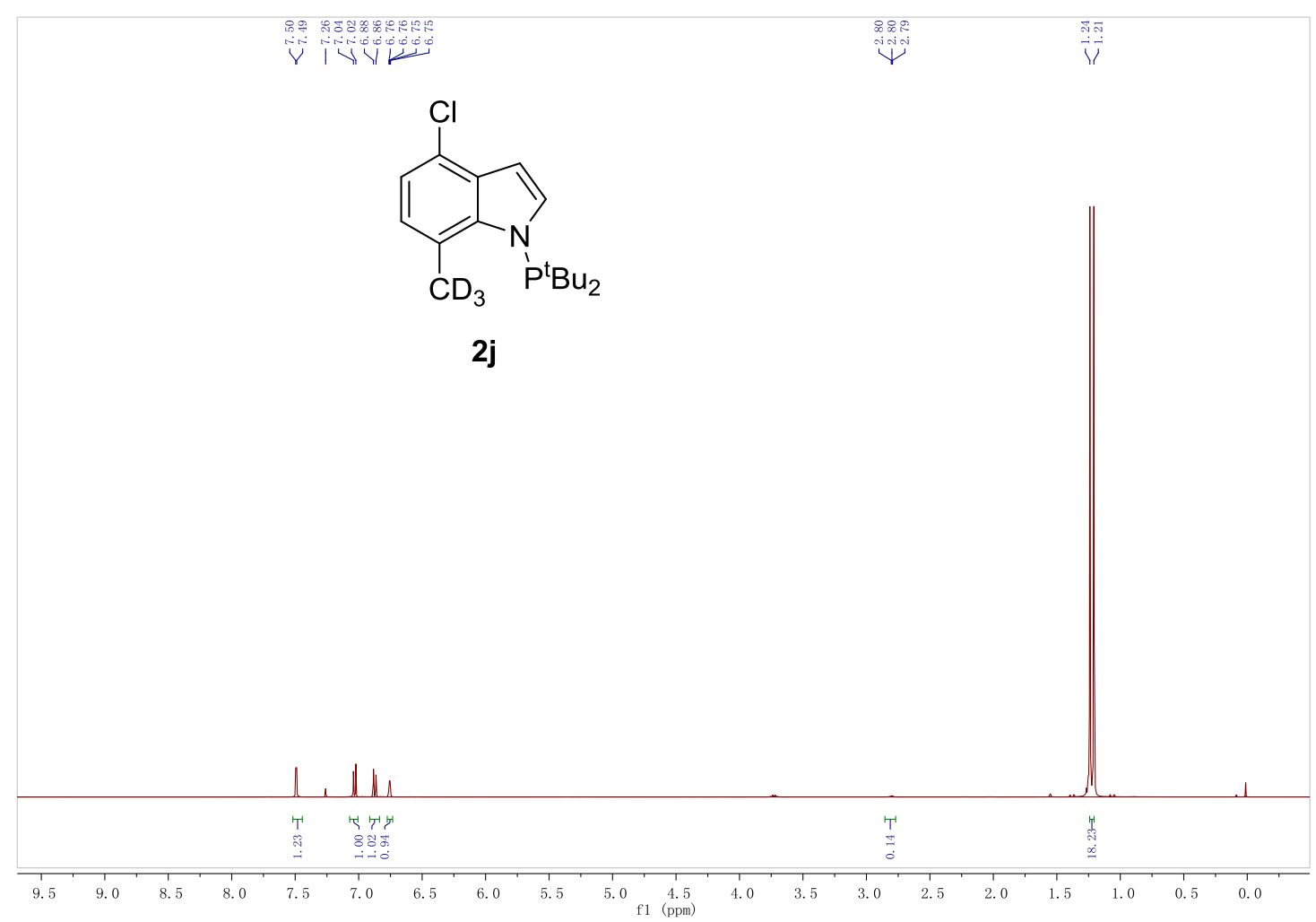


${ }^{1} \mathrm{H}$ NMR (400 MHz, $\left.\mathrm{CDCl}_{3}\right)$

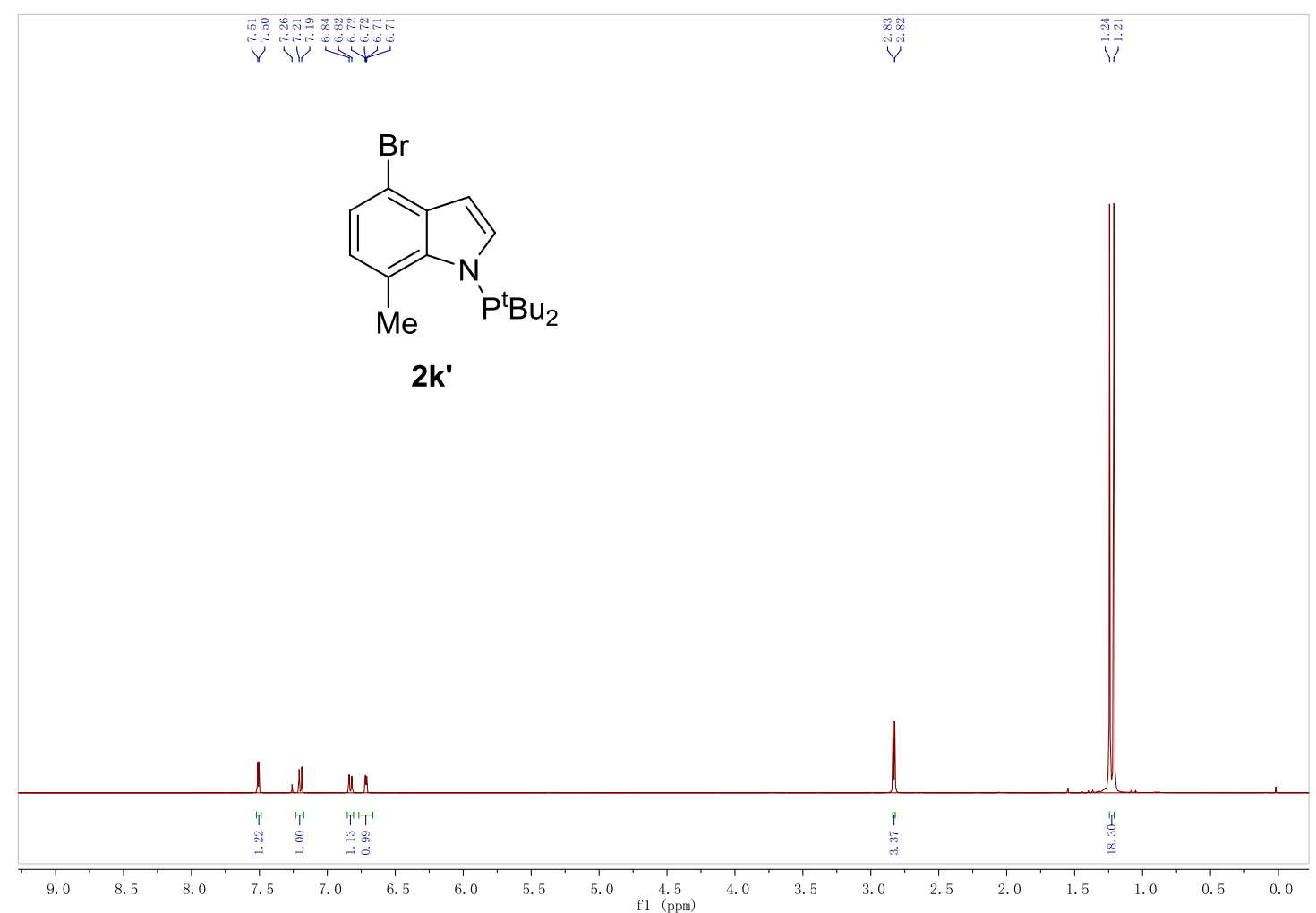

${ }^{13} \mathrm{C}$ NMR (400 MHz, $\mathrm{CDCl}_{3}$ )
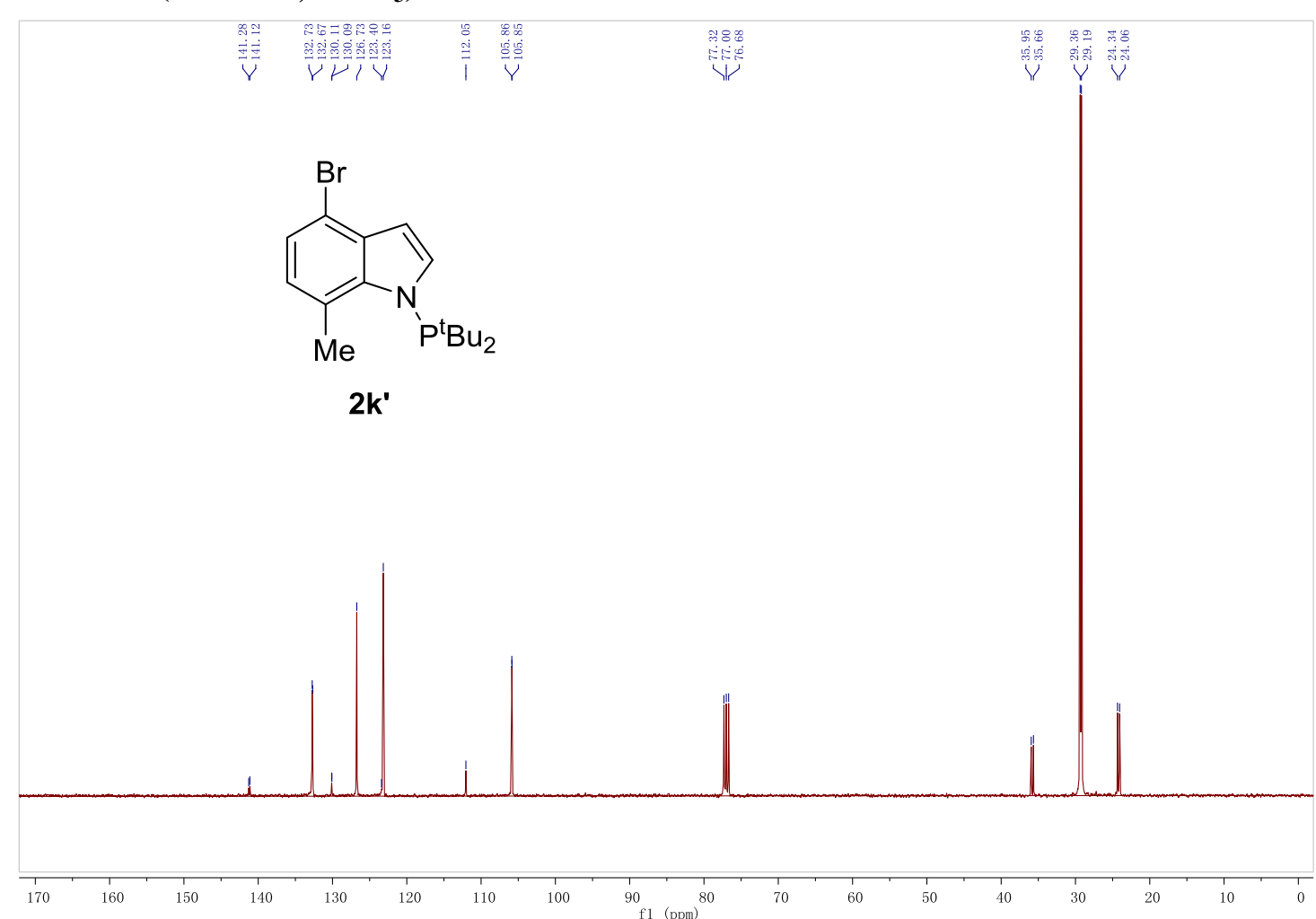
${ }^{31} \mathrm{P}$ NMR (400 MHz, $\mathrm{CDCl}_{3}$ )

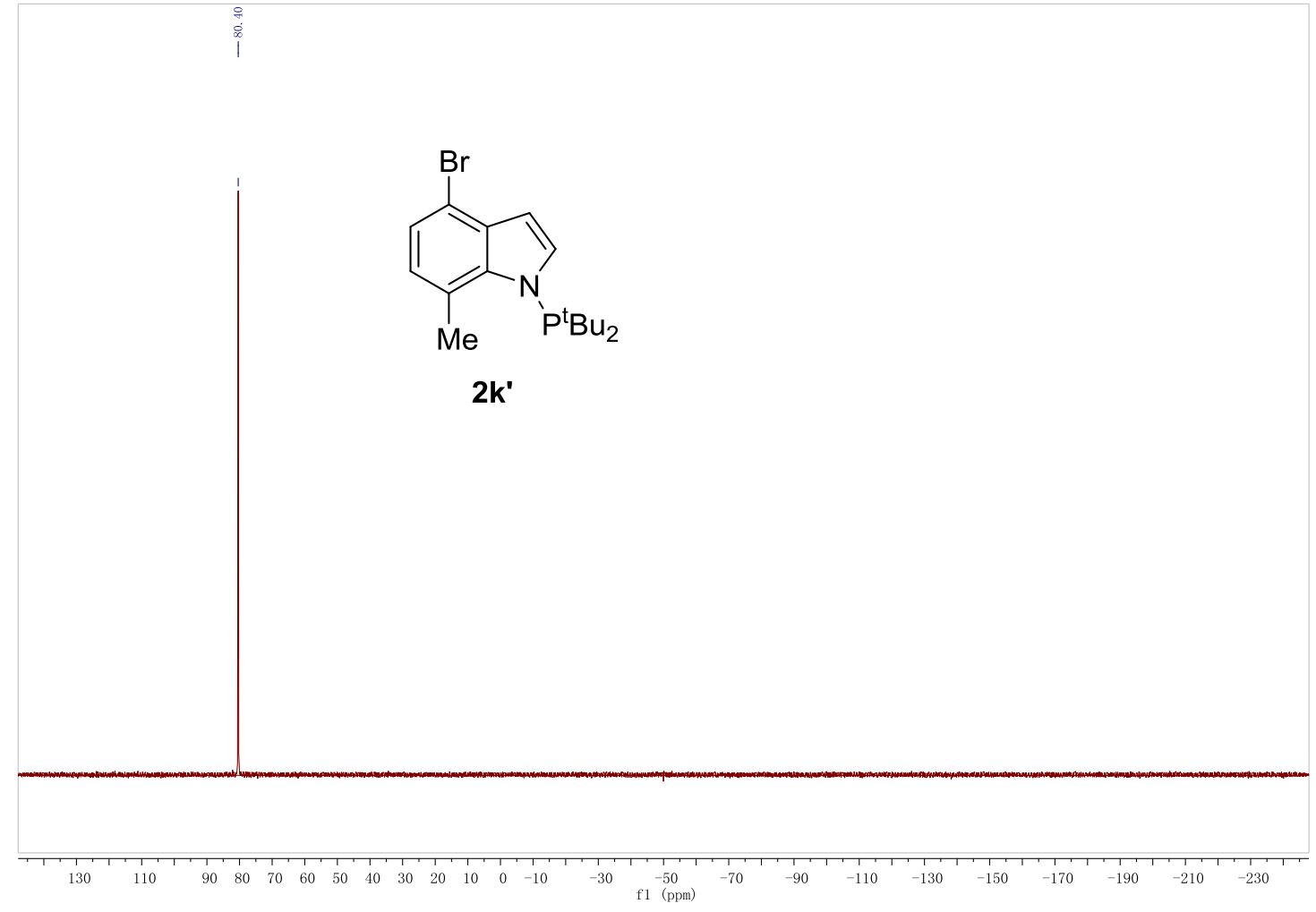

${ }^{1} \mathrm{H}$ NMR (400 MHz, $\left.\mathrm{CDCl}_{3}\right)$

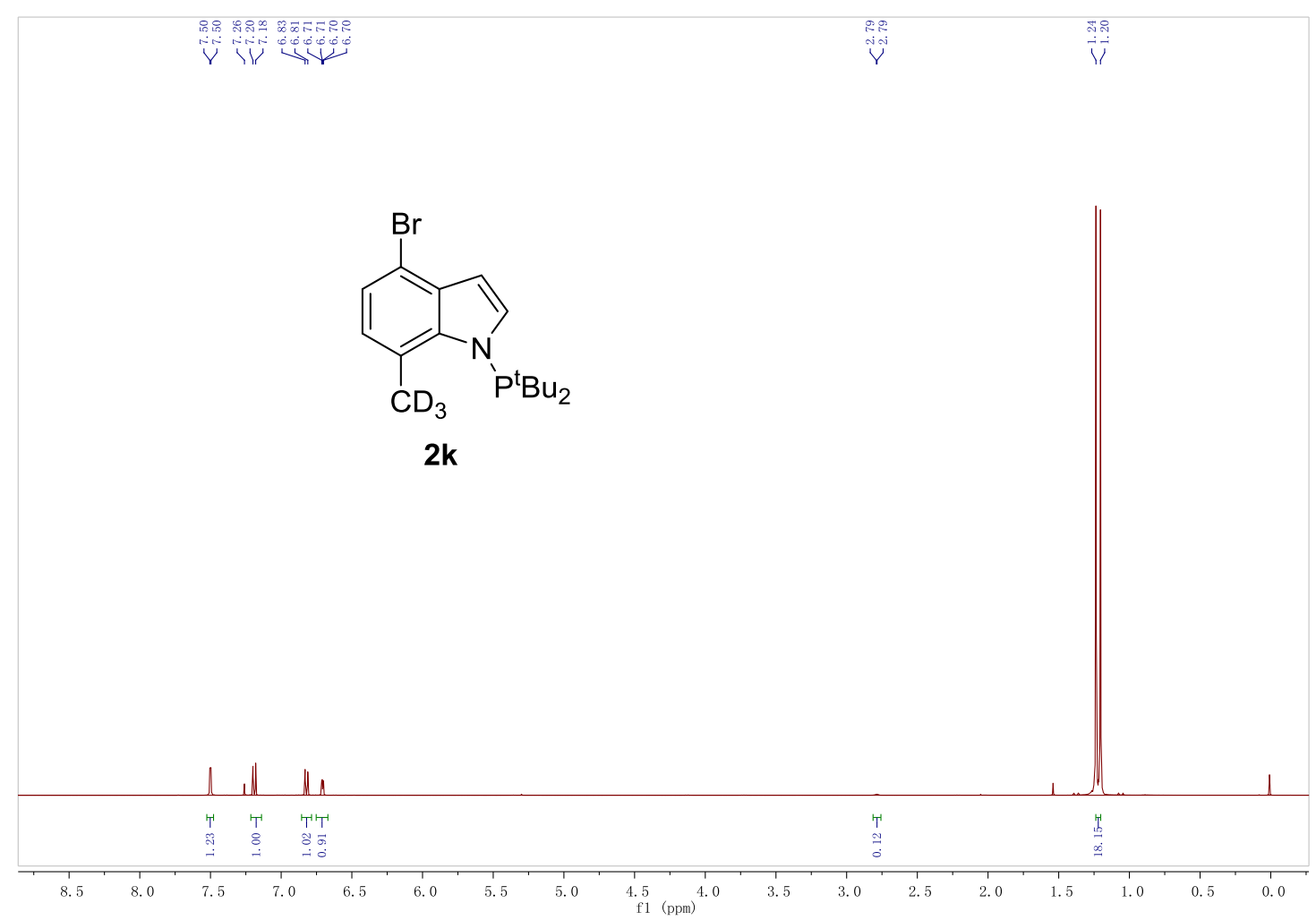


${ }^{1} \mathrm{H}$ NMR (400 MHz, $\left.\mathrm{CDCl}_{3}\right)$

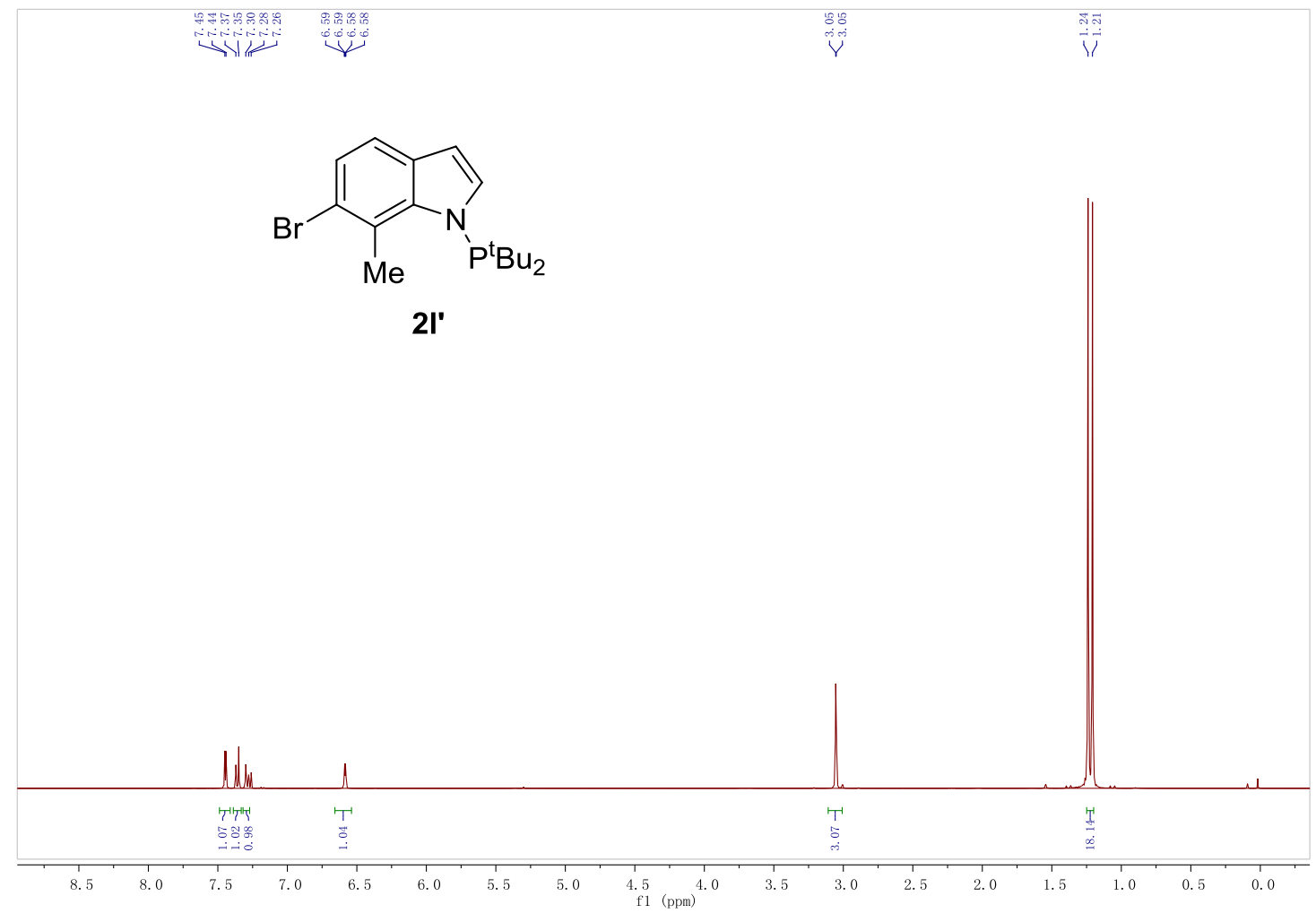

${ }^{13} \mathrm{C}$ NMR (400 MHz, $\left.\mathrm{CDCl}_{3}\right)$

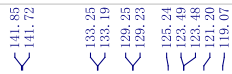

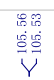

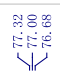

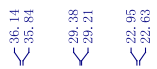

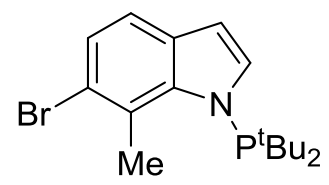

2l'

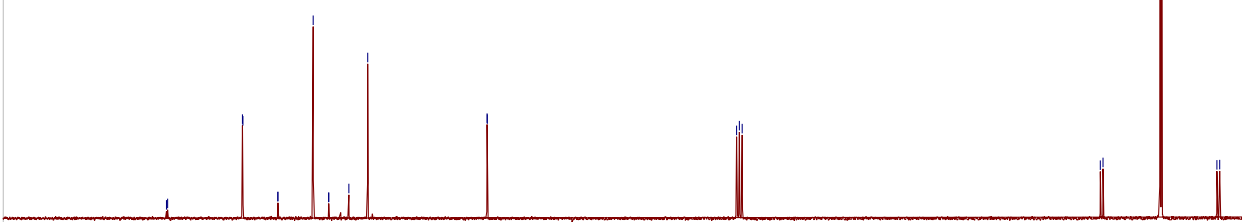

60

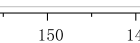

$140 \quad 130$
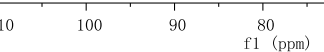
${ }^{31}$ P NMR (400 MHz, $\left.\mathrm{CDCl}_{3}\right)$

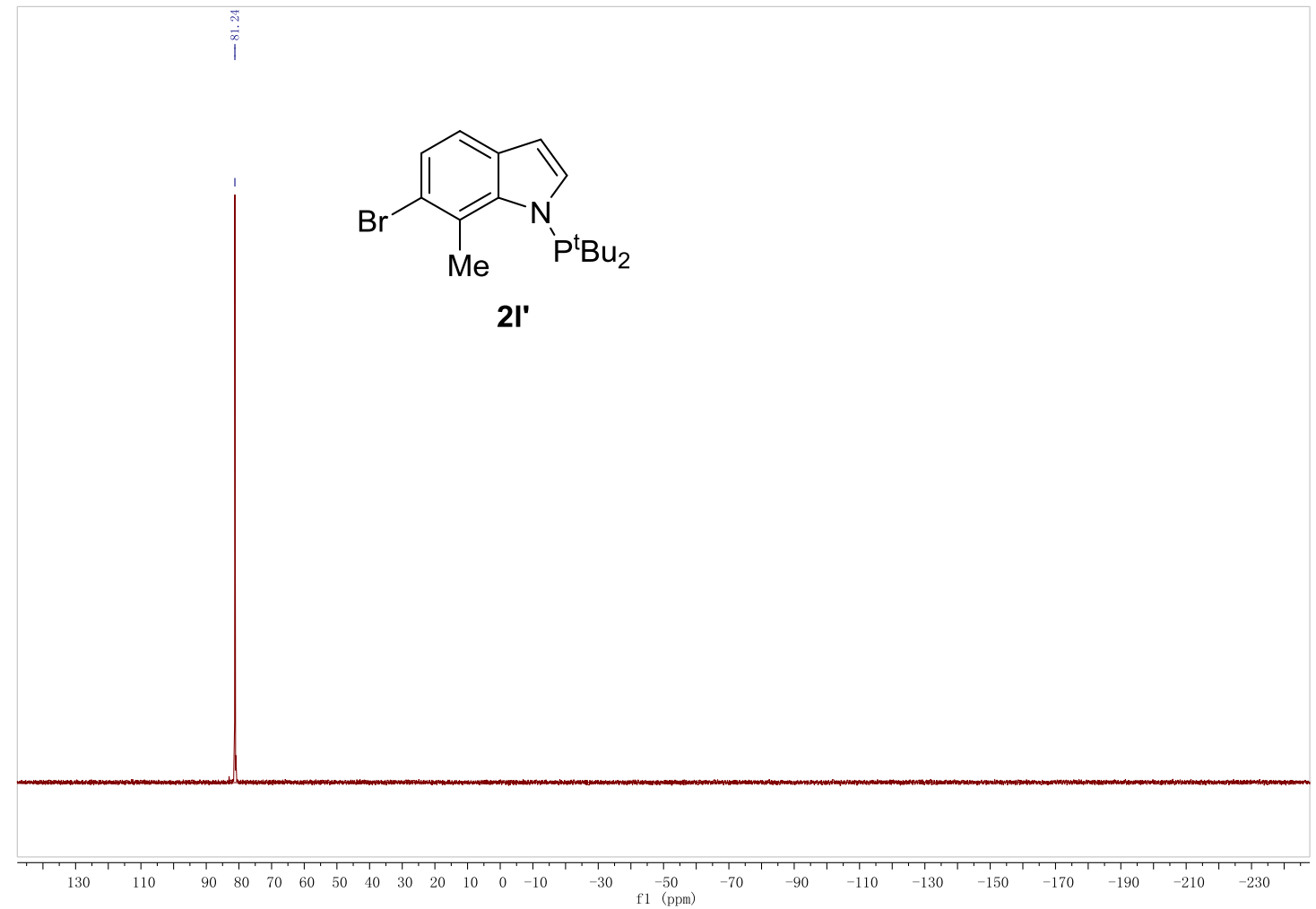

${ }^{1} \mathrm{H}$ NMR (400 MHz, $\mathrm{CDCl}_{3}$ )

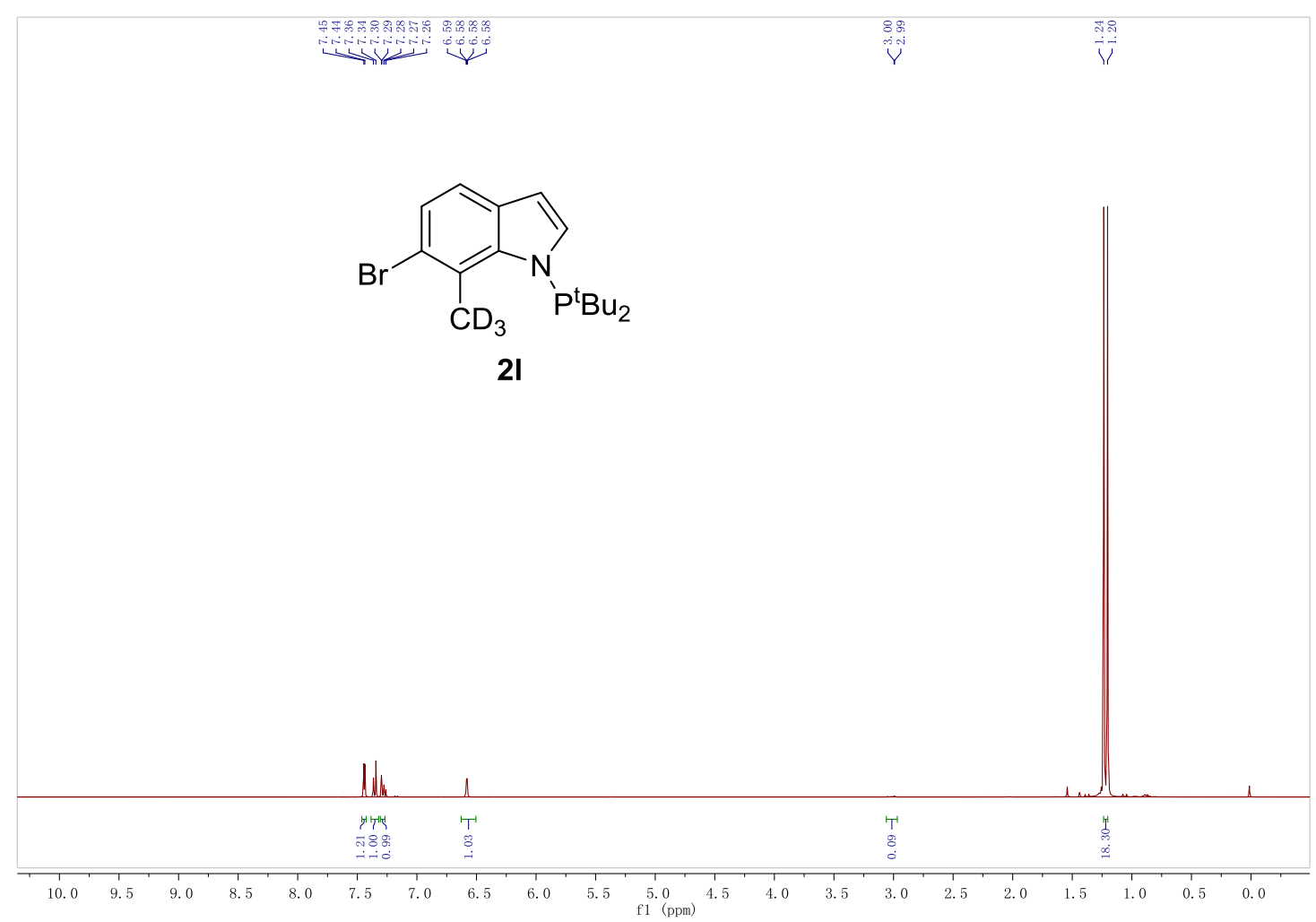


${ }^{1} \mathrm{H}$ NMR (400 MHz, $\left.\mathrm{CDCl}_{3}\right)$

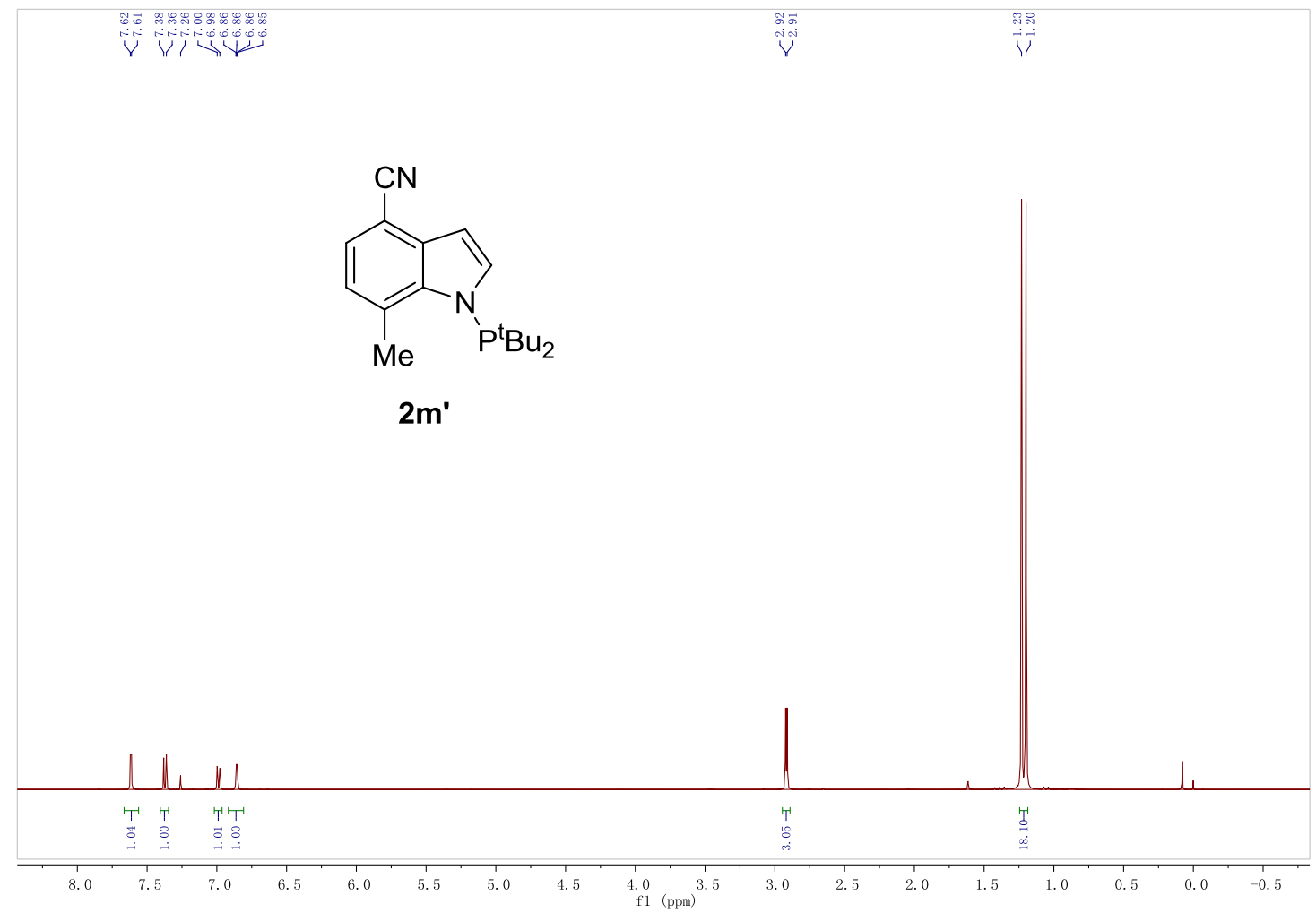

${ }^{13} \mathrm{C}$ NMR (400 MHz, $\left.\mathrm{CDCl}_{3}\right)$

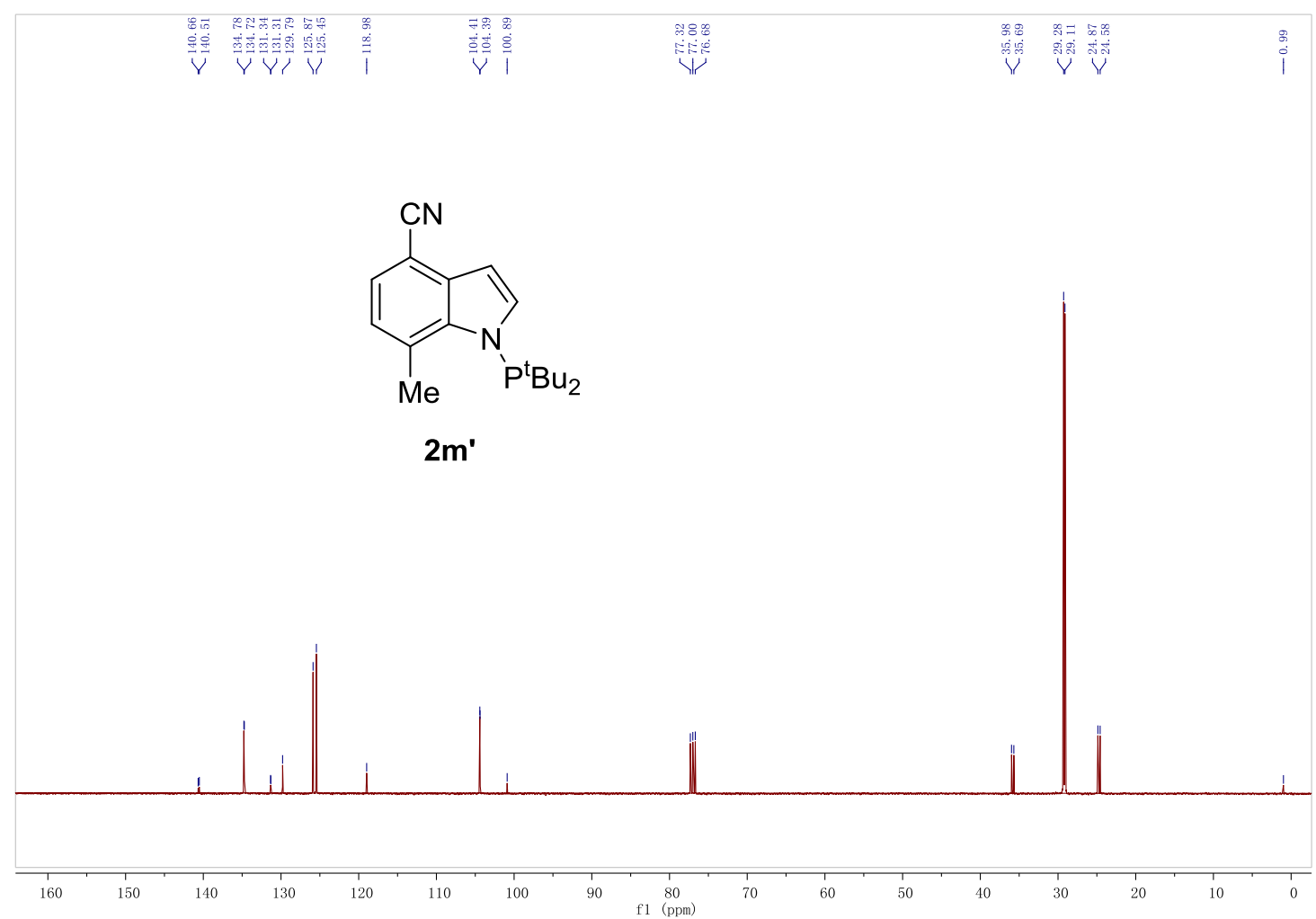


${ }^{31}$ P NMR (400 MHz, $\mathrm{CDCl}_{3}$ )

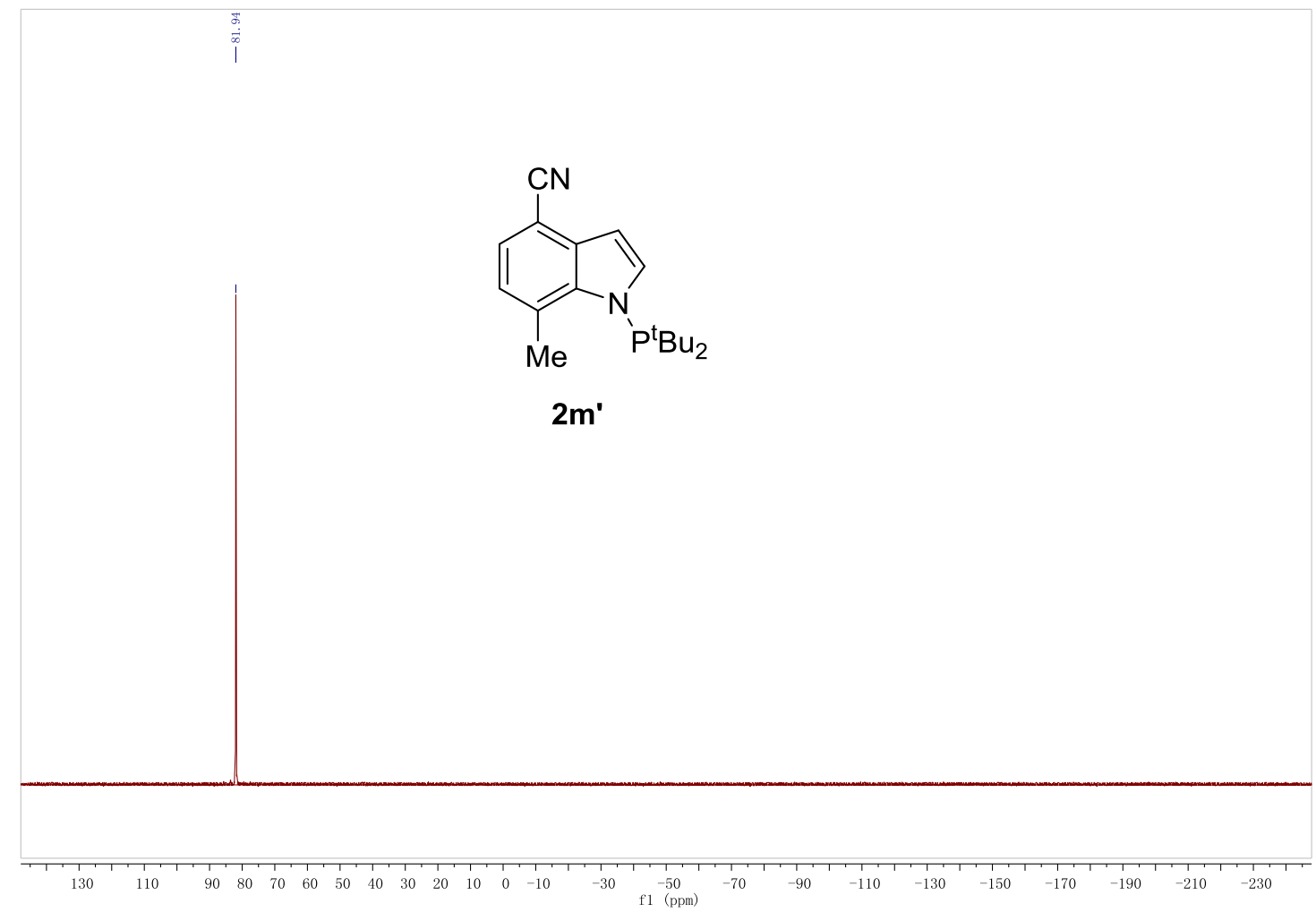

${ }^{1} \mathrm{H}$ NMR (400 MHz, $\left.\mathrm{CDCl}_{3}\right)$

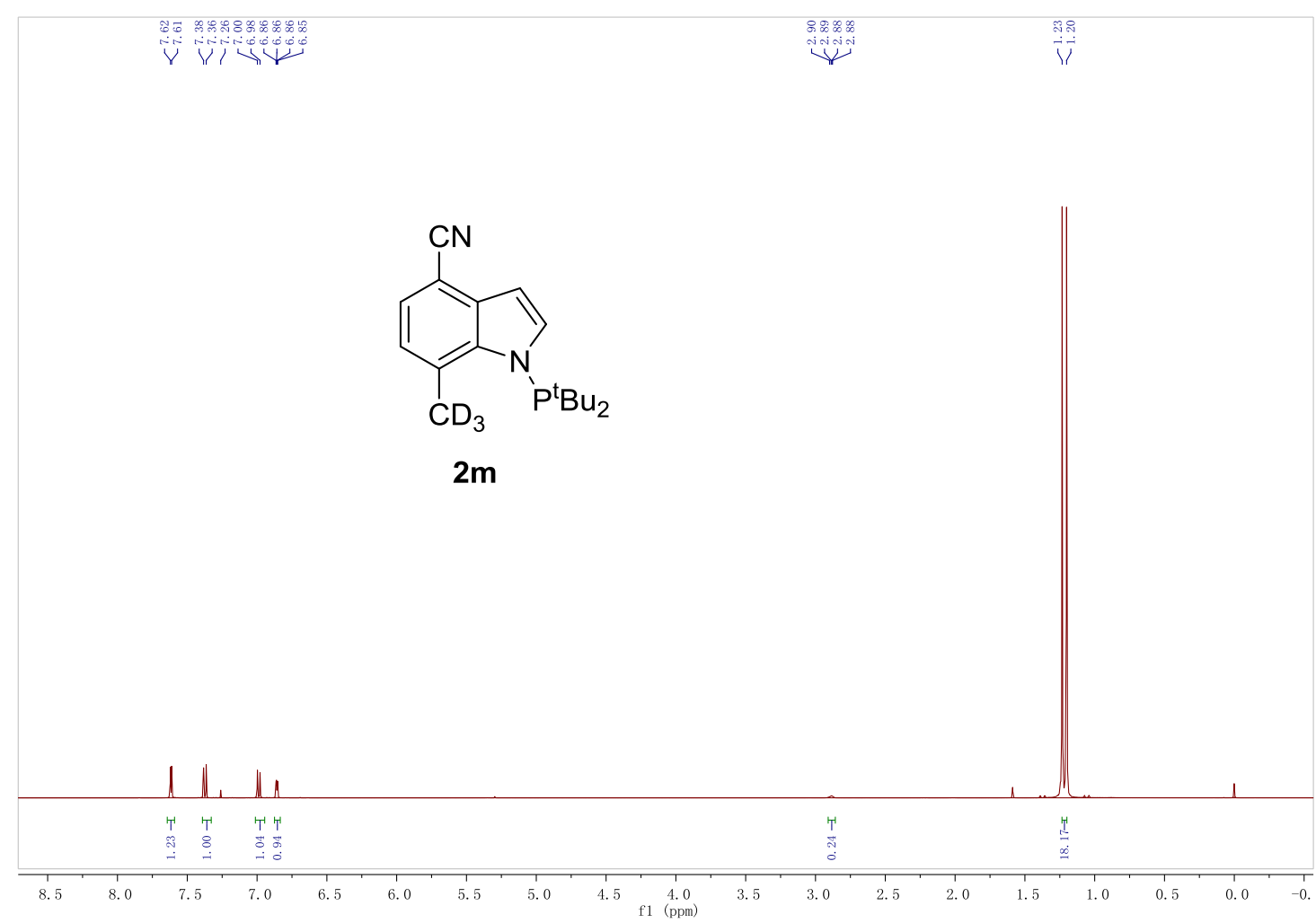


${ }^{1} \mathrm{H}$ NMR (400 MHz, $\left.\mathrm{CDCl}_{3}\right)$

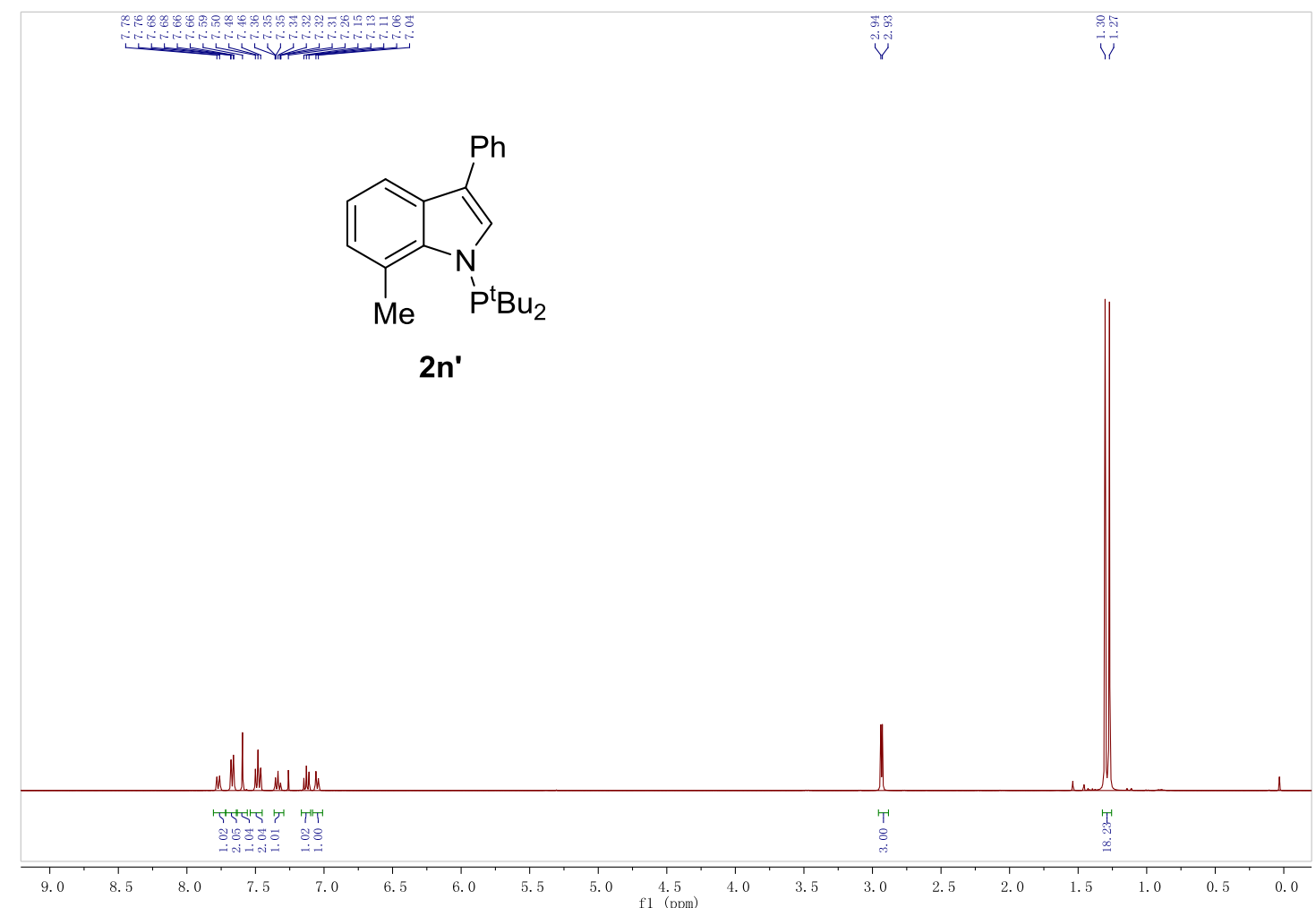

${ }^{13} \mathrm{C}$ NMR (400 MHz, $\left.\mathrm{CDCl}_{3}\right)$

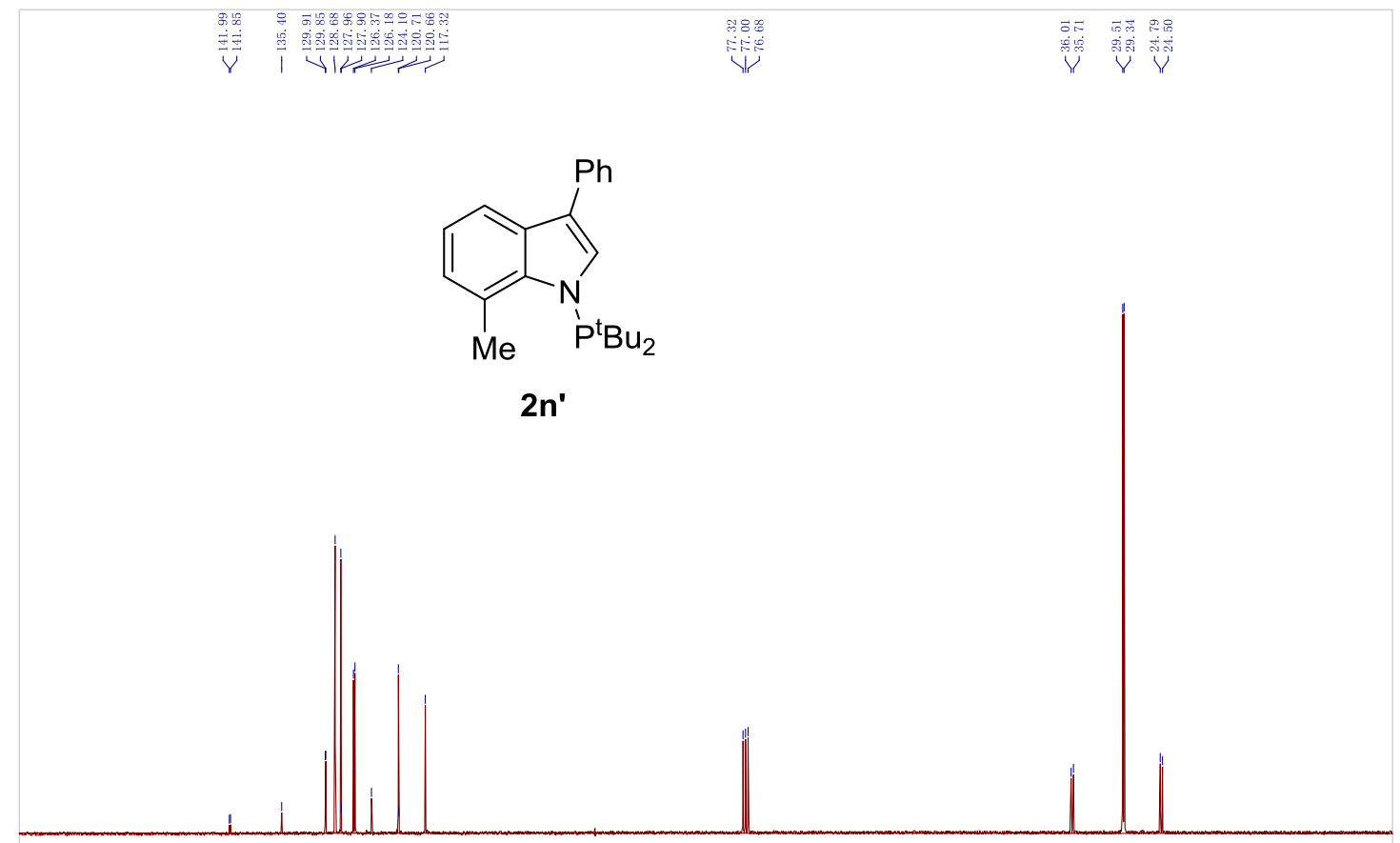

$\begin{array}{llllllllllllllllllll}1 & 1 \\ 160 & 150 & 140 & 130 & 120 & 110 & 100 & 90 & \begin{array}{c}80 \\ \mathrm{f} 1\end{array}(\mathrm{ppm}) & 70 & 60 & 50 & 40 & 30 & 20 & 10 & 0\end{array}$ 
${ }^{31} \mathrm{P}$ NMR (400 MHz, $\mathrm{CDCl}_{3}$ )

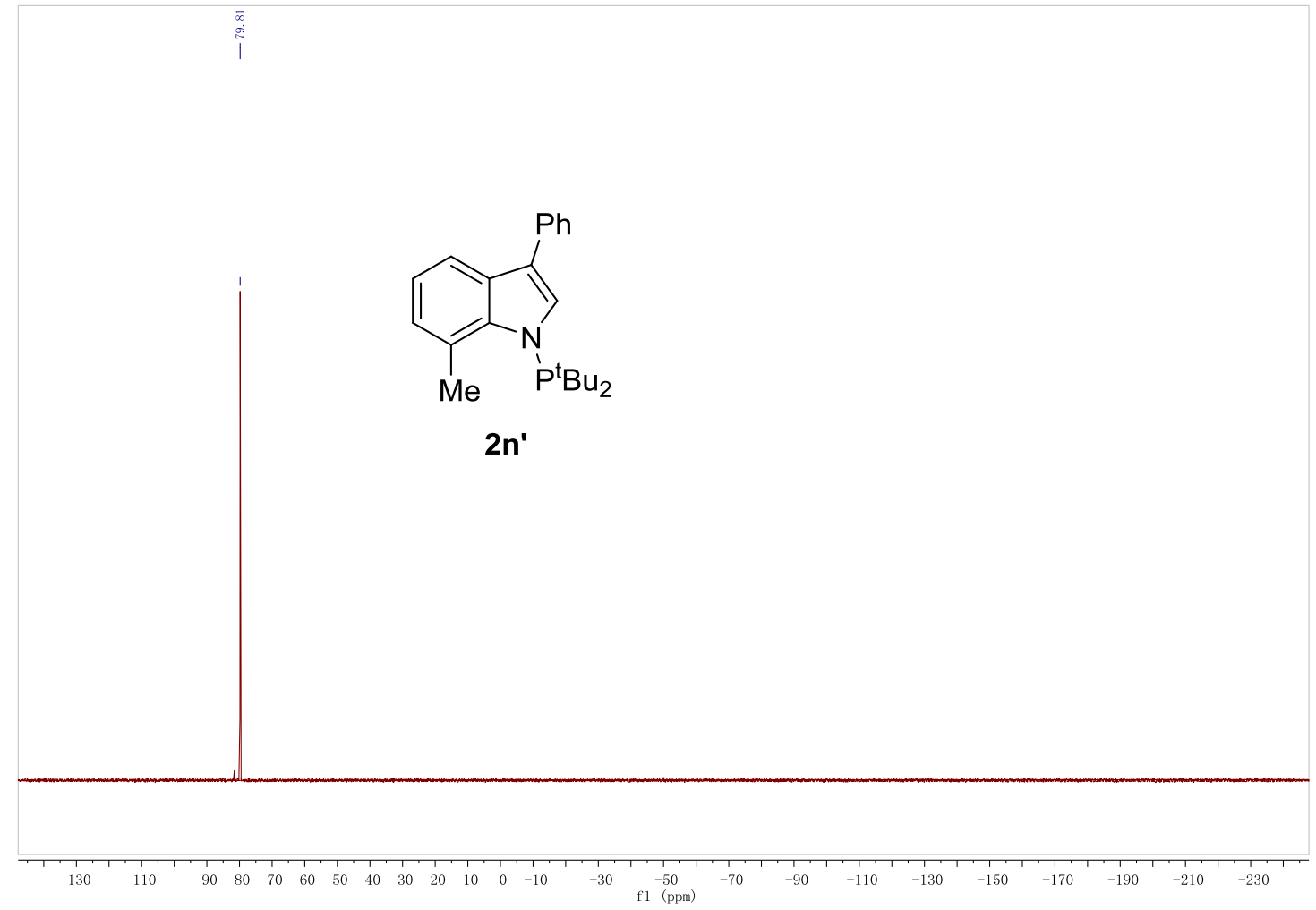

${ }^{1} \mathrm{H}$ NMR (400 MHz, $\left.\mathrm{CDCl}_{3}\right)$

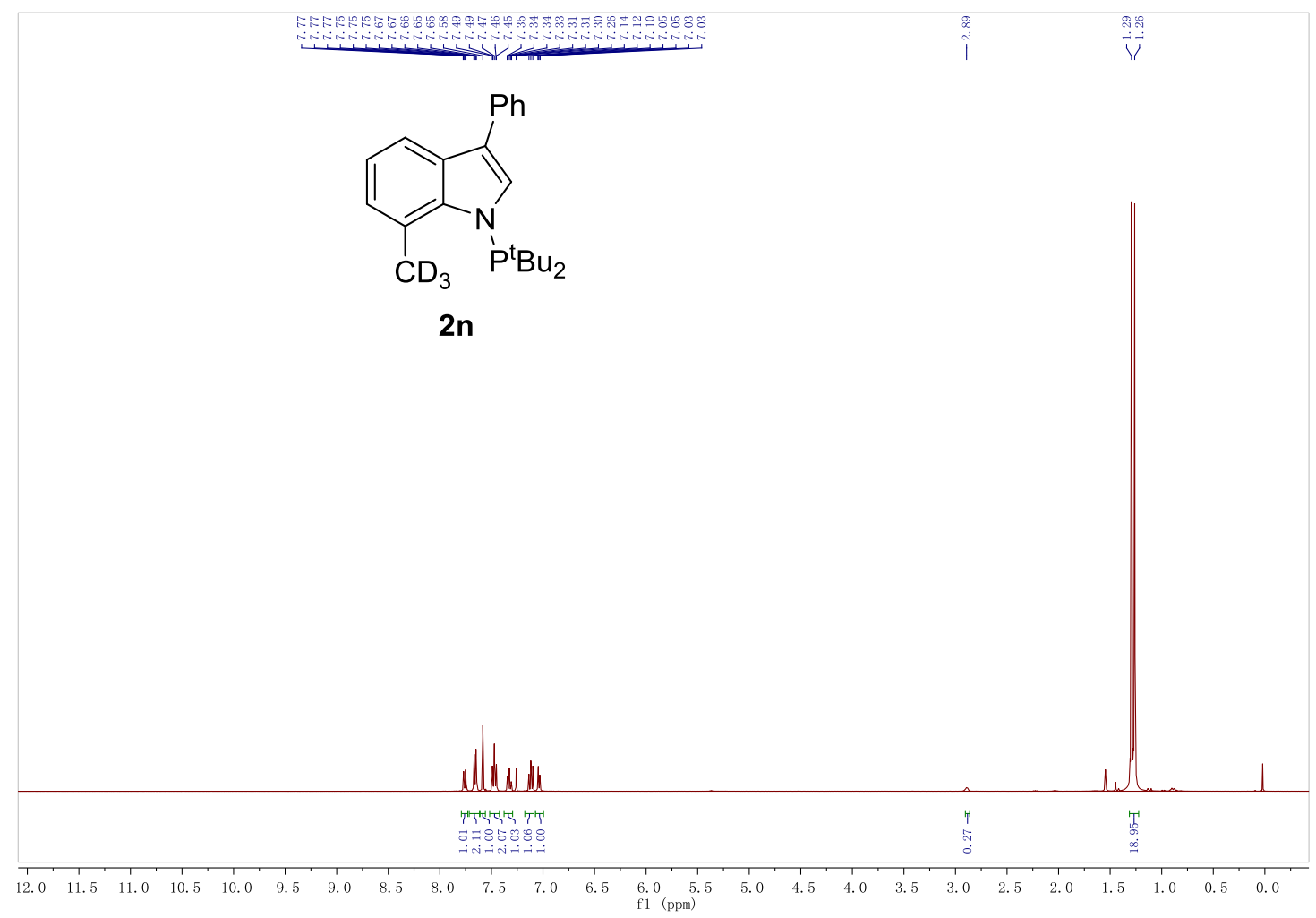


${ }^{1} \mathrm{H}$ NMR (400 MHz, $\left.\mathrm{CDCl}_{3}\right)$

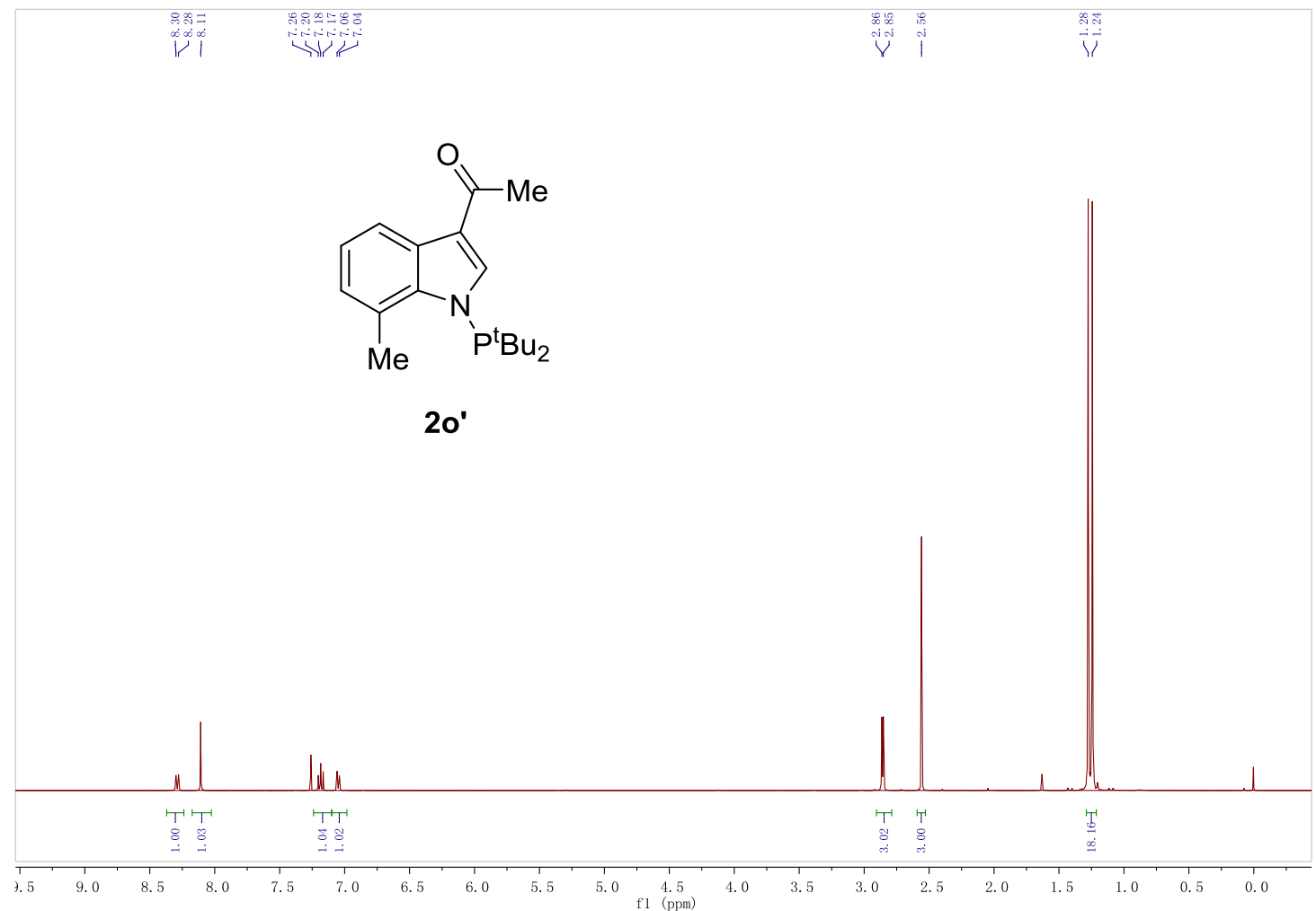

${ }^{13} \mathrm{C}$ NMR (400 MHz, $\left.\mathrm{CDCl}_{3}\right)$
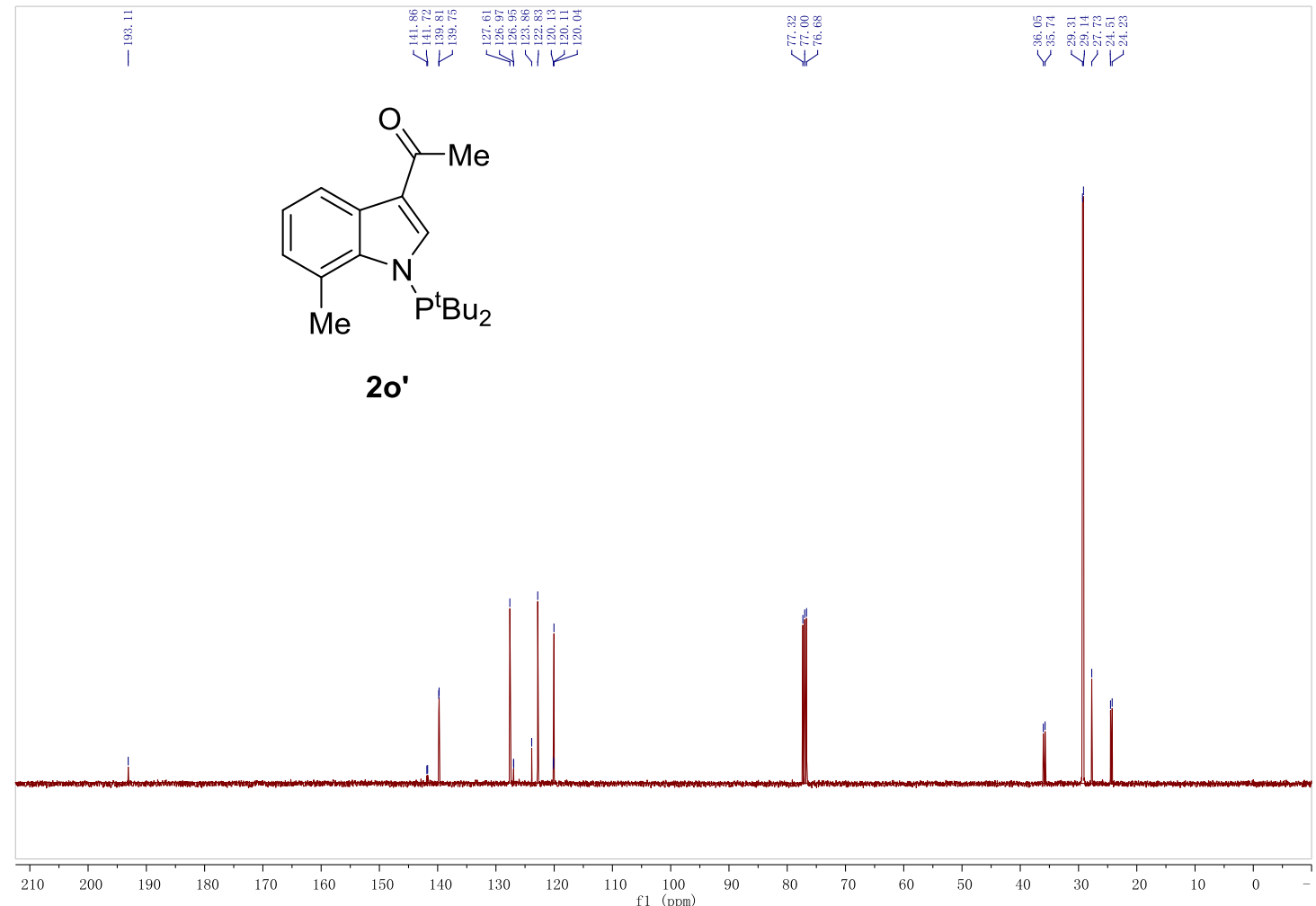
${ }^{31} \mathrm{P}$ NMR (400 MHz, $\mathrm{CDCl}_{3}$ )
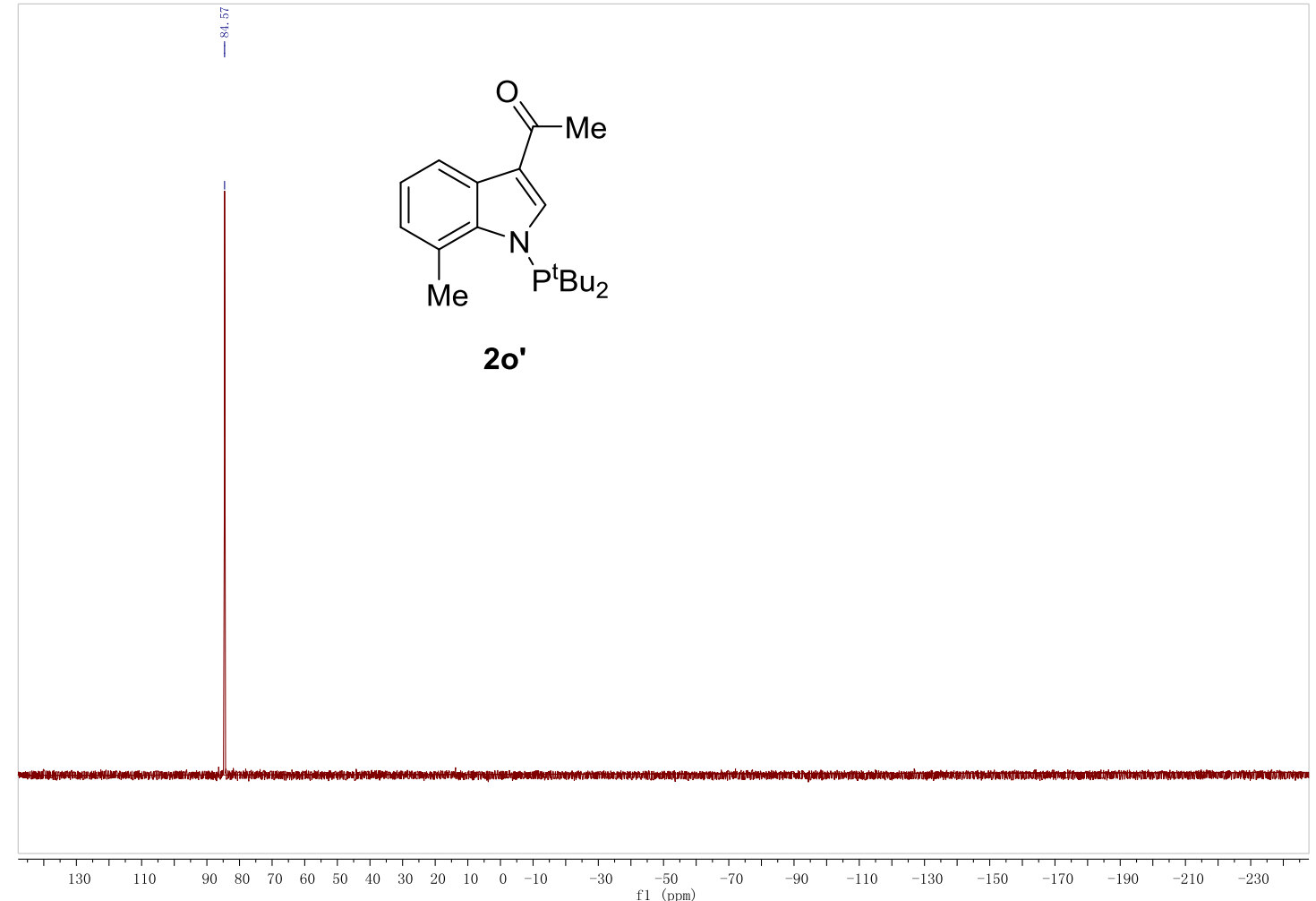

${ }^{1} \mathrm{H}$ NMR (400 MHz, $\left.\mathrm{CDCl}_{3}\right)$

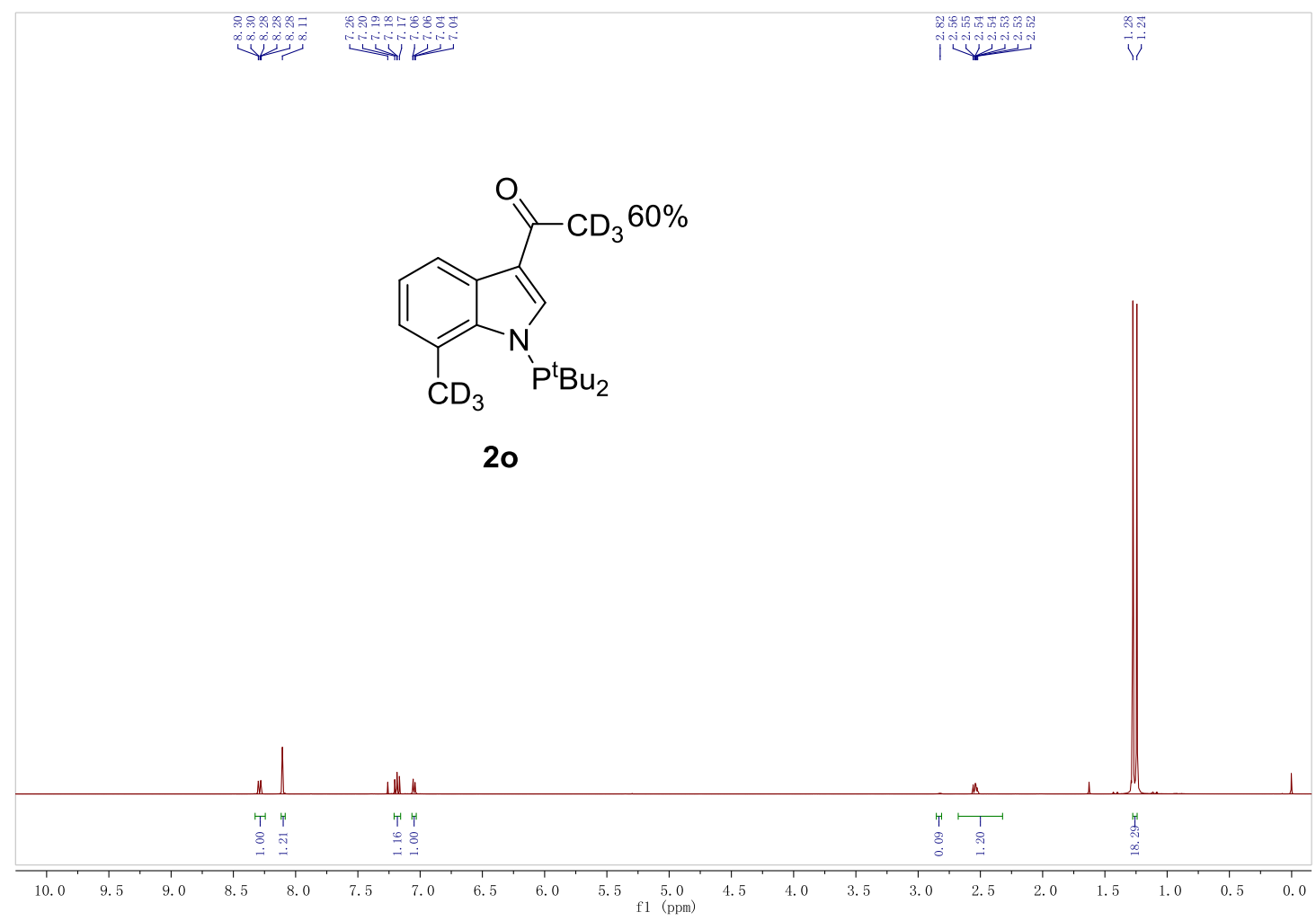


${ }^{1} \mathrm{H}$ NMR (400 MHz, $\mathrm{CDCl}_{3}$ )

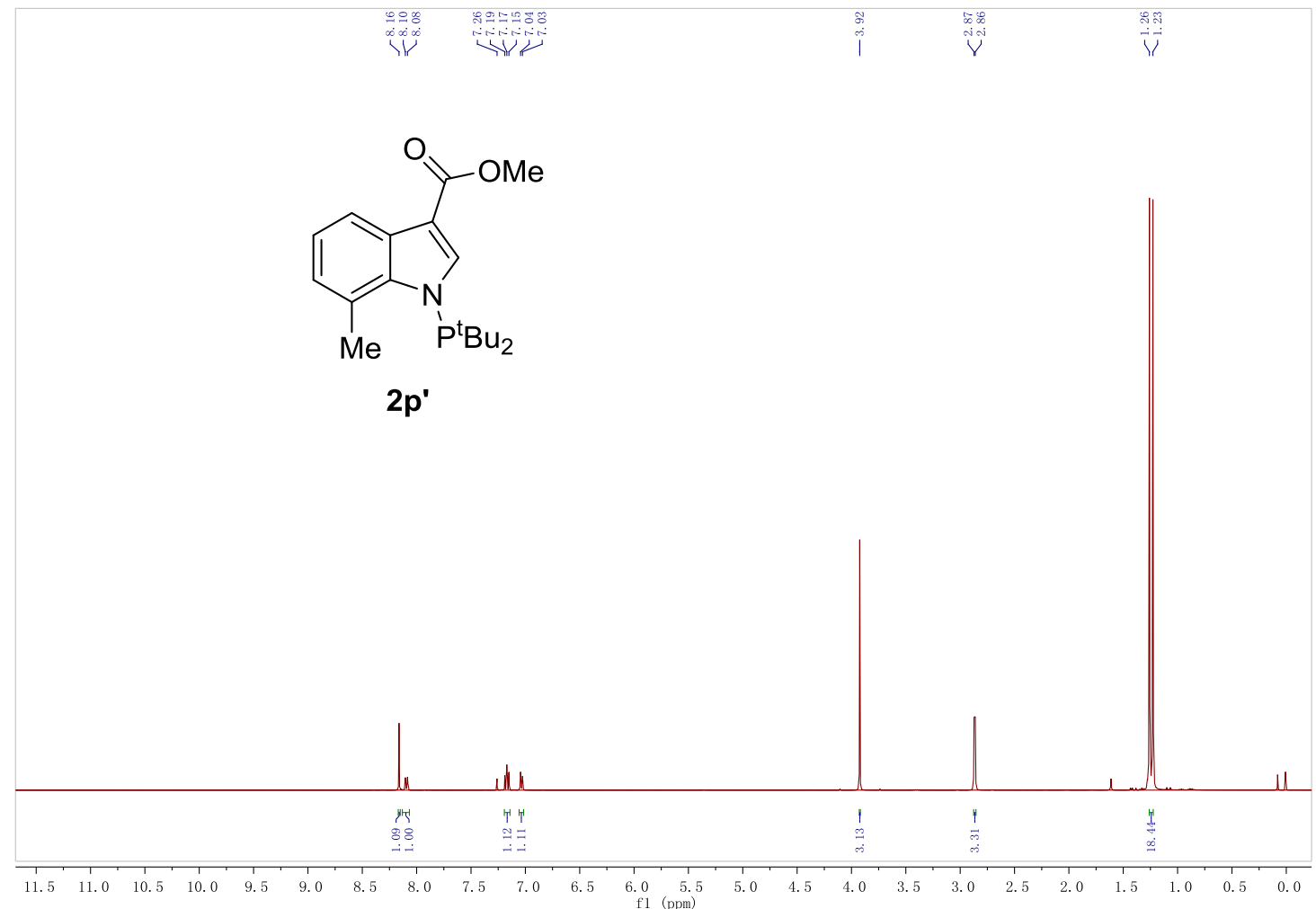

${ }^{13} \mathrm{C}$ NMR (400 MHz, $\mathrm{CDCl}_{3}$ )

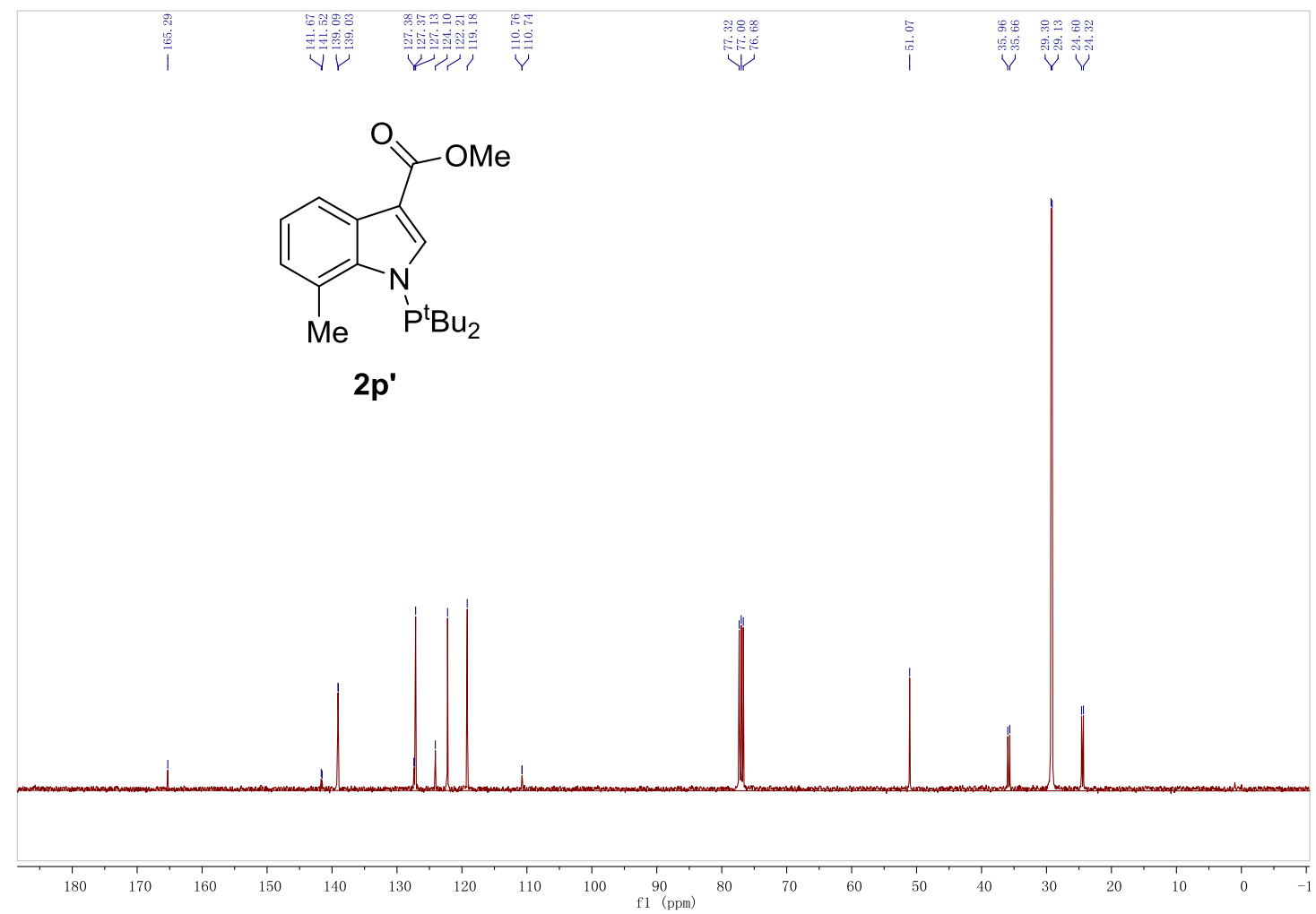


${ }^{31}$ P NMR (400 MHz, $\mathrm{CDCl}_{3}$ )
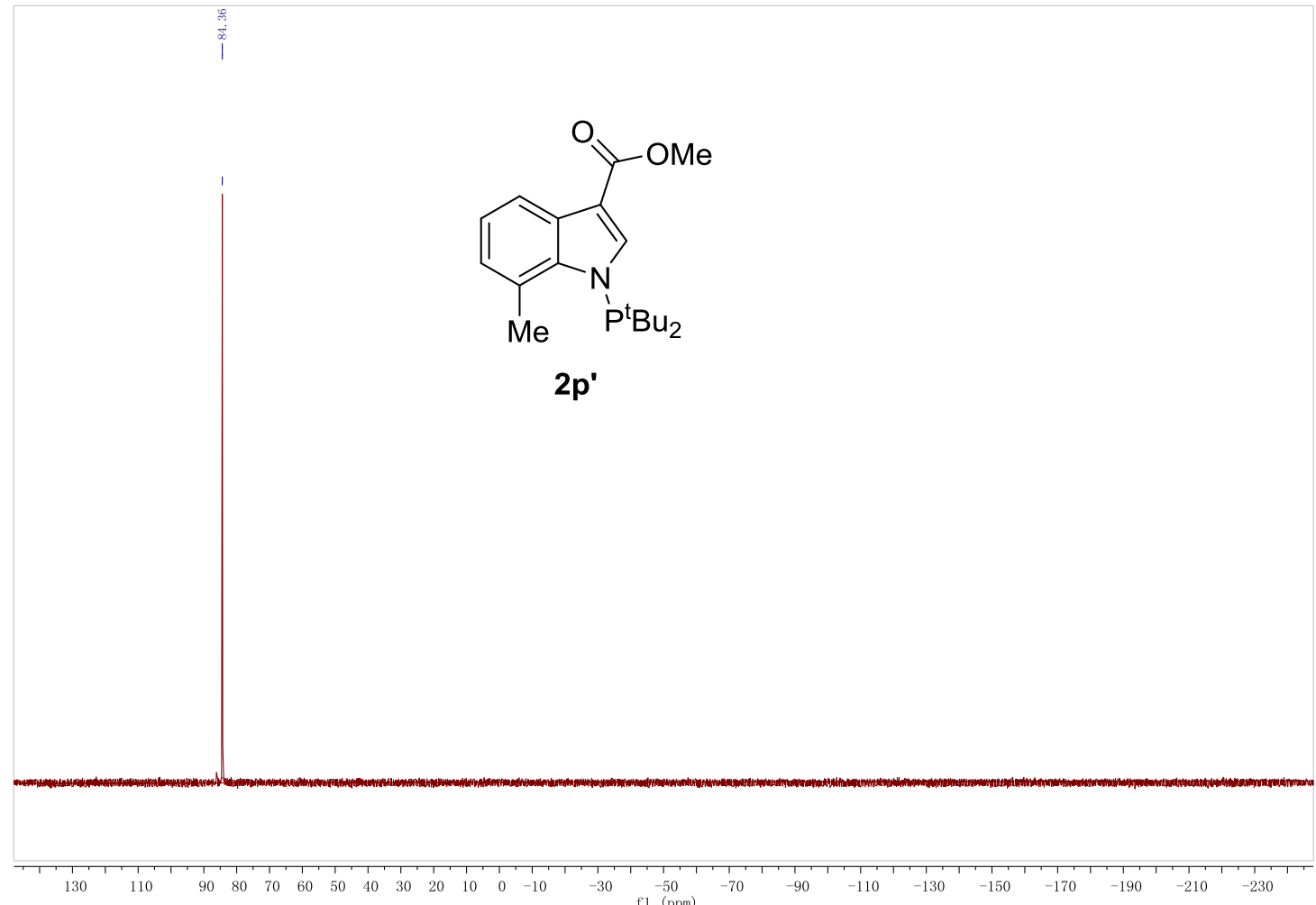

${ }^{1} \mathrm{H}$ NMR (400 MHz, $\left.\mathrm{CDCl}_{3}\right)$

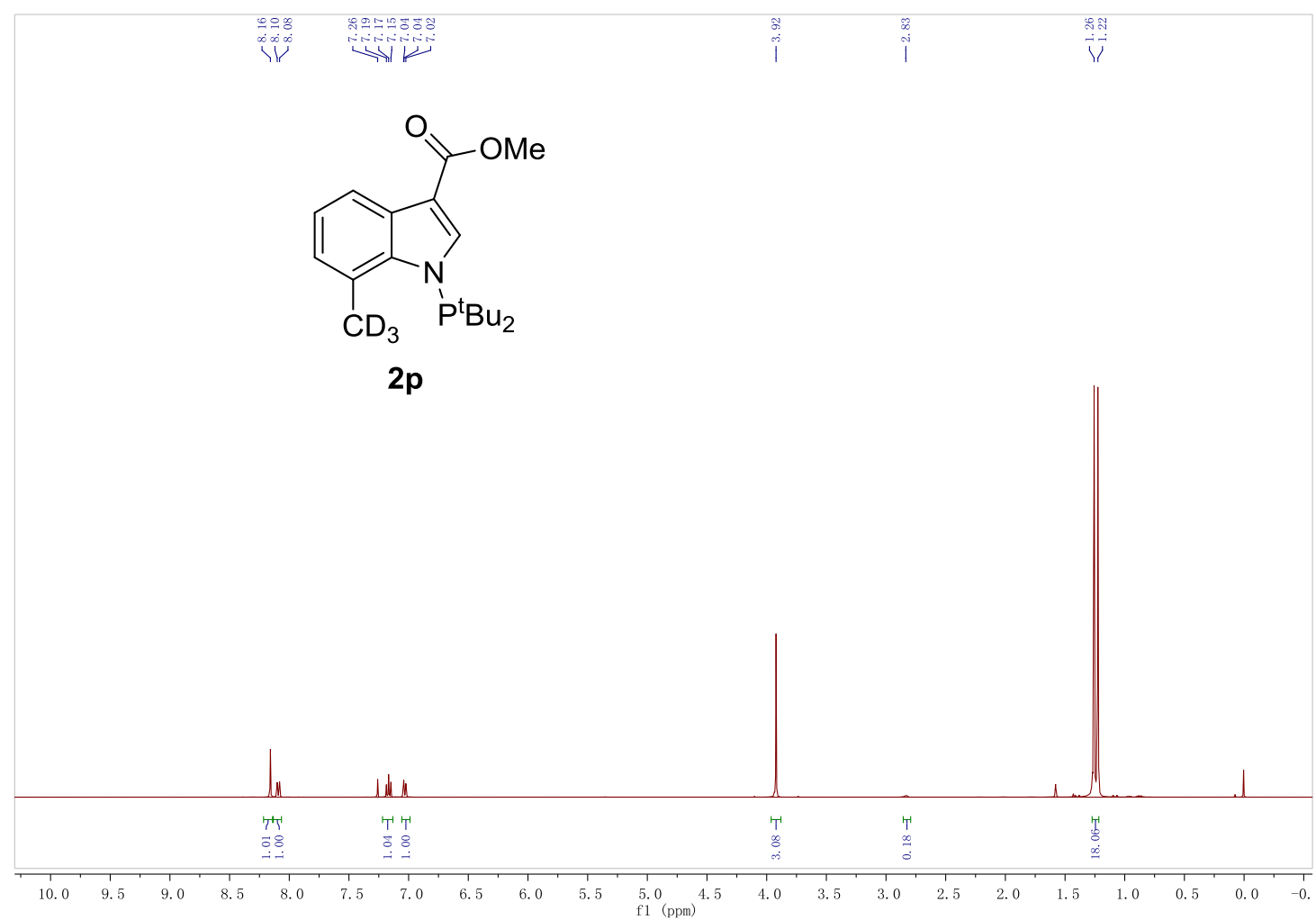


${ }^{1} \mathrm{H}$ NMR (400 MHz, $\left.\mathrm{CDCl}_{3}\right)$

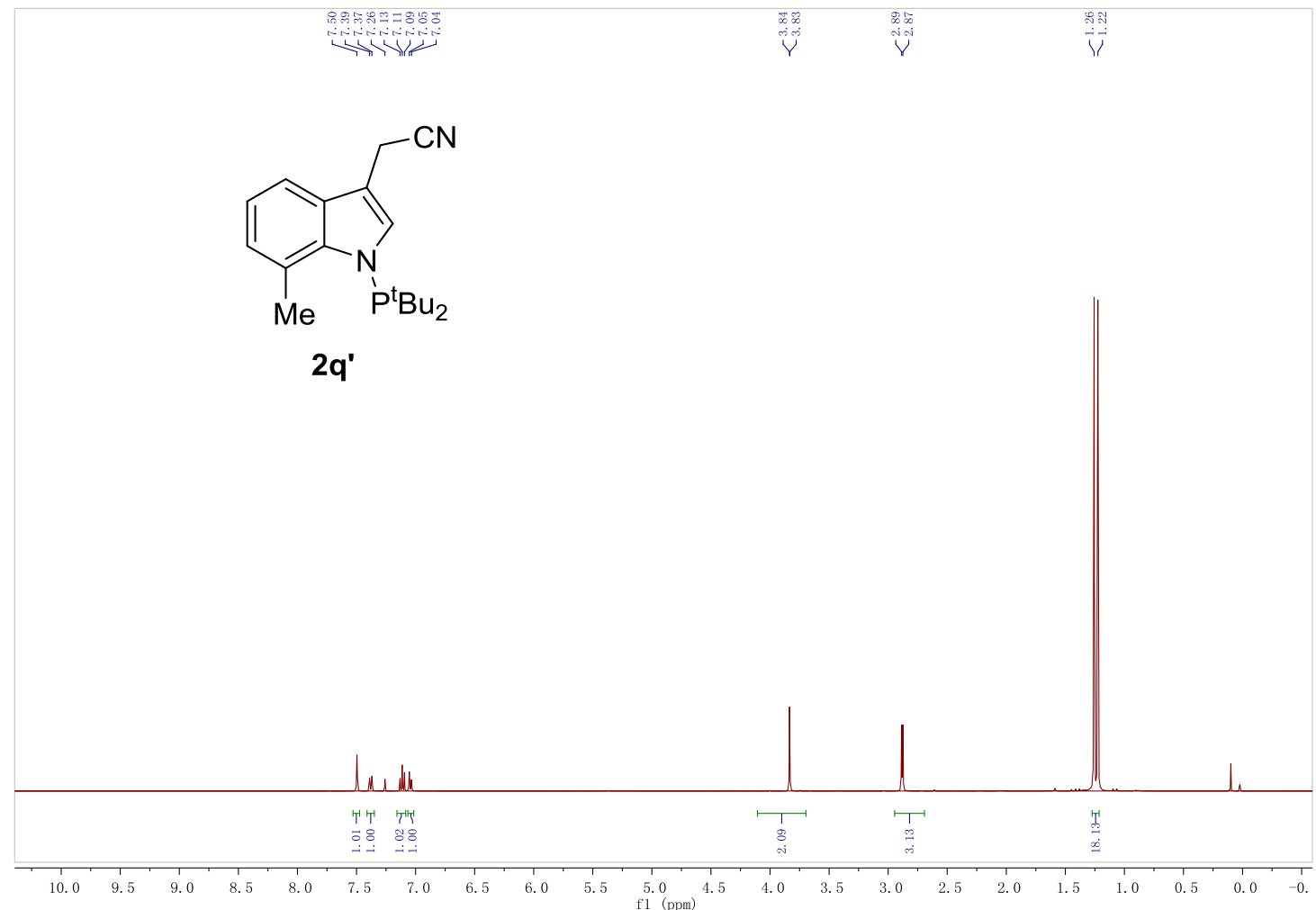

${ }^{13} \mathrm{C}$ NMR (400 MHz, $\left.\mathrm{CDCl}_{3}\right)$

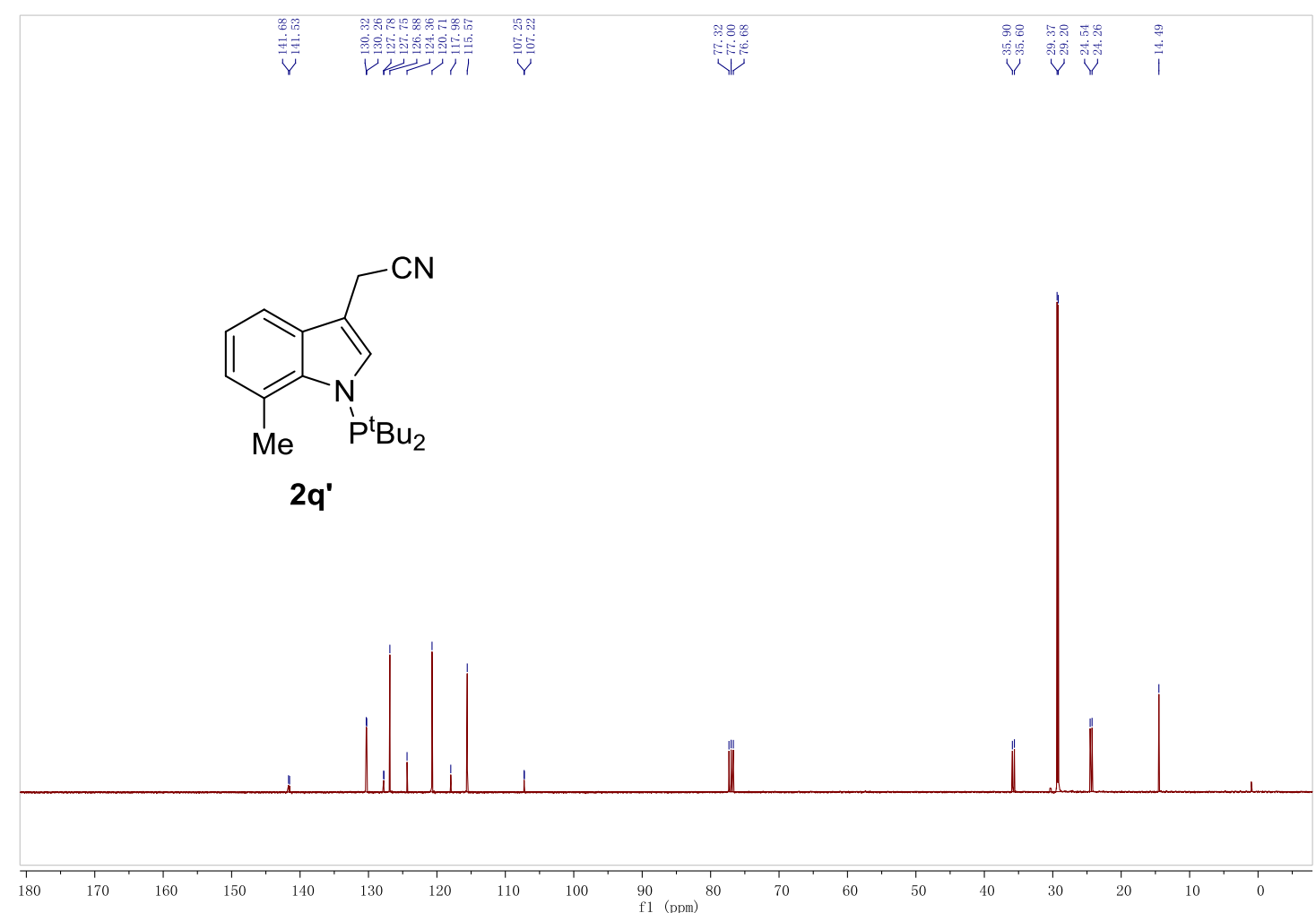


${ }^{31}$ P NMR (400 MHz, $\left.\mathrm{CDCl}_{3}\right)$

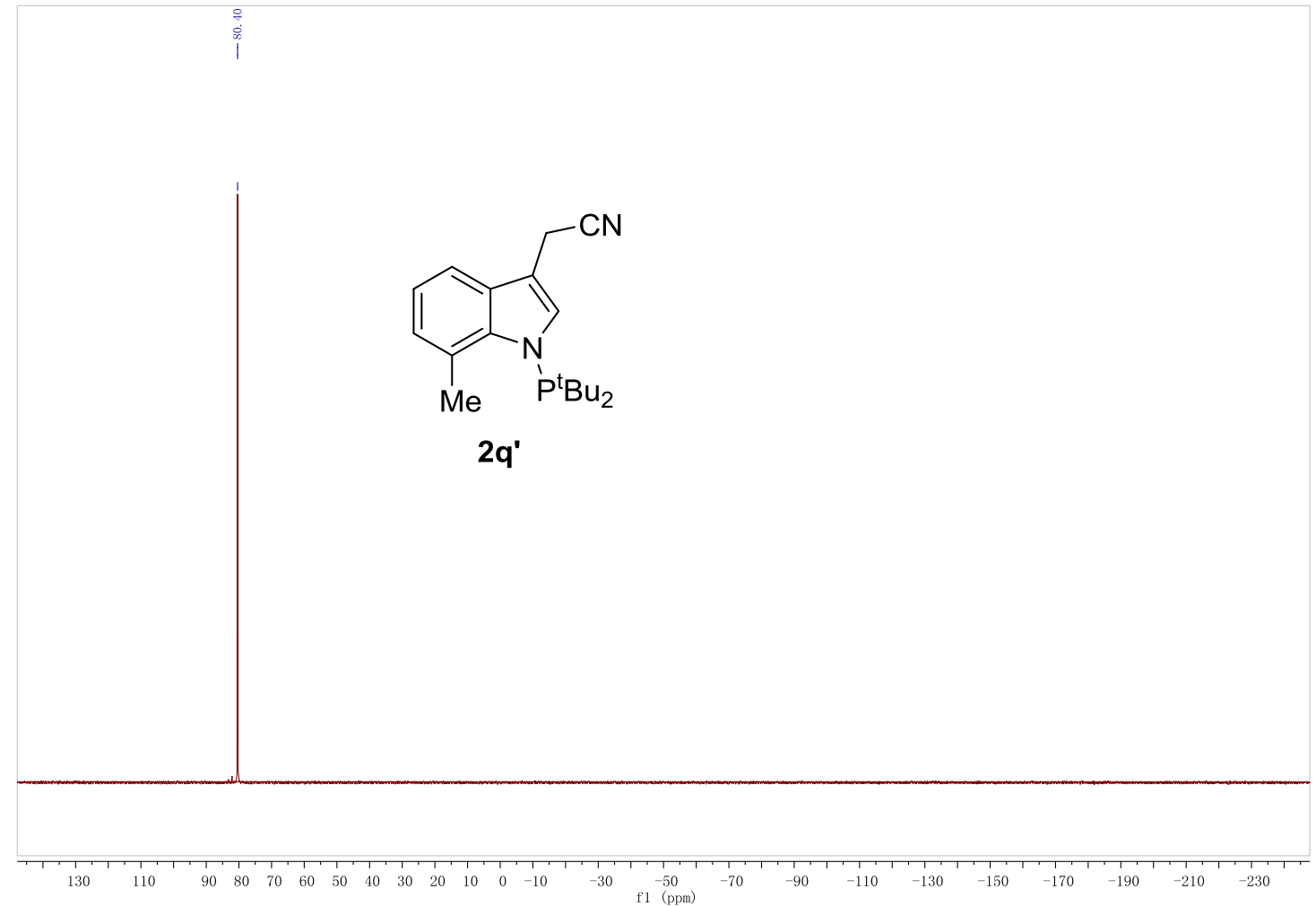

${ }^{1} \mathrm{H}$ NMR (400 MHz, $\left.\mathrm{CDCl}_{3}\right)$

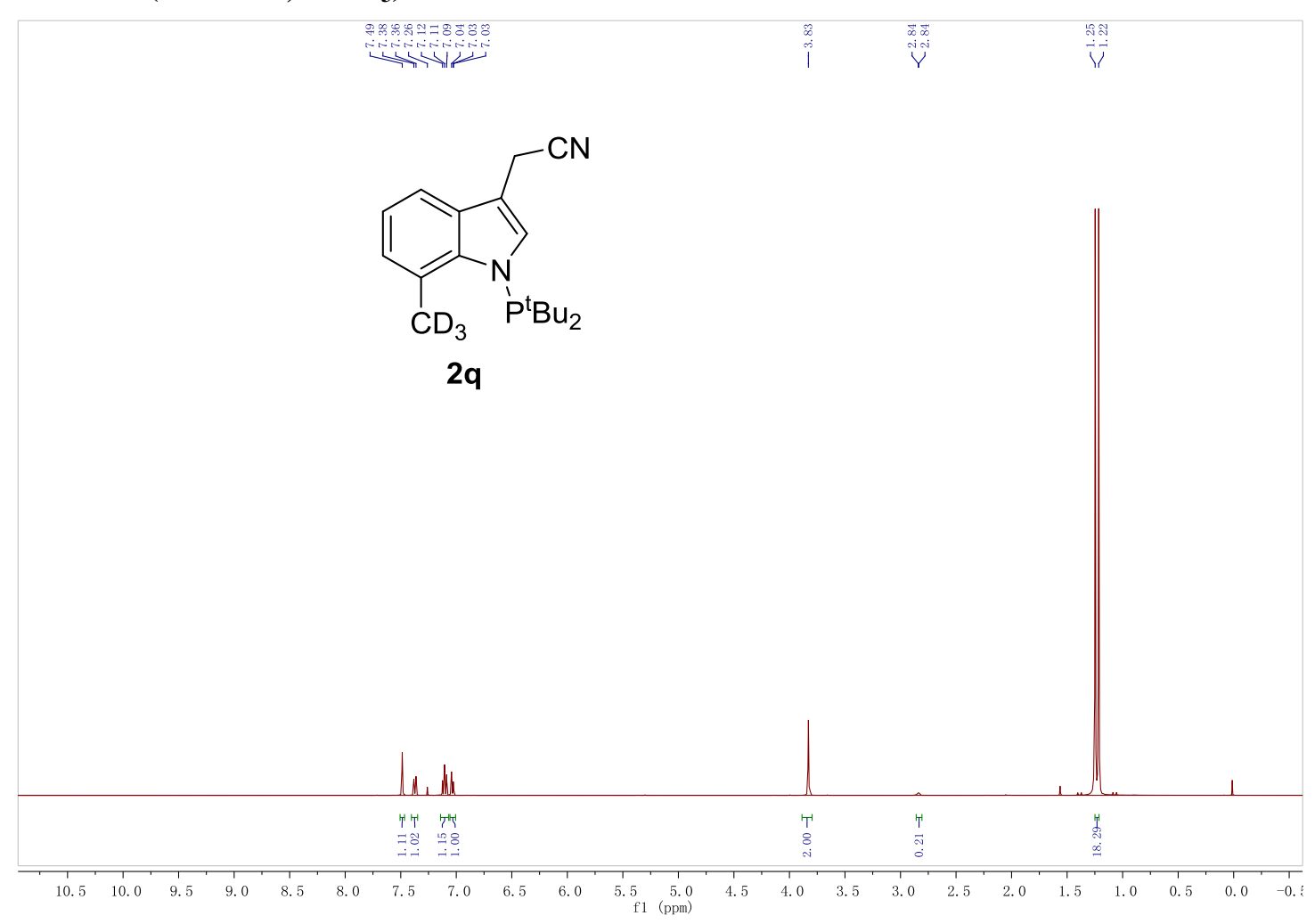


${ }^{1} \mathrm{H}$ NMR (400 MHz, $\left.\mathrm{CDCl}_{3}\right)$

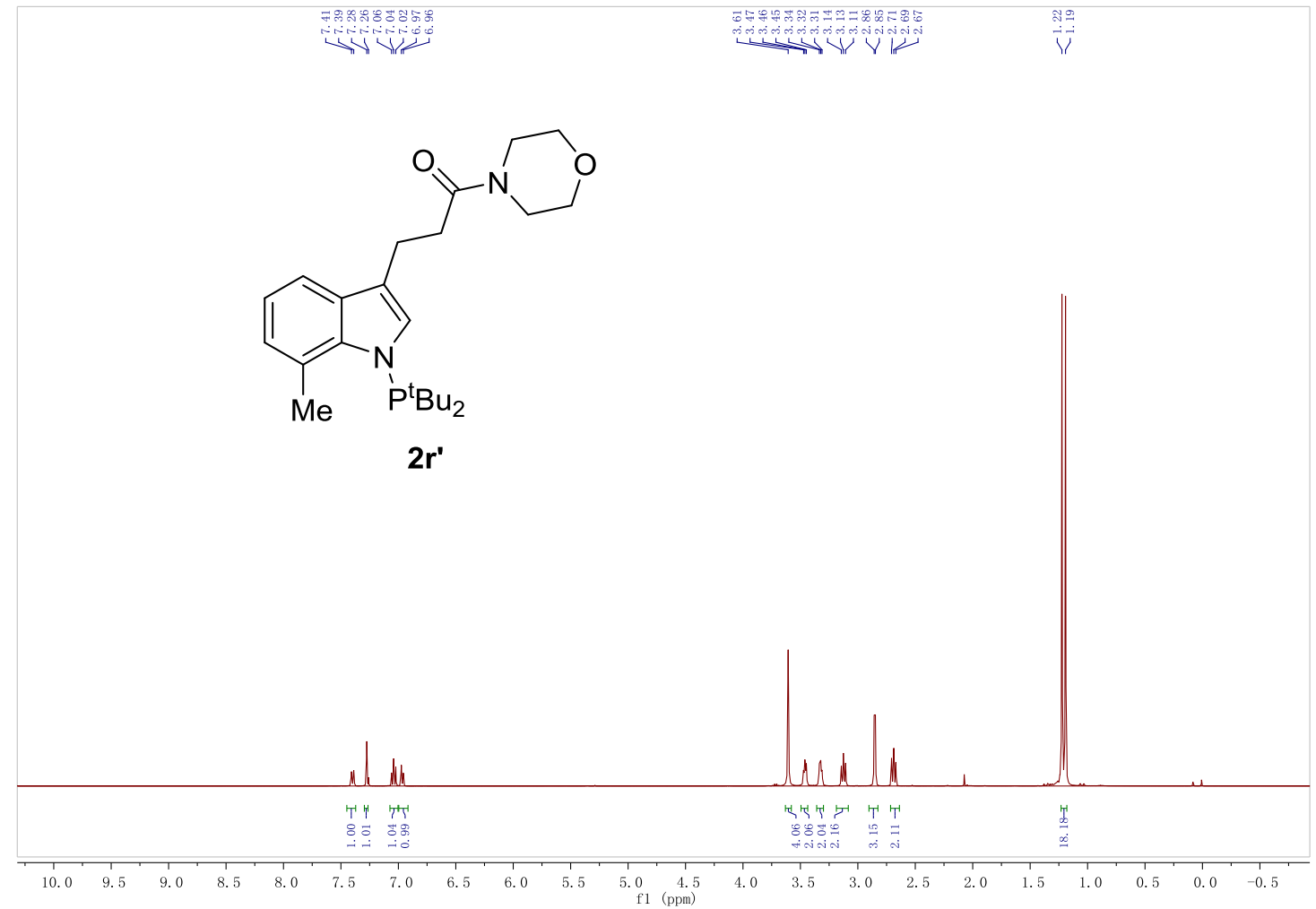

${ }^{13} \mathrm{C}$ NMR (400 MHz, $\mathrm{CDCl}_{3}$ )
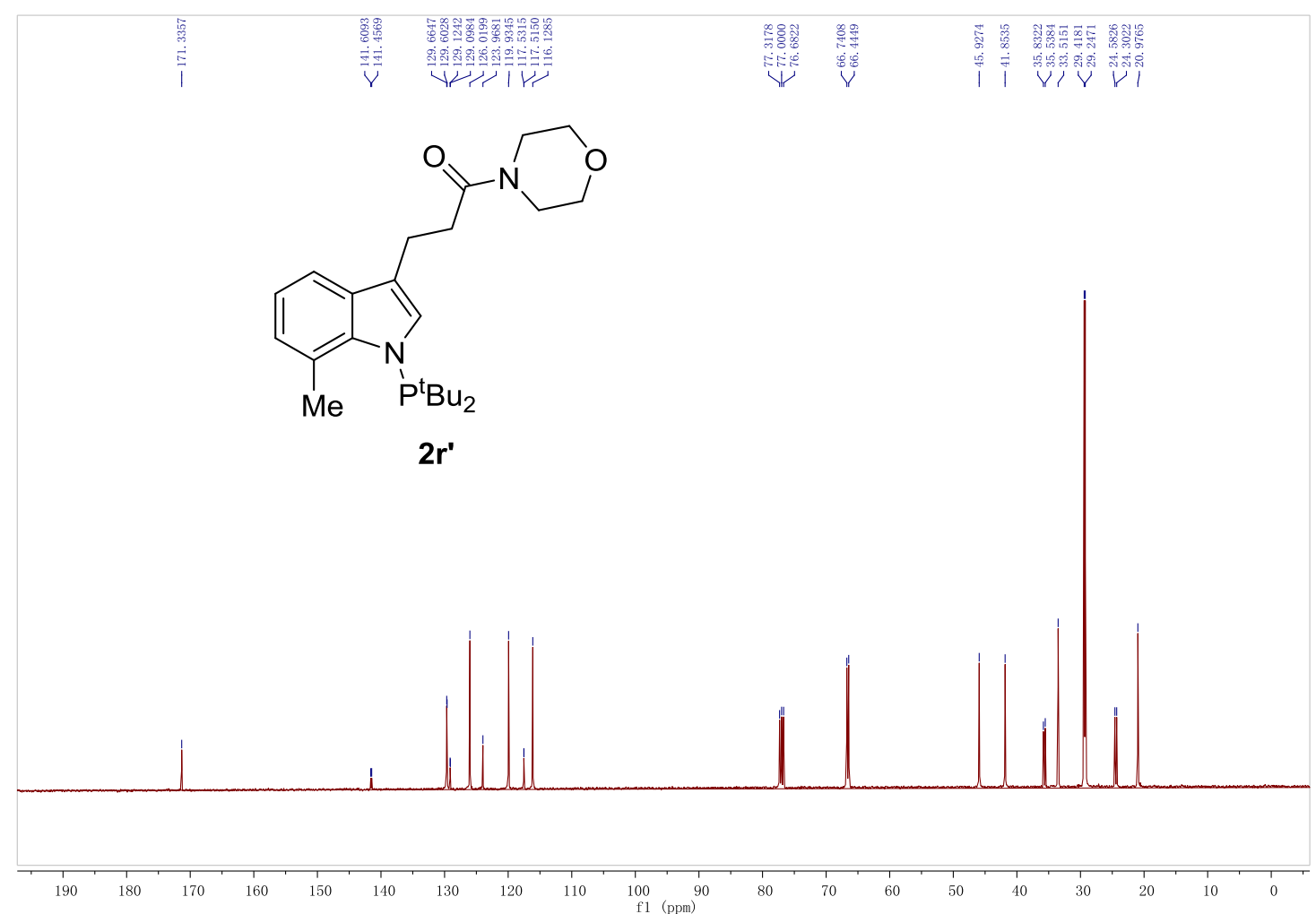
${ }^{31}$ P NMR (400 MHz, $\left.\mathrm{CDCl}_{3}\right)$

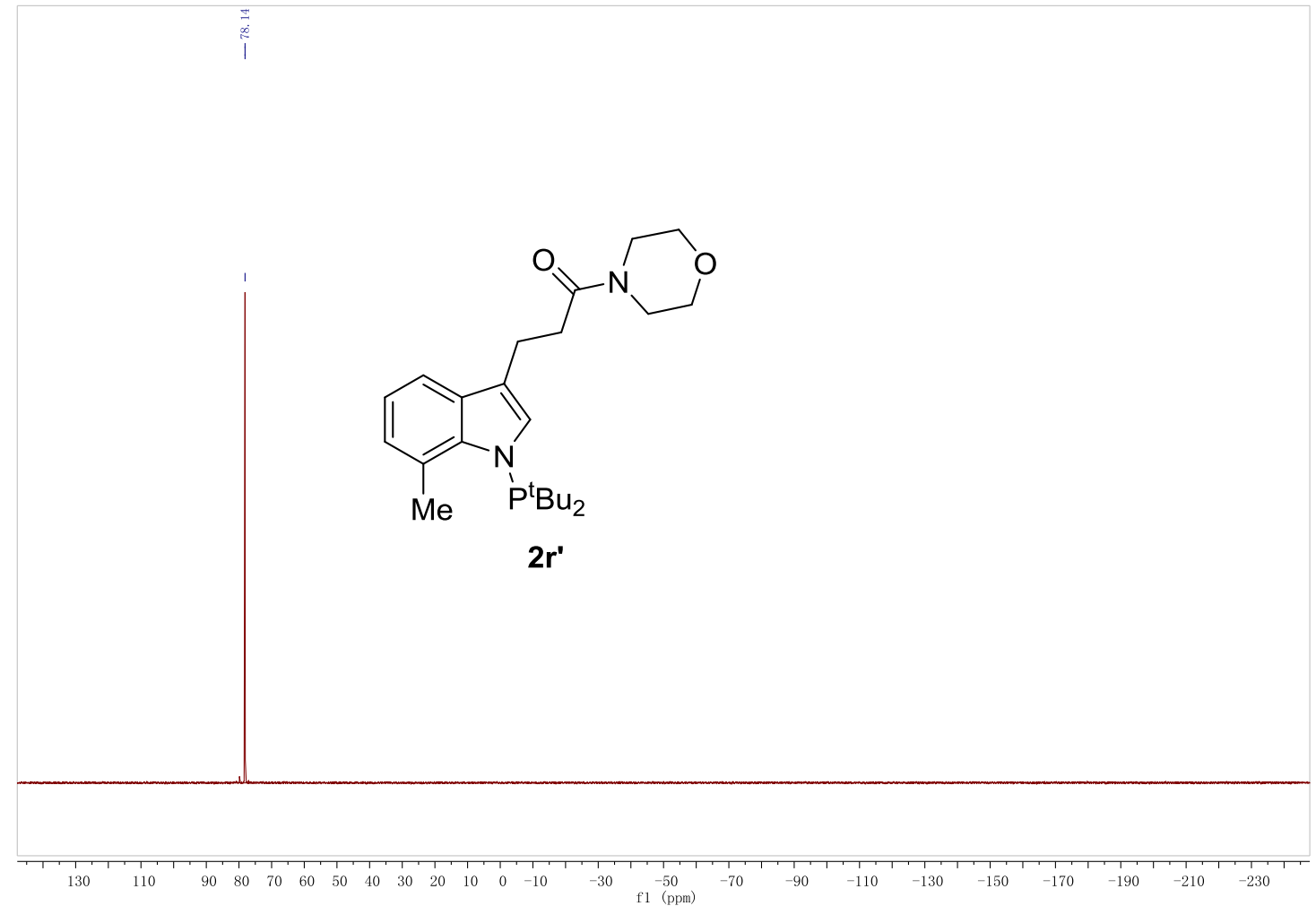

${ }^{1} \mathrm{H}$ NMR (400 MHz, $\left.\mathrm{CDCl}_{3}\right)$

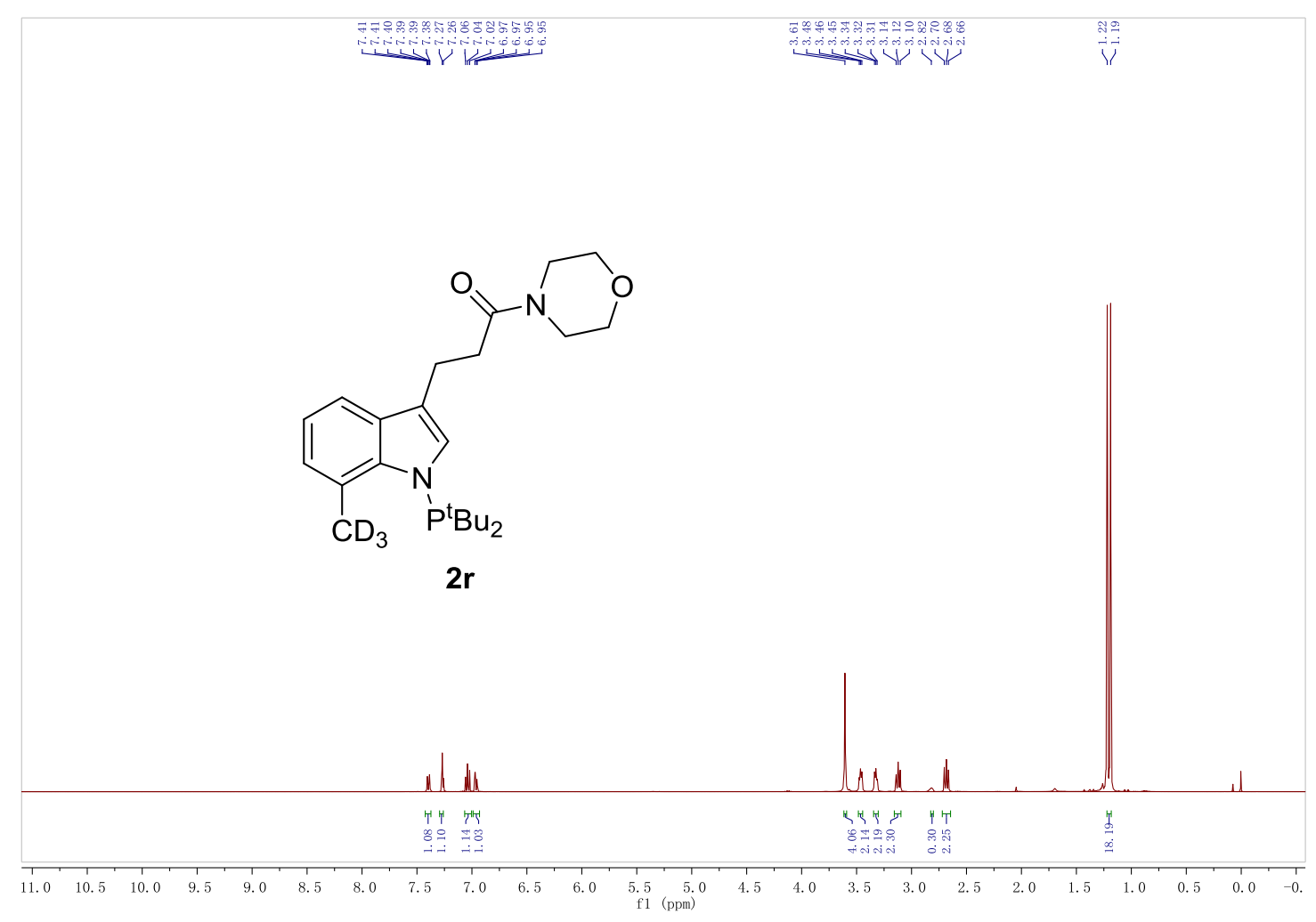


${ }^{1} \mathrm{H}$ NMR (400 MHz, $\left.\mathrm{CDCl}_{3}\right)$

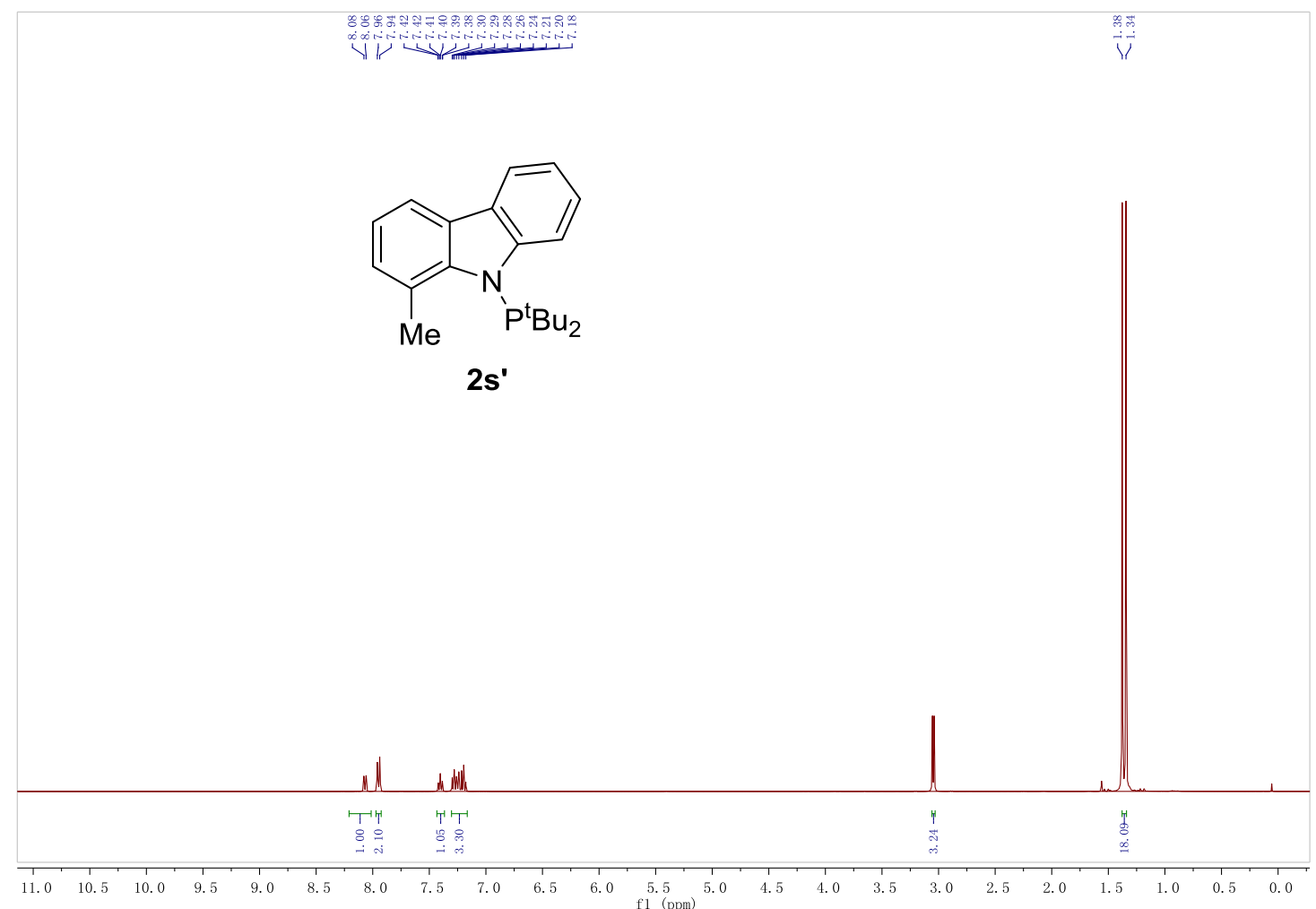

${ }^{13} \mathrm{C}$ NMR (400 MHz, $\mathrm{CDCl}_{3}$ )

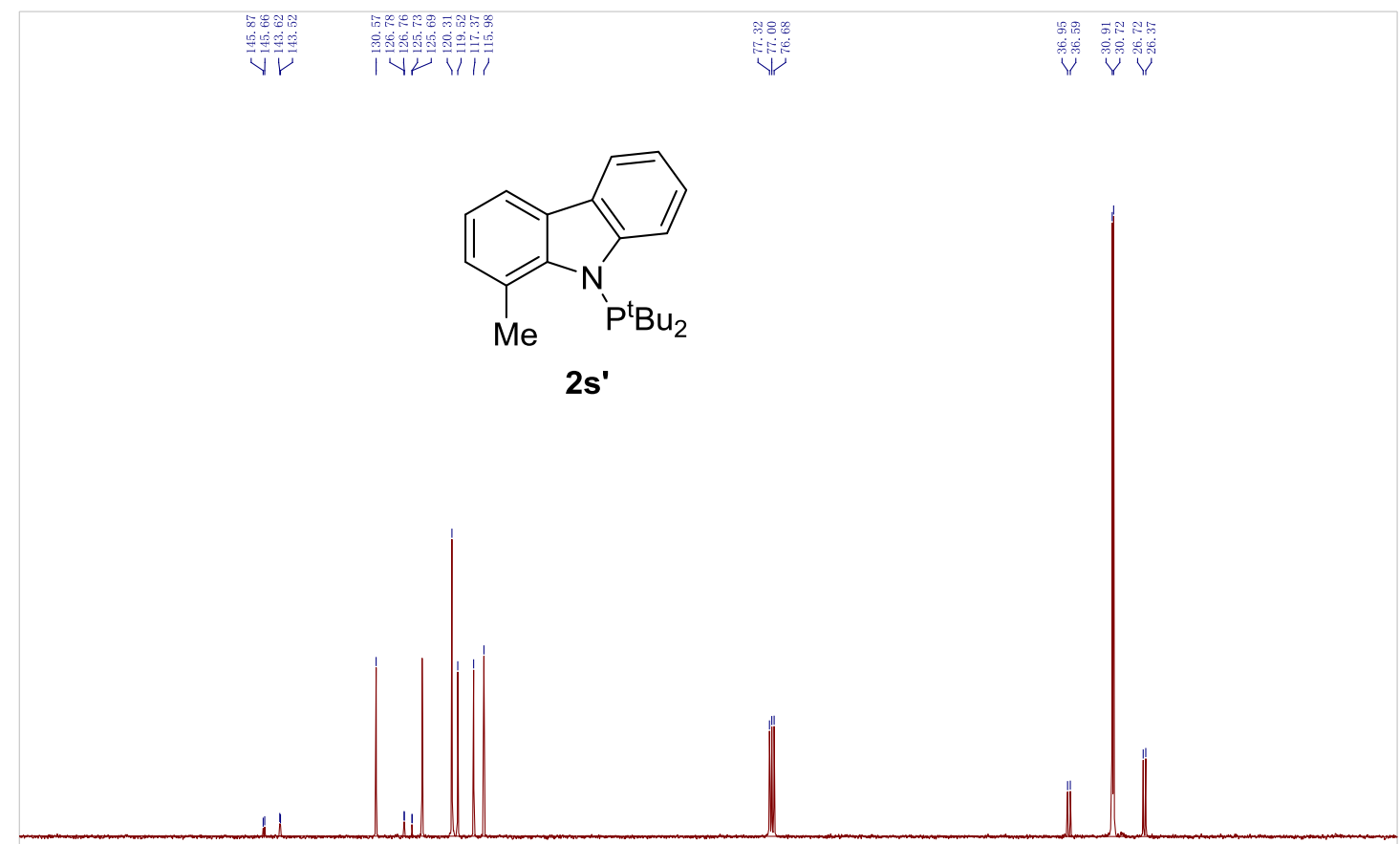

$\begin{array}{rrrrrrrrr}170 & 160 & 150 & 140 & 130 & 120 & 110 & 100 & 90 \\ \mathrm{f} 1 & (\mathrm{ppm}) & 80\end{array}$ 
${ }^{31}$ P NMR (400 MHz, $\left.\mathrm{CDCl}_{3}\right)$

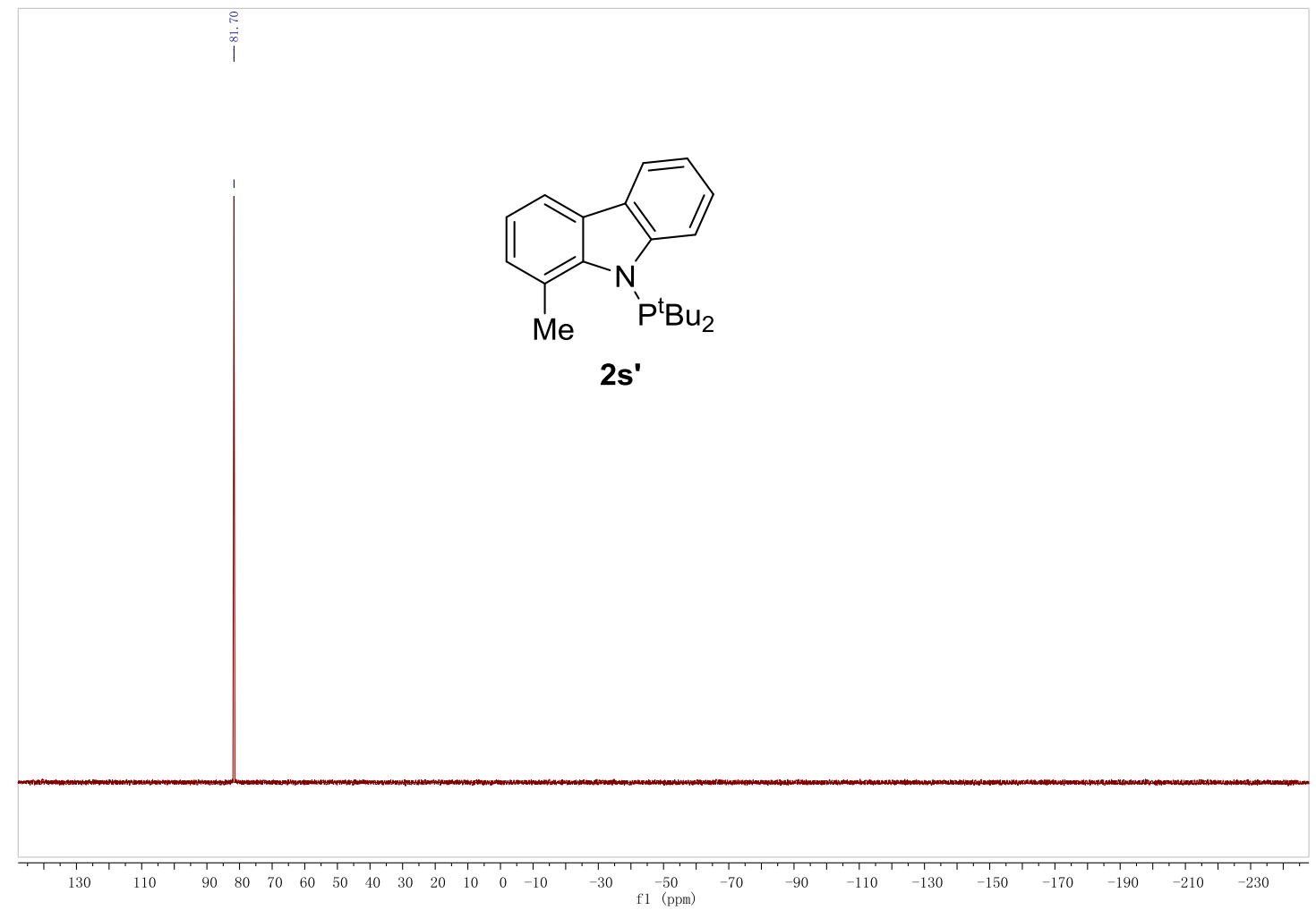

${ }^{1} \mathrm{H}$ NMR (400 MHz, $\mathrm{CDCl}_{3}$ )

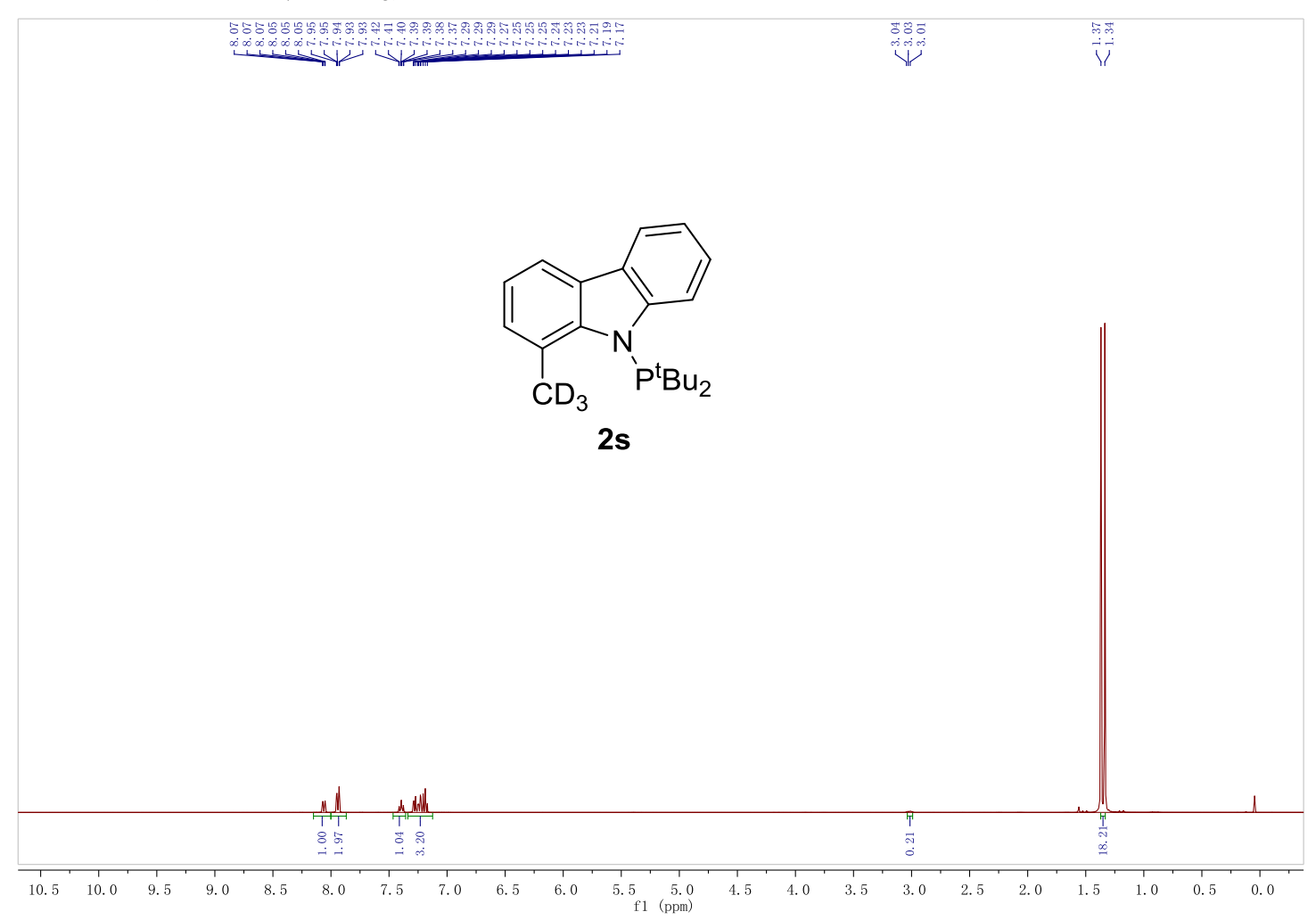


${ }^{1} \mathrm{H}$ NMR (400 MHz, $\left.\mathrm{CDCl}_{3}\right)$

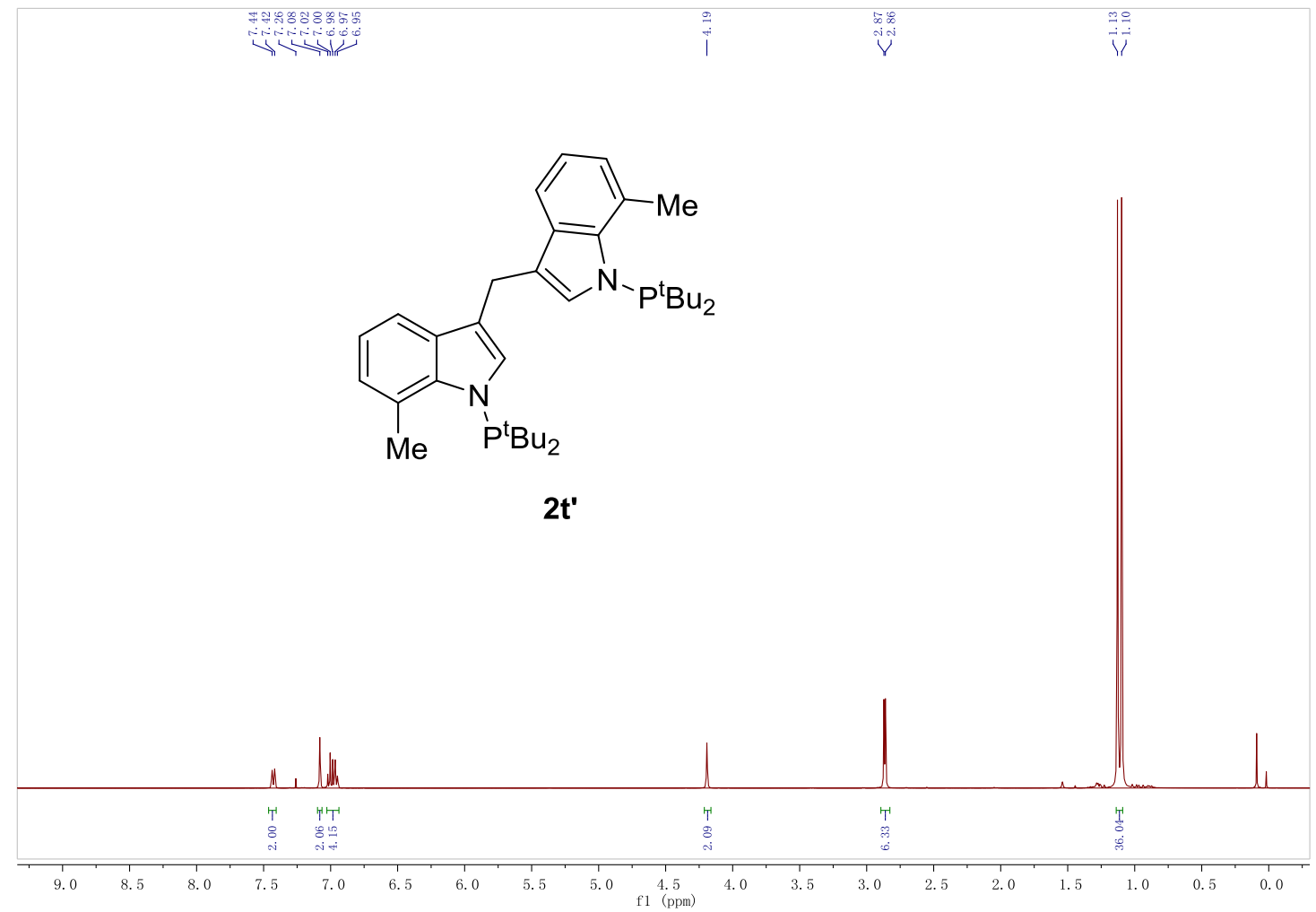

${ }^{13} \mathrm{C}$ NMR (400 MHz, $\mathrm{CDCl}_{3}$ )
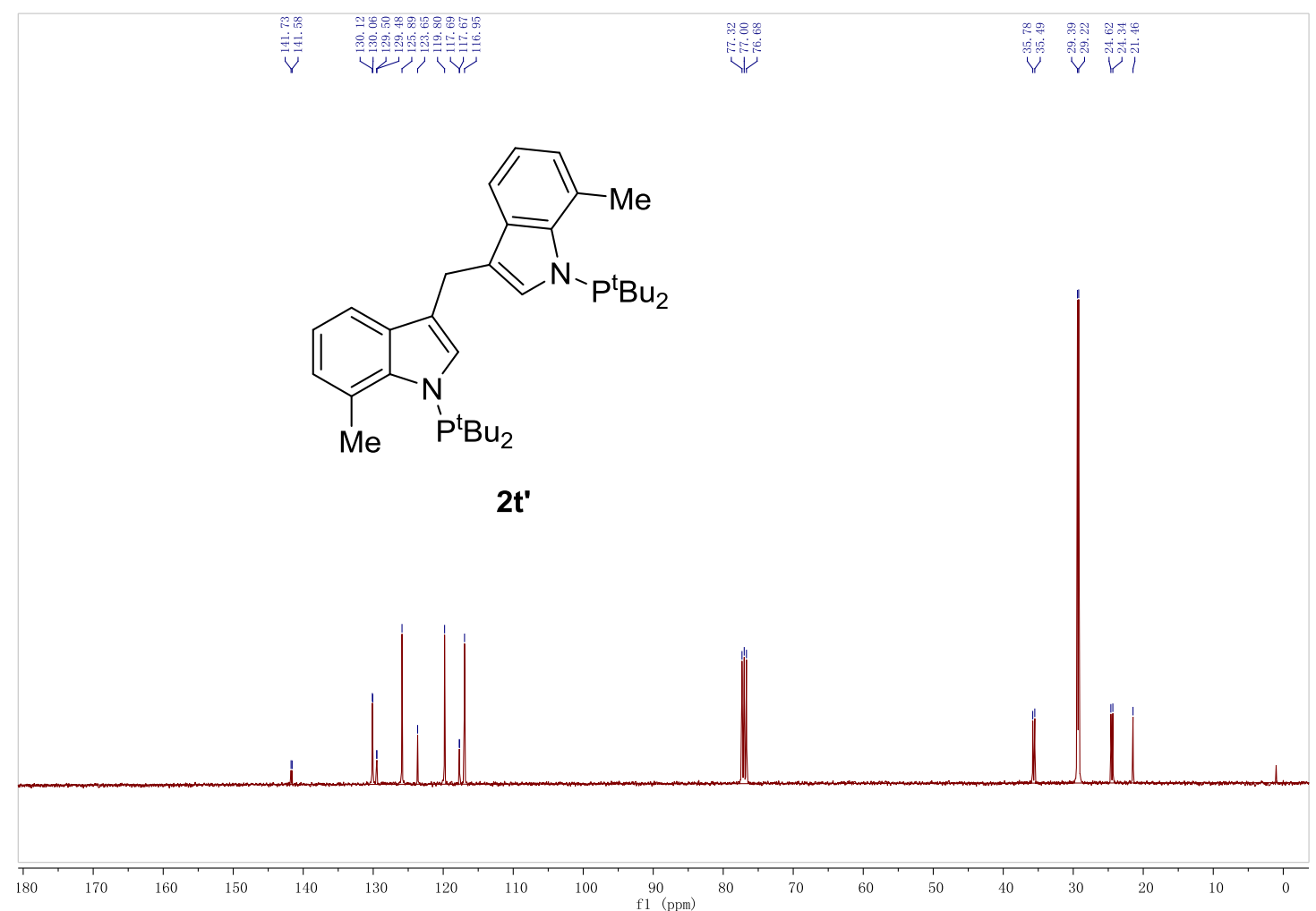
${ }^{31}$ P NMR (400 MHz, $\mathrm{CDCl}_{3}$ )

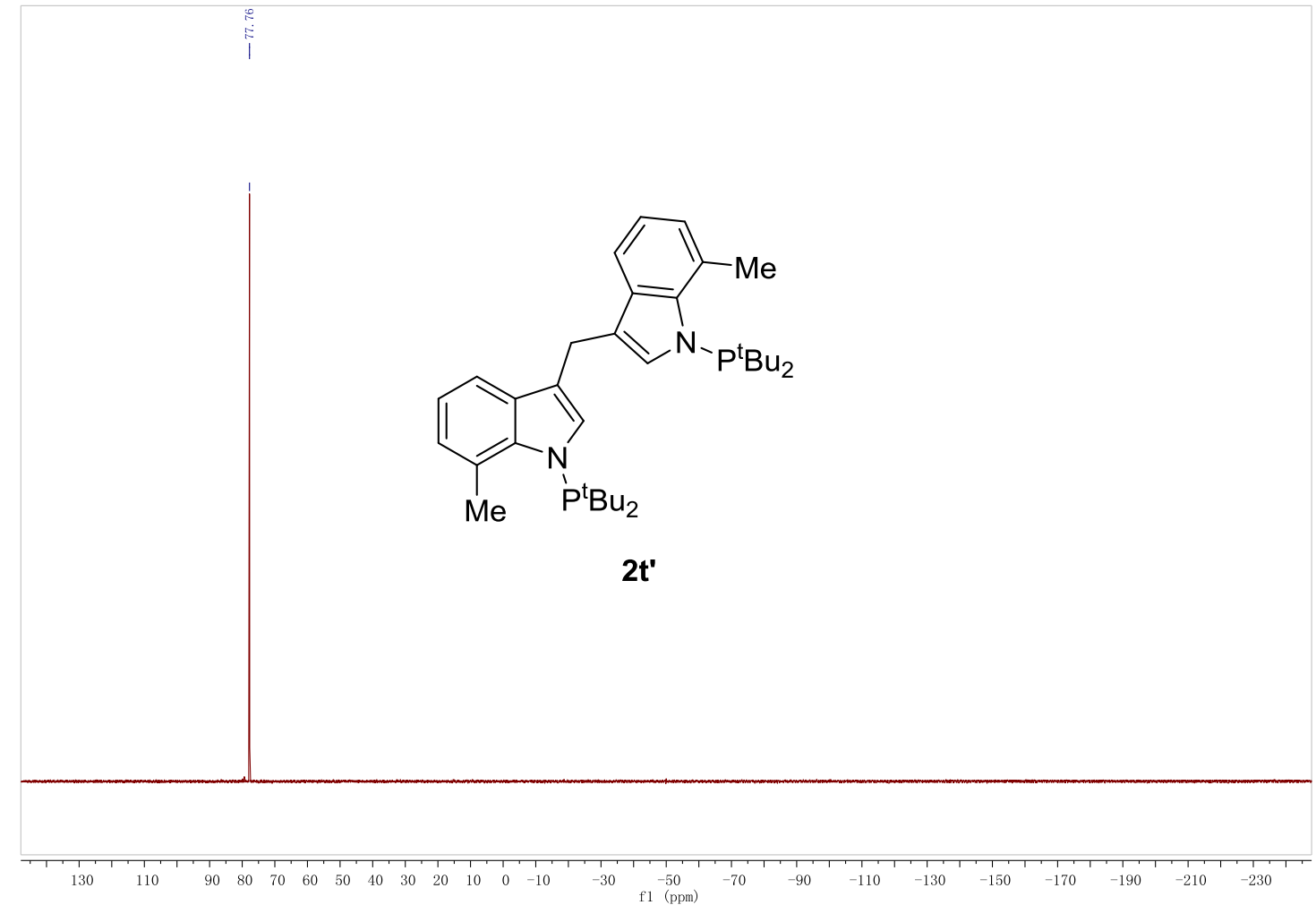

${ }^{1} \mathrm{H}$ NMR (400 MHz, $\left.\mathrm{CDCl}_{3}\right)$

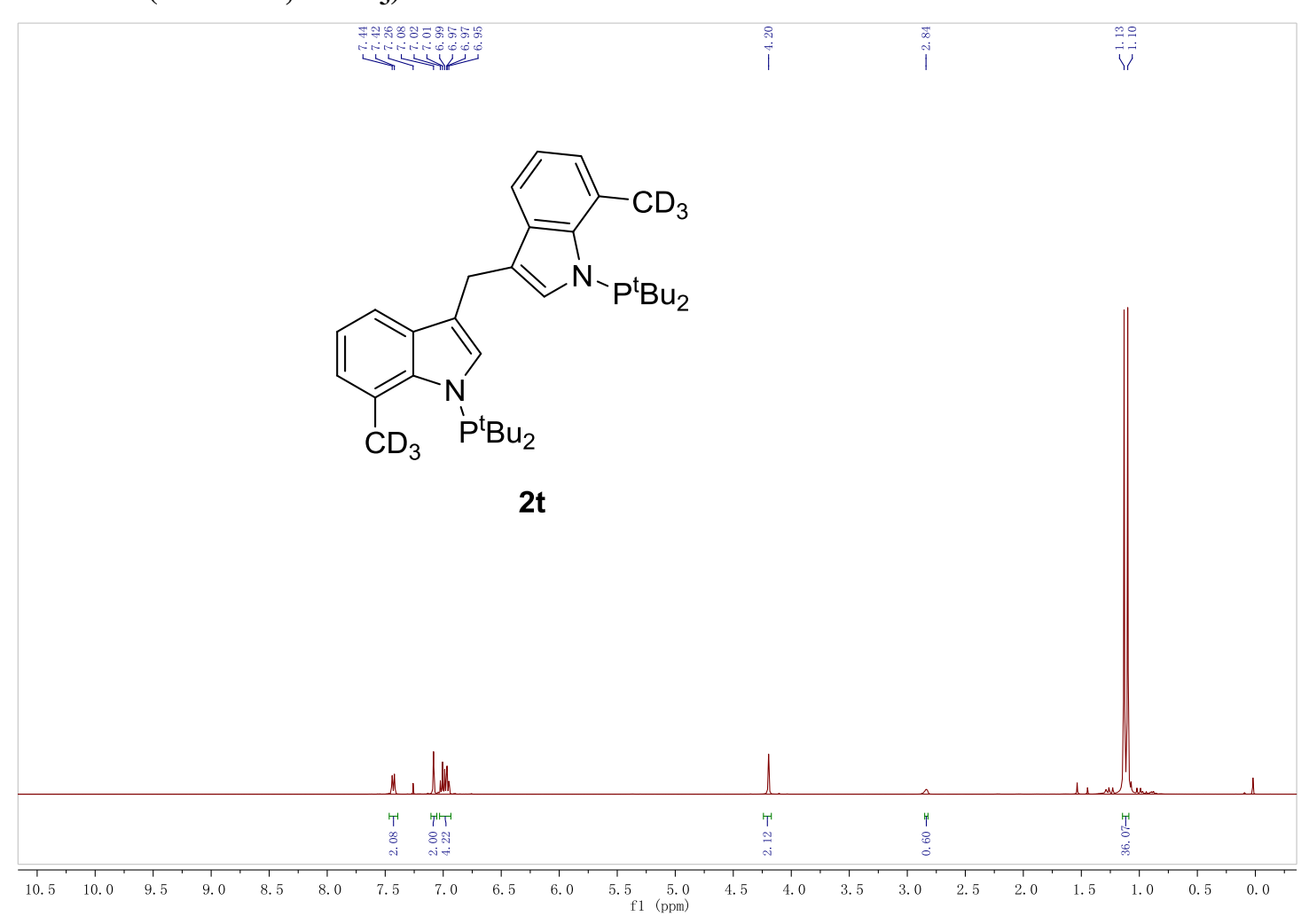


${ }^{1} \mathrm{H}$ NMR (400 MHz, $\left.\mathrm{CDCl}_{3}\right)$

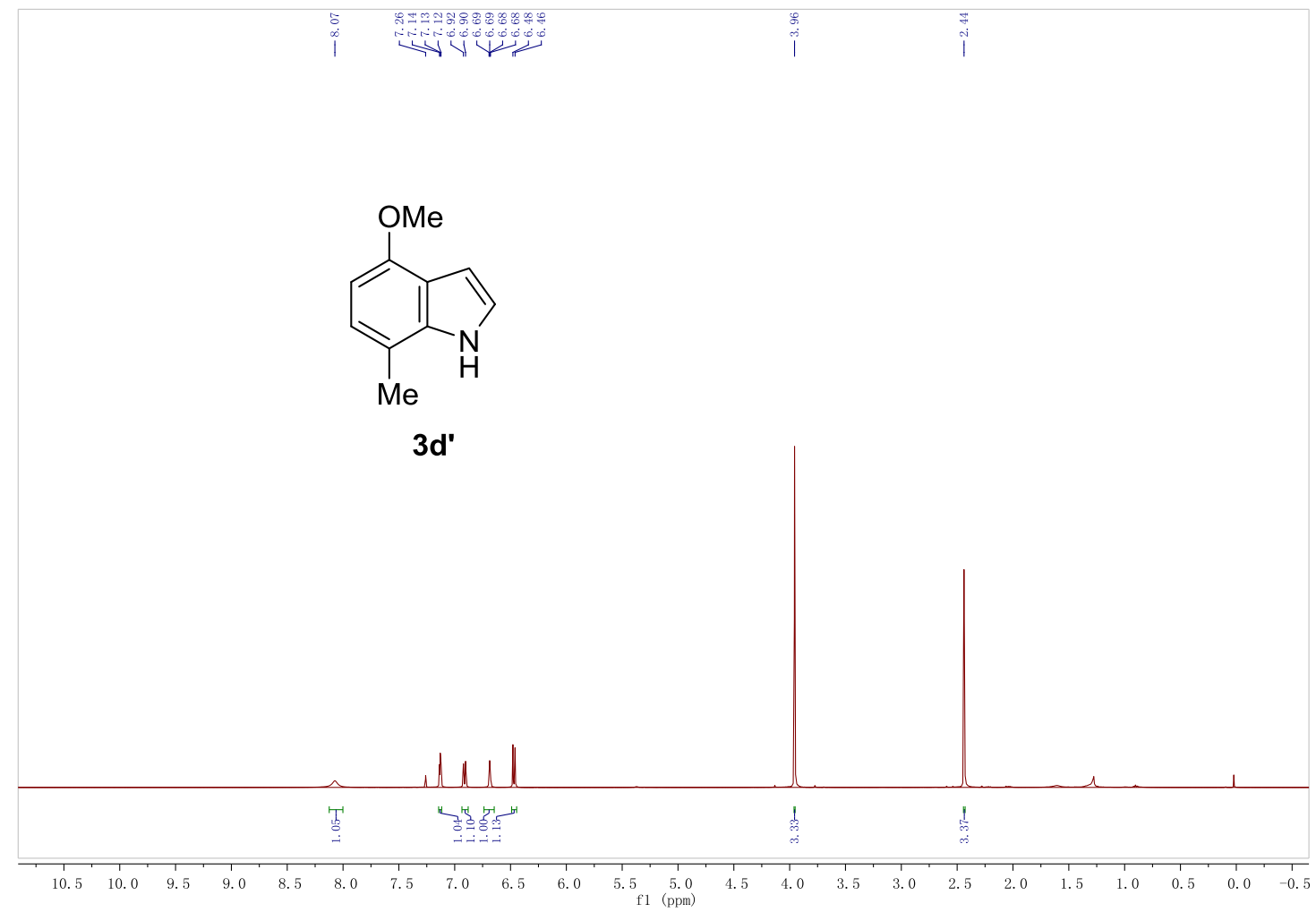

${ }^{13} \mathrm{C}$ NMR (400 MHz, $\mathrm{CDCl}_{3}$ )

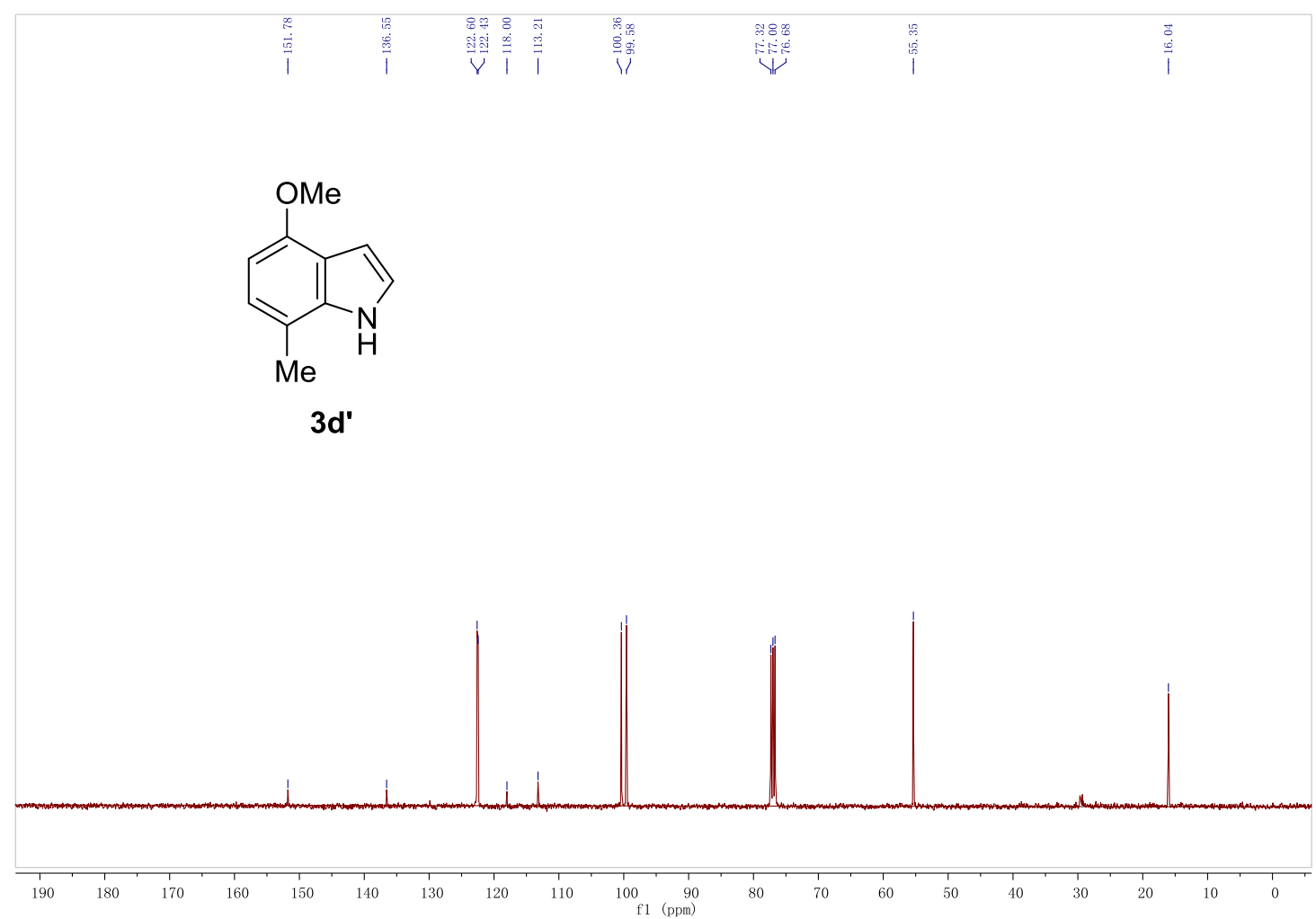


${ }^{1} \mathrm{H}$ NMR (400 MHz, $\mathrm{CDCl}_{3}$ )

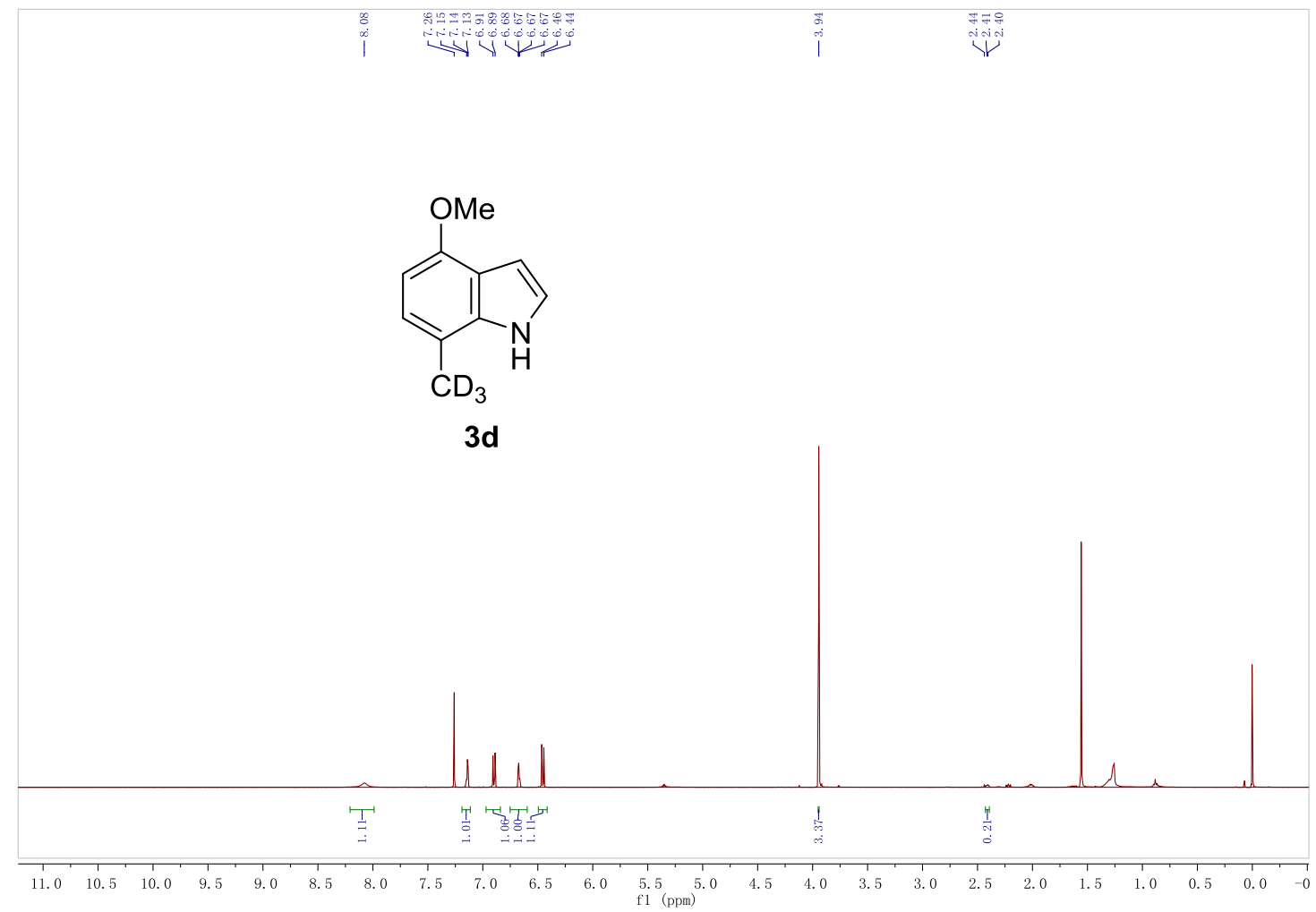

${ }^{1} \mathrm{H}$ NMR (400 MHz, $\left.\mathrm{CDCl}_{3}\right)$

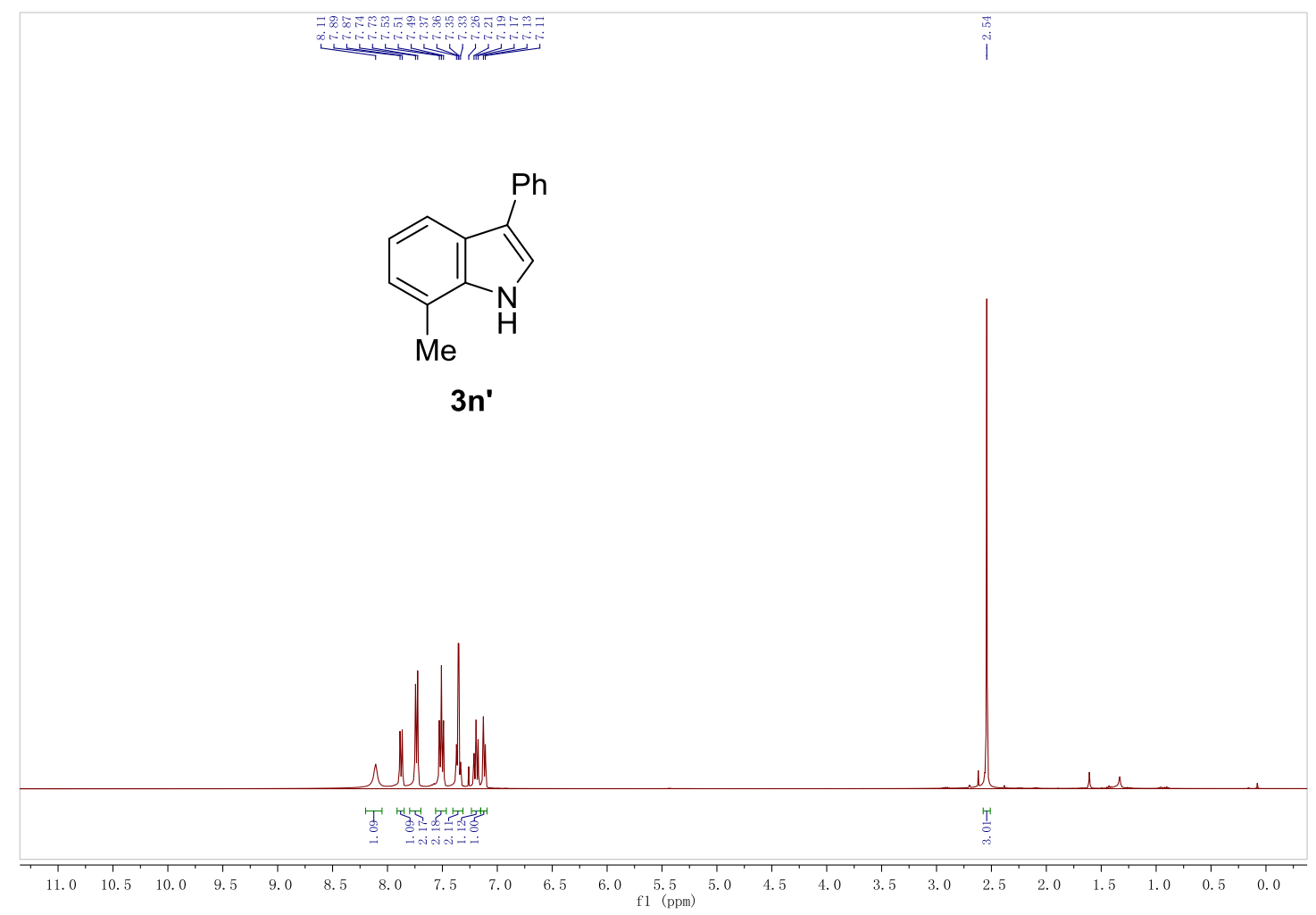


${ }^{13} \mathrm{C}$ NMR (400 MHz, $\mathrm{CDCl}_{3}$ )

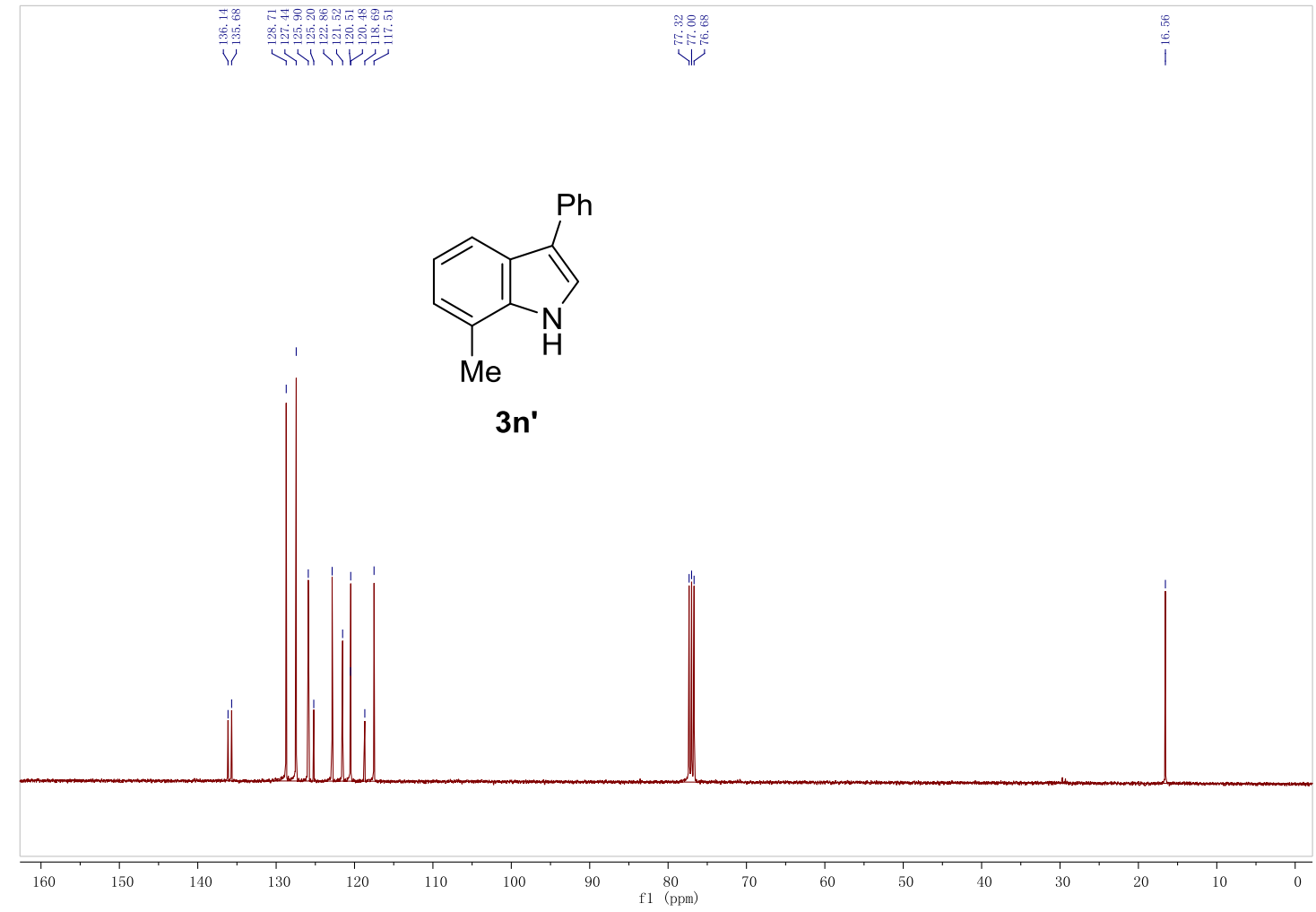

${ }^{1} \mathrm{H}$ NMR (400 MHz, $\left.\mathrm{CDCl}_{3}\right)$

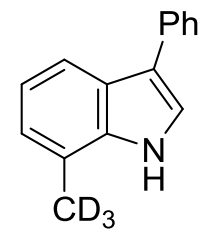

$3 n$

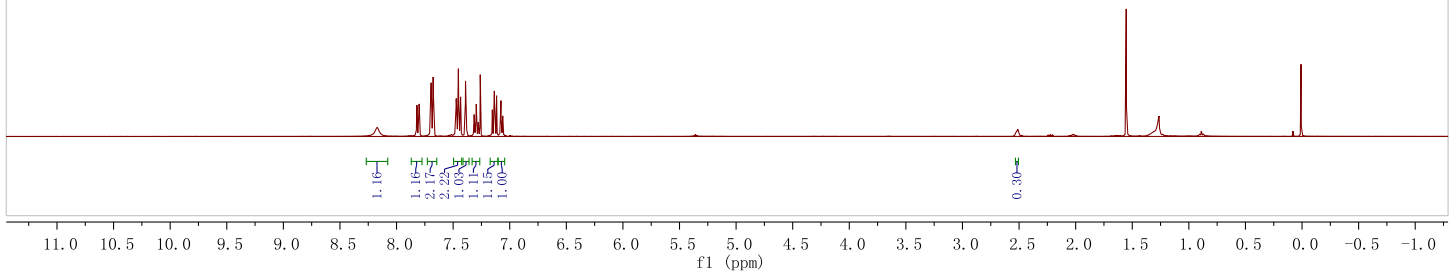

